\title{
Biology of Endophytic Fungi
}

\author{
Selim KA ${ }^{1, *}$, El-Beih AA ${ }^{1}$, AbdEl-Rahman TM$^{2}$ and El-Diwany AI ${ }^{1}$ \\ ${ }^{1}$ Chemistry of Natural and Microbial Product Department, National Research Center, 12622 Dokki, Cairo, Egypt. \\ ${ }^{2}$ Botany Department, Faculty of Science, Cairo University, Giza, Egypt.
}

Selim KA, El-Beih AA, AbdEl-Rahman TM, El-Diwany AI. 2012 - Biology of Endophytic Fungi. Current Research in Environmental \& Applied Mycology 2(1), 31-82, Doi 10.5943/cream/2/1/3

Endophytic fungi that are residing asymptomatically in internal tissues of all higher plants are of growing interest as promising sources of biologically active agents. This review focuses on the biology of endophytic fungi, their discovery, isolation, identification, and diversity and their biological activities in environmental and agricultural sustainability. It also considersand their medicinal applications especially in the production of anticancer, antimicrobial, antioxidant, and antiviral compounds. Endophytic fungi are one of the most creative groups of secondary metabolite producers that play important biological roles for human life. They are potential sources of novel natural agents for exploitation in the pharmaceutical industry, agriculture, and in environmental applications.

Key words - Biological Roles - Ecology - Endophytic Fungi - Identification - Isolation Secondary Metabolites

\section{Article Information}

Received 30 January 2012

Accepted 4 May 2012

Published online 20 June 2012

*Corresponding author: Khaled A. Selim - e-mail - elkas_sci@yahoo.com

\section{Introduction}

\section{Natural Products as Important Sources in the Drug Discovery Process}

There is a need to search new ecological niches for potential sources of natural bioactive agents for different pharmaceutical, agriculture, and industrial applications; these should be renewable, eco-friendly and easily obtainable (Liu et al. 2001). Natural products discovery have played major role in the search for new drugs, and is the most potent source for the discovery of novel bioactive molecules. Natural products are chemical compounds derived from living organisms. The most prominent producers of natural products can be found within different groups of organisms including plants, animals, marine macro-organisms (sponge, corals and algae), and microorganisms (bacteria, actinomycetes, and fungi). The discovery of natural products involves isolation, structural elucidation and establishing the bio-synthetic pathway of the secondary metabolites. This is an area of considerable interest to scientists due to the structural diversity, complexity and various bioactivities of isolated compounds. Crude natural products have been used directly as drugs which were low cost and important sources of traditional medicines. They also provided the basic chemical architecture for deriving semi-synthetic natural products (Suryanarayanan et al. 2009).

The role of natural products in discovery of new therapeutic agents can be demonstrated by an analysis of the number and sources of bioactive agents. There are at least 200,000 natural metabolites with various bioactive properties (Bérdy 2005). According to Cragg et al. (1997) anti-cancer and anti- 


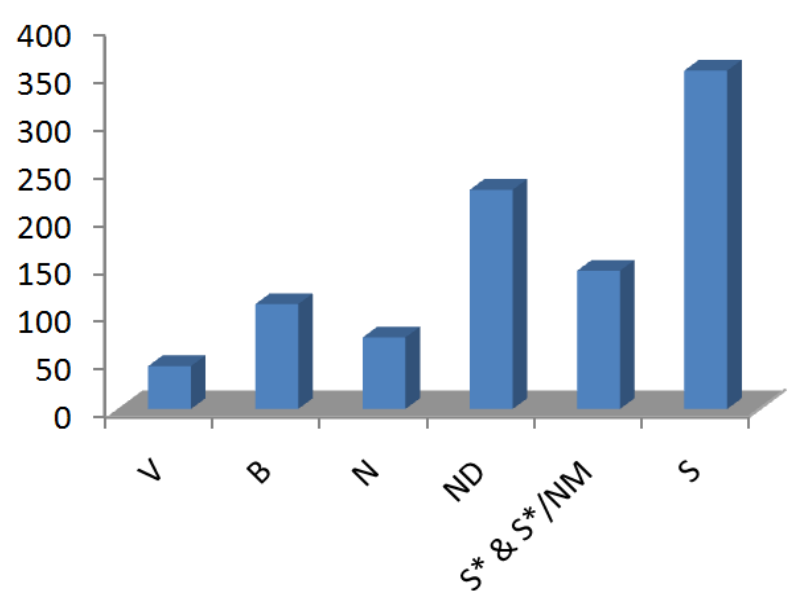

Fig. 1 - Distribution of Natural Products as Drugs

Adapted from (Newman et al. 2003)

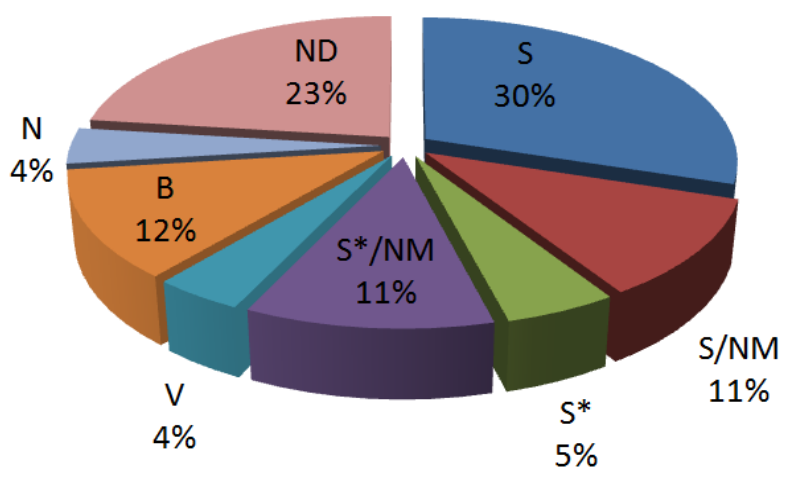

New Chemical Entities in Time Frame 19812006

(Newman \& Cragg 2007)

"B" Biological; usually a large ( $>45$ residues) peptide or protein, generally isolated from an organism/cell line or produced by biotechnological means in a surrogate host; "N" Natural product; "ND" Derived from a natural product, usually a semisynthetic modification; "S" Totally synthetic drug, mostly found by random screening or modification of an existing agent; "S*" Made by total synthesis, but the pharmacophore is/was from a natural product; "V" Vaccine; "NM" Natural Product mimic.

infective agents that were approved as drugs were more than $60 \%$ from natural origin.

Between 1981-2006, about 100 anticancer agents have been developed, $25 \%$ of them were natural product derivatives, $18 \%$ were natural product mimics, $11 \%$ candidates were derived from a natural product pharmacophore, and 9\% were pure natural products. Actually $47 \%$ of total anticancer drugs and $52 \%$ of new chemicals introduced into the market are of natural origin (Chin et al. 2006, Newman \& Cragg 2007). In the USA more than $50 \%$ of prescribed drugs are natural products or semi-synthetic derivatives. In addition, a number of chemicals used in crop protection are also of natural origin (Schneider et al. 2008). Thus natural sources make a very significant contribution to the health care) Fig.1.

Since, the discovery of potent antibiotic against Gram-positive bacteria, penicillin from culture of fungus Penicillium notatum by Fleming in 1929, the search for new drugs from microbial origin started. Koehn \& Carter (2005) and Newman \& Cragg (2007) reported many of secondary microbial metabolites which show potent pharmaceutical application against various diseases. This included the therapeutically used ergotamine, the immunosuppressive peptide cyclosporine A, peptidic antibiotic compounds like the penicillin $\mathrm{V}$ and cephalosporin $\mathrm{C}$, the polyketide lovastatin used in cholesterol treatment and the antibacterial terpenoid fusidic acid (Fig 2).

\section{Fungi as Producers of Biologically Active Metabolites}

More than 20,000 bioactive metabolites are of microbial origin (Bérdy 2005). Fungi are among the most important groups of eukaryotic organisms that are well known for producing many novel metabolites which are directly used as drugs or function as lead structures for synthetic modifications (Kock et al. 2001, Bode et al. 2002, Donadio et al. 2002, Chin et al. 2006, Gunatilaka 2006, Mitchell et al. 2008, Stadler \& Keller 2008). The success of several medicinal drugs from microbial origin such as the antibiotic penicillin from Penicillium sp., the immunosuppressant cyclosporine from Tolypocladium inflatum and Cylindrocarpon lucidum, the antifungal agent griseofulvin from Penicillium griseofulvum fungus, the cholesterol biosynthesis inhibitor lovastatin from Aspergillus terreus fungus, and $\beta$-lactam antibiotics from various fungal taxa, has shifted the focus of drug discovery from plants to microorganisms. 


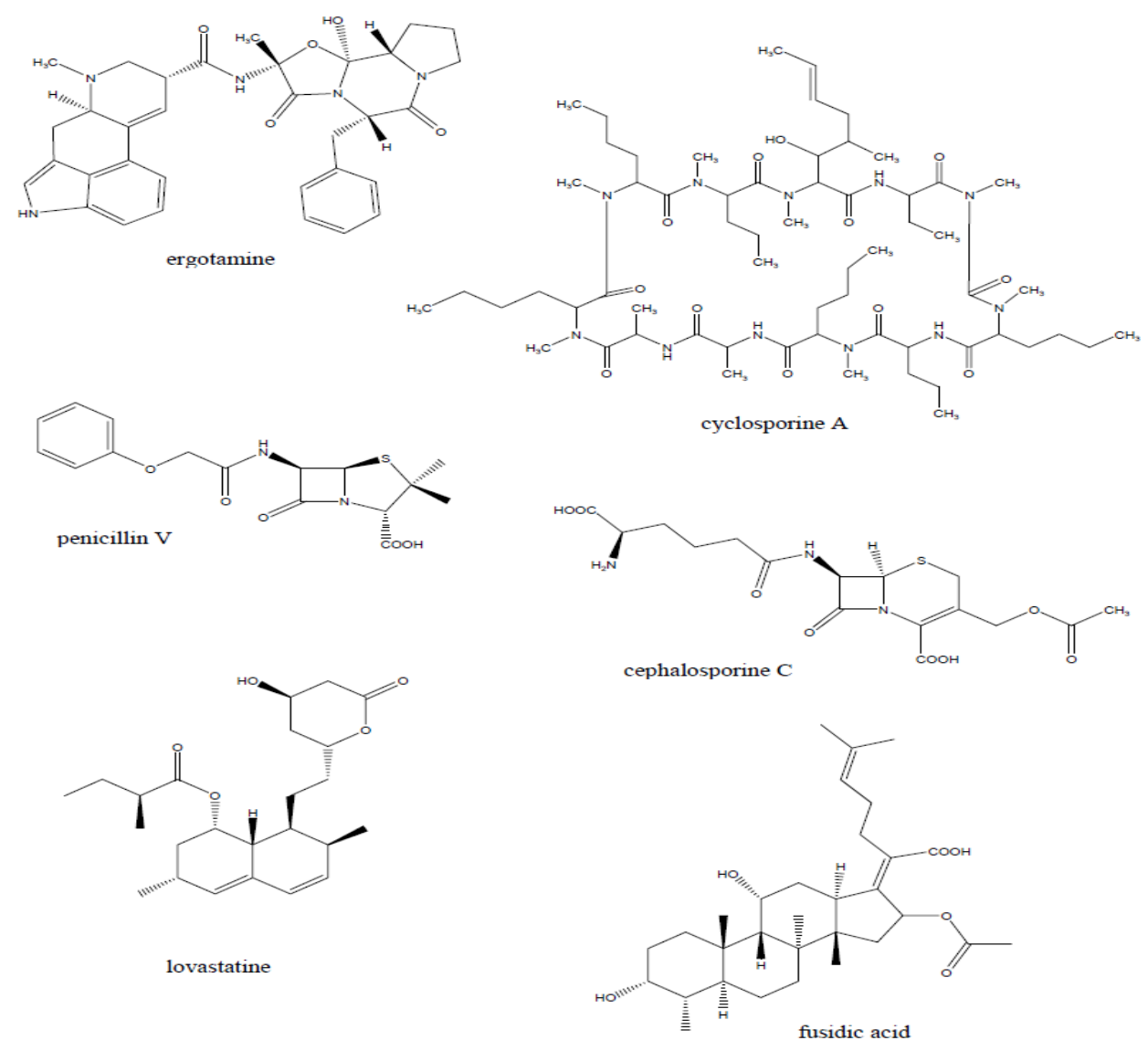

Fig. 2 - Structure of some biological active microbial metabolites

Suryanarayanan et al. (2009) discussed many fungal secondary metabolites with various chemical structures and their wide ranging biological activities and this reflects the high synthetic capability of fungi (Suryanarayanan \& Hawksworth, 2005). About 1500 fungal metabolites had been reported to show anti-tumor and antibiotic activity (Peláez 2005) and some have been approved as drugs. These include micafungin, an anti-fungal metabolite from Coleophoma empetri (Frattarelli et al. 2004), mycophenolate, a product of Penicillium brevicompactum, which is used for preventing renal transplant rejection (Curran \& Keating 2005), rosuvastatin from Penicillium citrinum and P. brevicompactum, which used for treating dyslipidemias (Scott et al. 2004) and cefditoren pivoxil, a broad spectrum antibiotic derived from Cephalosporium sp. (Darkes \& Plosker 2002). Others include derivatives of fumagillin, an antibiotic produced by Aspergillus fumigates (Chun et al. 2005), and illudin-S, a sesquiterpenoid from Omphalotus illudens (McMorris et al. 1996) which exhibits anti- cancer activities. Also, fungal metabolites are important in agriculture applications (Anke \& Thines 2007).

It has been estimated that there may be 1.5 million fungal species, while only about 100,000 species are presently known (Hawksworth 2004). Only a few taxa have tested for their biological applications including their ability for drug production and biological control. Thus it seems that the discovered percentage of economically valuable fungal metabolites is small.

Soil fungi have been the most studied of fungi, and typical soil genera such as Acremonium, Aspergillus, Fusarium and Penicillium have shown ability to synthesis a diverse range of bioactive compounds. More than $30 \%$ of isolated metabolites from fungi are from Aspergillus and Penicillium (Bérdy 2005). Fungi however were usually obtained from the same ecological niche using the same fungal isolation methods. Therefore the the same fungal strains were re-isolated and this lead to the re-discovery of known compounds as the same taxa produce the same metabolites. 


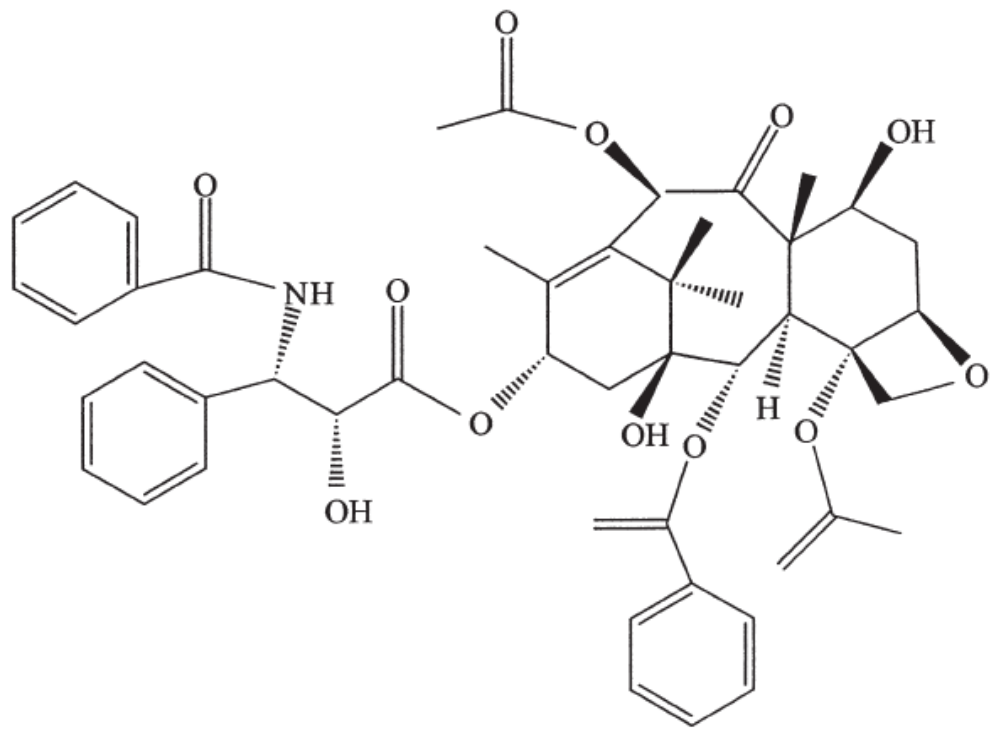

Fig. 3 - Taxol, anticancer drug produced by many endophytic fungi.

Dreyfuss \& Chapella (1994) assumed that different environmental factors including different physical conditions and different biological situations in the nature, may change behavior of microbes and favor the production of diverse range of secondary metabolites, so the search for alternatively unexplored ecological niches should be targeted. The investigation of fungal isolates from ecological niches other than soil may lead to investigating novel fungal groups with novel and diverse of secondary metabolites. Fungi occupy every living and non-living niche on earth, this includes those in the thermal vents, in deep rock sediments, and in desert as well as marine environments (Strobel 2003). Some of unexplored fungal groups derived from such ecosystems are endophytic fungi, fresh-water fungi, and marine-derived fungi (Dreyfuss \& Chapella 1994). In this review we will focus and concentrate on endophytic fungi that reside in plants, and the importance of their secondary metabolites.

\section{Endophyte}

Plants may serve as a reservoir of large numbers of microorganisms known as endophytes (Bacon \& White 2000). Endophytes are microorganisms (mostly fungi and bacteria) that inhabit plant hosts for all or part of their life cycle. They colonize the internal plant tissues beneath the epidermal cell layers without causing any apparent harm or symptomatic infection to their host, living within the intercellular spaces of the tissues and its seems that they may penetrate the living cells (Strobel 2003). Endophytes form inconspicuous infections within tissues of healthy plants for all or nearly all their life cycle and their host tissues appear symptomless, and they remain asymptomatic for many years and only become parasitic when their hosts are stressed (Firáková et al. 2007, Limsuwan et al. 2009). Endophytic fungi are an ecological, polyphyletic group of highly diverse fungi, mostly belonging to ascomycetes and anamorphic fungi (Huang et al. 2001, Arnold 2007).

Approximately, there are near to 300,000 plant species on earth and each individual plant is the host to one or more endophytes, and many of them may colonize certain hosts. It has been estimated that there may be as many as one million different endophytic fungal taxa, thus endophytes may be hyperdiverse (Petrini 1991, Strobel \& Daisy 2003, Huang et al. 2007). Endophytesmay produce a plethora of bioactive metabolites that may be involved in the host-endophyte relationship (Strobel 2003), and may serve as potential sources of novel natural products for exploitation in medicine, agriculture, and industry (Bacon \& White 2000, Strobel \& Daisy 2003). The described populations of endophytic strains are few, which means the opportunity to find new strains and targeting natural products from endophytic microorganisms that colonize plants in different niches and ecosystems is great. 


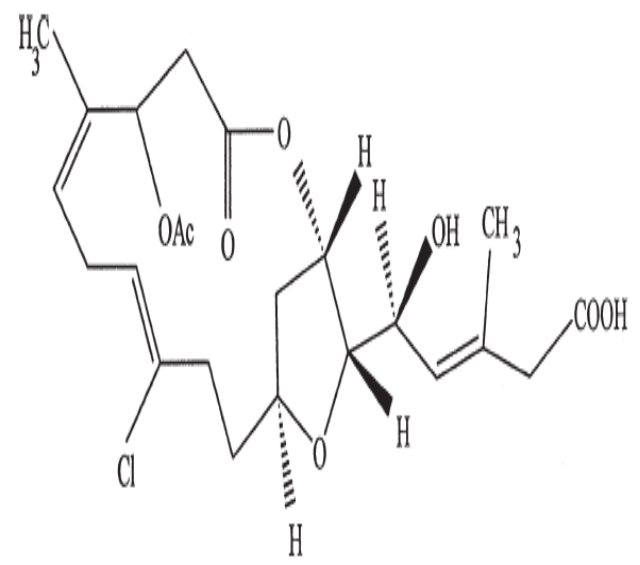

Fig. 4 - Oocydin A, antifungal agent isolateded from Serratia marcescens.

\section{Discovery the Importance of Endophytic Fungi}

The importance of endophytes had been demonstrated over a long period as potential sources of pharmaceutical leads, as many of endophytic fungi were reported to produce novel bioactive metabolites such as antimicrobial, anticancer, and antiviral agents. The discovery of taxol producing fungi increased the importance of endophytes and shifted natural products research to endophytic fungi.

Taxol (Fig 3), a highly functionalized diterpenoid, is found in each yew (Taxus) species, but was originally isolated from Taxus brevifolia (Suffness 1995, Wani et al. 1971). This compound is the world's first billion dollar anticancer drug, and it is used for treatment of ovarian and breast cancers, but now it is used to treat a number of other human tissue-proliferating diseases as well. Its cost makes it unavailable to the most of world's people (Nicolaou et al. 1994). It was suggested by Stierle et al. (1993) that yew trees might support certain endophytic microorganisms that may also synthesize taxol.

In the early 1990s, a novel taxolproducing endophytic fungus, Taxomyces andreanae, was isolated from Taxus brevifolia (Strobel et al. 1993). This set the stage for a more comprehensive examination of the ability of other Taxus species and other plants to yield endophytes producing taxol. An examination of the endophytes of Taxus wallichiana yielded the endophytic fungus Pestalotiopsis microspora, and a preliminary screening indicated that it produced taxol (Strobel et al.
1996). Furthermore, several other $P$. microspora isolates were obtained from bald cypress in South Carolina and were also shown to produce taxol ( $\mathrm{Li}$ et al. 1996). This was the first indication that other endophytes than $T$. andreanae residing in plants other than Taxus spp. were producing taxol. Numerous reports have shown that many of other endophytic fungi such as Pestalotiopsis guepini and Periconia sp. also produce taxol (Li et al. 1998, Strobel et al. 1997). Also endophytic Fusarium solani isolated from Taxus chinensis and other common endophytic genera such as Alternaria and Aspergillus isolated from Ginkgo biloba and Podocarpus sp. respectively, had been reported as producers of taxol (Kim et al. 1999, Sun et al. 2008, Liu et al. 2009).

Thus, the presence of a microbial source of the drug could eliminate the need to harvest and extract the slow growing and relatively rare yew trees, and the price for the drug would also be reduced and the drug will be available to cancer patients, since taxol could be produced via fermentation in the same way that penicillin is fermented (Strobel 2003). However, despite the promised concerning the production of taxol by endophytes, this has not materialized into industrial production. It may be that the fungi carry residue of taxol over from the plant or rapidly lose their abilities to produce taxol in vitro.

\section{Isolation and Cultivation of Endophytes Fungi from Plants}

Isolation of endophytes is a critical step, because it requires sensitivity to recover a maximum number of colonized endophytes and 
should be accurate enough to eliminate the epiphytic microbes which are present on the plant surface. Endophytes can be isolated from various plant parts such as seeds, leaves and stems. The collected plants for studying endophytic communities should look apparently healthy and disease free plant, i.e. they do not display any visual symptoms of diseases, in order to minimize the presence of plant pathogenic and saprobic species, and to prevent the isolation of localized pathogenic endophytic microorganisms (Strobel 2003, Strobel \& Daisy 2003).

\section{Selection of Plant Material}

It is important to understand the methods and rationale used to provide the best opportunities to isolate endophytes, since the number of plant species in the world is so great and each individual plant may be host to numerous endophytes. Creative and imaginative strategies must therefore be used to quickly narrow the search for the host plants for isolation and target endophytes displaying bioactivity (Mittermeier et al. 1999, Strobel 2003, Strobel \& Daisy 2003). Several criteria must be considered in plant selection strategy, and these are as follows (Strobel \& Daisy 2003):

1. Plants from a unique ecological environmental niche, and growing in special habitats, especially those with an unusual biology and possessing novel strategies for survival should seriously be considered for study. Strobel et al. (1999a) showed that an aquatic plant, Rhyncholacis penicillata, which lives in harsh aquatic environment which may be constantly wounded by passing rocks and other debris, resists infection by common oomyceteous fungi (water molds that are phytopathogenic) that cause disease. The possibility that endophytes associated with this aquatic plant may produce antifungal agents that protect the plant from attack by pathogenic fungi is feasible. A novel antioomycetous compound, oocydin A (Fig 4) was discovered from the endophytic strain Serratia marcescens from this plant.

2. Plants that have an ethnobotanical history, and are used for traditional medicines should be selected for study, as inhabiting endophytes may be the source of the medicinal properties of this plant. For example, the endophtic fungus Fusarium proliferatum possessing antimicrobial activity, was isolated from traditional Chinese medicinal plant Celastrus angulatus (Ji et al. 2005).

3. Plants that are endemic, having an unusual longevity, or have occupied a certain ancient land mass, are appropriate for study. An endophytic fungus Chaetomium globosum, isolated from leaf of endemic plant Maytenus hookeri, which is only distributed in areas of Yunnan, China, was found to produce Chaetoglobosin B which showed antituberculosis activity (Ni et al. 2008).

4. Plants growing in areas of great biodiversity also have the potential for housing endophytes with great diversity. Kumaresan \& Suryanarayanan (2001) found that many endophytic fungi colonized trees in mangrove forests.

5. Plants surrounded by pathogen infected plants, and showing no symptoms are more likely to lodge endophytes possessing antimicrobial activity than other plants. For example Tuntiwachwuttikul et al. (2008) reported an endophyte showing antimicrobial activity against plant pathogen Colletotrichum musae.

6. Young plant tissue is more suitable for isolation of endophytic fungi than older tissues which often contain many additional fungi that make isolation of slow growing fungi difficult to isolate. The collected plant samples are stored at $4^{\circ} \mathrm{C}$ until the isolation procedure is carried out, and isolation should be as soon as possible after collection to avoid contamination by air microspora (Bacon \& White 1994).

Acquiring endophytes which may display bioactivity, needs selection of plant species that may be of interest because of their unique biology, age, endemism, ethnobotanical history, and/or environmental setting. Yu et al. (2010) showed that medical plants and plants in special environments were frequently studied for screening for presence of endophytes that produce antimicrobial agents (Fig 5). 


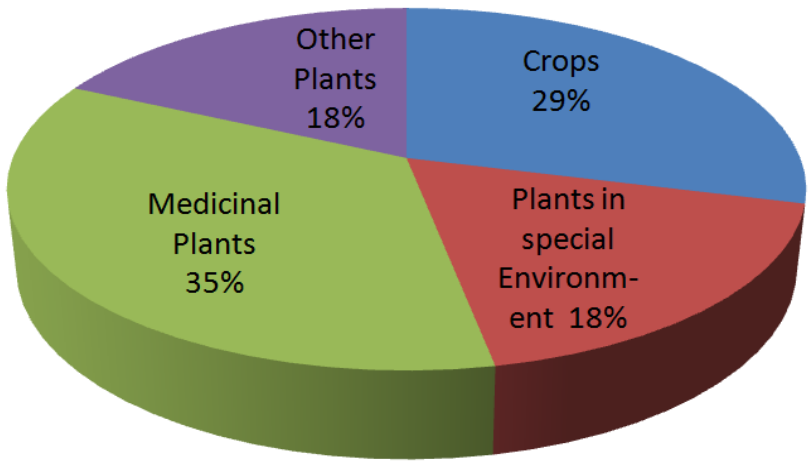

Fig. 5 - Proportion of biologically active endophytic fungal isolates from different sources with antimicrobial activities. Adapted from: (Yu et al. 2010).

\section{Isolation of Endophytic Fungi}

The most important step for the isolation of endophytic fungi that reside in plant tissues is surface sterilization and the plant parts under investigation should be cut into small pieces to facilitate sterilization and isolation processes. To achieve complete surface sterilization, there are various methods to eliminate most of the epiphytic fungi from the exterior tissues and encourage the growth of the internal mycota, according to the type of tissue as well as its location (Strobel 2003, Strobel \& Daisy 2003).

\section{Identification of Endophytic Fungi}

Identification of endophytic fungi based is mainly on morphological methods, using characters of the phenotype of the fungal culture, i.e. colony or hyphae, the characters of the spore, or reproductive structure if these features were discernible (Wei 1979, Carmichael et al. 1980, Barnett \& Hunter 1998). Most of endophytic fungi belong to the ascomycetes and asexual fungi (Huang et al. 2001), but some endophytic isolates may fail to produce reproductive structures even after several months. These isolates cab be encouraged to sporulate on medium contains stripes or extract of host plant (Matsushima 1971). Sterile isolates should be checked regularly for fruiting bodies over a period of 34 months and the isolates that failed to sporulate are referred to as mycelia sterilia, ar divided into different morphotypes according to their culture characteristics. These groups of fungi are considerably common in endophytes studies (Lacap et al. 2003). Guo et al. (1998) reported other methods using twigs in conical flasks over a three months period to promote sporulation of morphospecies (Fig 6).

Endophytes are diverse and often grow readily in culture. With recent technological advances, the use of culture-free methods promises to discover ever-greater diversity and to expand our understanding of the structure of the fungal tree of life. One particularly useful aspect of culture-free methods may be to show that particular fungi are present in an environment, thus leading endophyte researchers to optimize culturing conditions as a means to capture those fungi in vitro. Such efforts are critical for establishing voucher specimens, which in turn can be used to empirically assess species interactions, as raw materials for bioprospecting or biological control, and as the basis for future research in systematics or genomics. Because many endophytes do not sporulate in culture, and thus are classified only as mycelia sterilia, they are not welcome at most established culture collections. Depositories are needed to house and maintain vouchers of these fungi, and to curate their ecological data (site of origin; host plant; season; tissue type). Both the specimens themselves and the data regarding their recovery have tremendous intrinsic value, (Arnold 2007).

According to Huang et al. (2008a) sterile mycelia are widely distributed among plant hosts as they were found in 27 medicinal plants of 29 host plants used for screening for endophytic fungi. High relative frequencies of $27 \%$ of endophytic fungal isolates from 29 medicinal plants were sterile (Fig7). Many variable proportions of mycelia sterilia ranging from $11 \%$ to $54 \%$ had been 


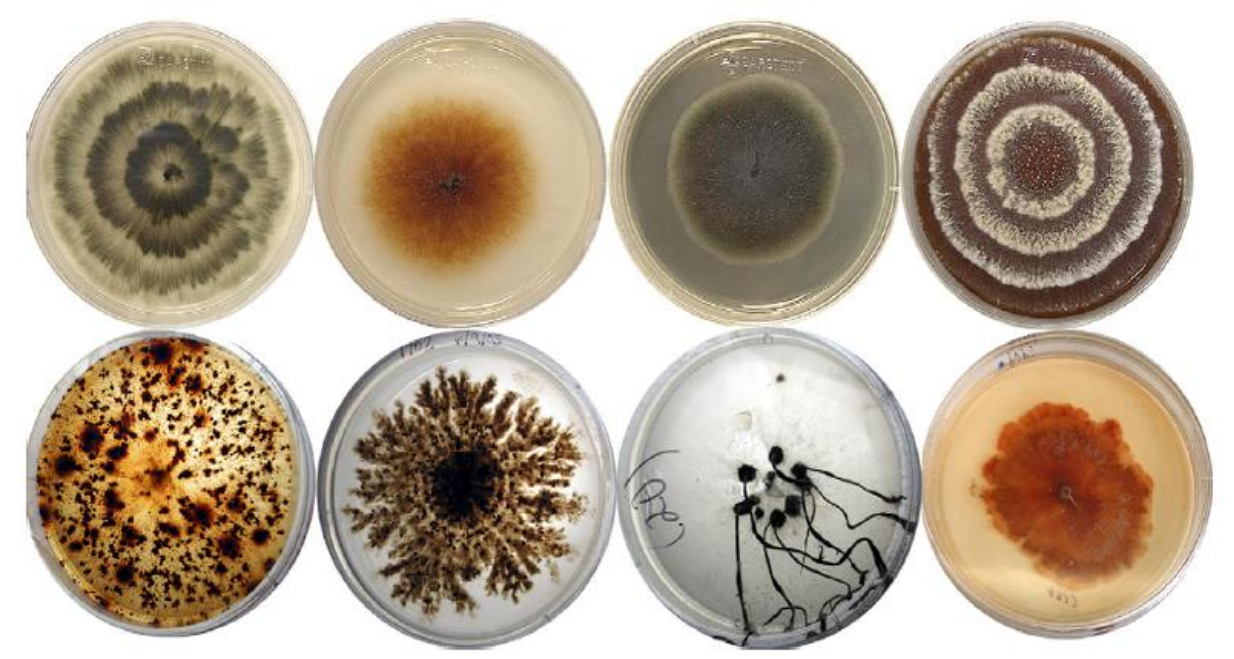

Fig. 6 - Assortment of ascomycetous endophytic fungi recovered from foliage of angiosperms and conifers in North America and Panama, Adapted from: (Arnold 2007).

reported (Petrini et al. 1982; Garcia \& Langenheim 1990, Fisher et al. 1994, Taylor et al. 1999, Fröhlich et al. 2000, Guo et al. 2000). Thus, the common problem concerning identification of endophytic fungi are that some of endophytes could not be identified to species or genus level (Gamboa \& Bayman 2001, Promputtha et al. 2005a \& b), and having many non-identified mycelia sterilia, raises the importance of use modern molecular techniques that could be the best alternative to identify this taxa.

\section{Molecular Characterization of Endophytic Fungi}

Molecular approaches have been used to resolve problems in fungal taxonomy and for direct detection and identification of fungi within natural habitats (Rollo et al. 1995, Ma et al. 1997, Zhang et al. 1997, Liew et al. 1998, Ranghoo et al. 1999). The most frequently accountered problem in endophytic fungi is the presence of mycelia sterilia, making their morphological identification difficult (Guo et al. 2000). Ribosomal DNA sequence analysis using specific PCR primers to amplify rDNA fragments of endophytes was used to validate the morphospecies of different groups of mycelia sterilia, and to resolve the identification problem associated with endophytic fungi (Doss \& Welty 1995, Lacap et al. 2003) (Fig 8).

According to Huang et al. (2009) rDNA sequence analysis is frequently used to confirm morphological identification of endophytic isolates, and to study phylogeny of endophytic fungi, about $24 \%$ of endophytic isolates from three Attemisia species were sterile, and with aid of molecular techniques the phylogeny of 34 endophytic fungi were studied, including identification of some sterile species and confirmation of some morphological identified species, using amplification of ITS1, 5.8S and ITS2 fragments of rDNA.

Molecular techniques can show hidden diversity and help reveal identities and diversity of sterile mycelia. However, the careless use of named GenBank sequences without questioning whether their identifications are correct has lead to many species in endophyte studies being wrongly named (Ko Ko et al. 2011). Extreme caution must be taken when using named sequences from GenBank as these are often wrongly named (Cai et al. 2009, Koko et al. 2011a,b).

\section{Ecology and Biodiversity of Endophytes}

Endophytic fungi represent an important and quantified component of fungal biodiversity, and are known to have an effect on and be affected by plant community diversity and structure (Sanders 2004, Gonthier et al. 2006, Krings et al. 2007). Almost all vascular plant species examined to date were found to harbor endophytes. Endophytes have been also recorded colonizing marine algae and grasses, mosses and ferns (Tan \& Zou 2001). Endophytes are present in virtually all organs of a given plant host, and some are seed-borne (Hyde \& Soytong 2008). Endophytes can be 

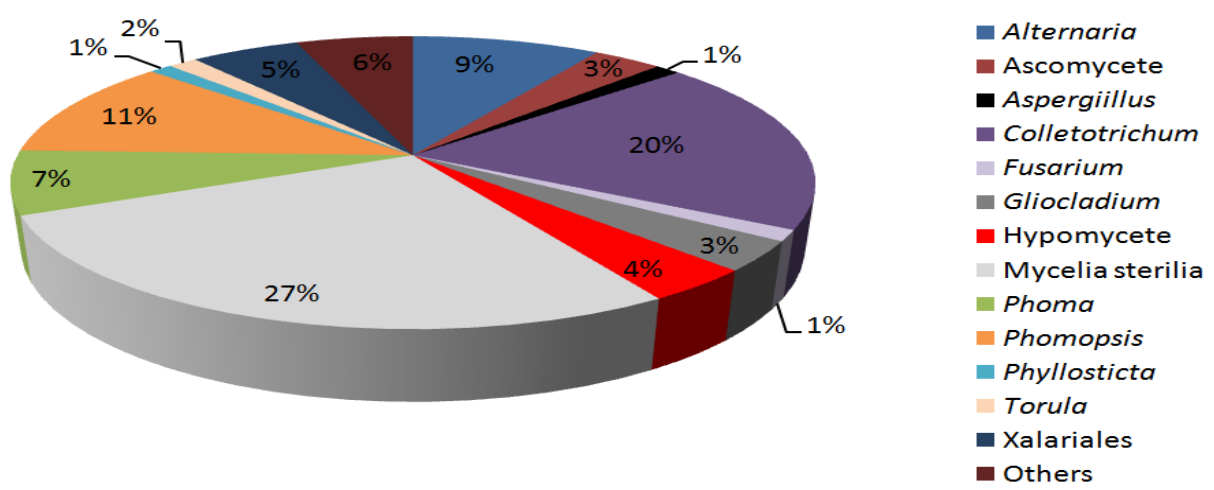

Fig. 7 - Relative frequencies of different endophytic taxa isolated from 29 Chinese medicinal plants showing high percent of Sterile Mycelia, Adapted from (Huang et al. 2008a).

transferred from plant to plant via seeds (Aly et al. 2011). The mycelium of the fungus then grows into the sheath, stem, and leaf tissues, finally enters the flowering stem and seeds (Firáková et al. 2007). The endophyte is passed to the next generation of plants through the seed, for instance asexual Acremonium grass endophytes are dispersed exclusively through the seeds of their hosts (Tan \& Zou 2001).

A variety of relationships can coexist between endophytes and their host plants, ranging from mutualism or symbiosis to antagonism or slightly pathogenic (Schulz \& Boyle 2005, Arnold 2007, Purahong \& Hyde 2011). The host-endophyte relationships can be described in terms of host-specificity, hostrecurrence, host-selectivity, or host preference (Zhou \& Hyde 2001, Cohen 2006).

Host-specificity (a phenomenon in endophytes-plant interaction) is a relationship in which microorganism is restricted to a single host or a group of related species, and such specificity implies that complex biochemical interaction occur between host and its associated endophytes (Holliday 1998, Strobel 2003, Strobel \& Daisy 2003). Host-specific strain formation can be interpreted as a form of ecological adaptation. It can be accepted that morphologically indistinguishable strains of the same species will exhibit different physiological traits that may be host-related (Petrini 1991). For example Pestalotiopsis microspora is one of the most commonly found endophytes in Taxa species (yews). Extracts of 15 isolates of Pestalotiopsis microspora, obtained from at least four continents, were examined and it was observed that no two chromatograms were identical. This is an indication that there is complex bio-chemical interaction between host and its associated endophytes, raising enormous variability between endophytes, through mutation, genetic crossing, or by unsubstantiated mechanisms such as developing genetic system allowing transferring of information between themselves and host plants (Tan \& Zou 2001, Firáková et al. 2007).

Host-recurrence refers to the frequent or predominant occurrence of endophytes on a particular host or a range of plant hosts, and endophytes can also found infrequently on other host plants in the same habitat (Zhou \& Hyde 2001). A single endophytic species may form relationships with two or many related host plants, but found in a preference for one particular host, and this phenomenon is defined as host selectivity (Cohen 2006).

The term host-preference is more frequently used to indicate a common occurrence or uniqueness of occurrence of endophytes to particular host, and also used to indicate the difference in endophytic community composition and relation frequencies from different host plants (Suryanarayanan \& Kumaresan 2000). Endophytes are also able to colonize multiple host species of the same plant family within the same habitat, and the distribution of some endophytes can be similar in closely related plant species (Huang et al. 2008a). Colletotrichum, Phoma, Phomopsis and Phyllosticta endophytes have a wide host range and colonize several taxonomically unrelated plant hosts (Pandey et al. 2003, Jeewon et al. 2004, Murali et al. 2006, Sieber 2007, Hyde et al. 2009, Udagaya et al. 2011, Wikee et al. 2011) suggesting that they have developed adaptations to overcome different types of host 


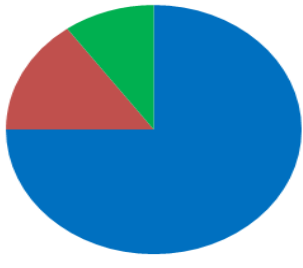

Fagaceae

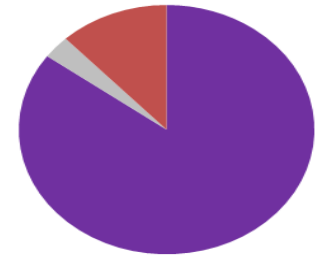

Pinaceae

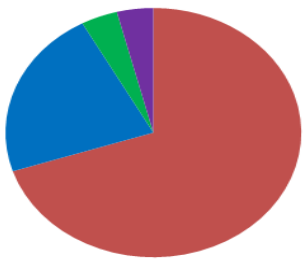

Cupressaceae

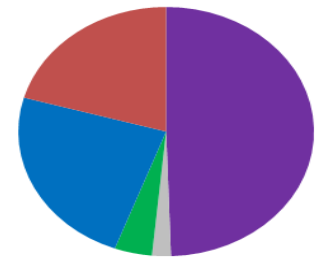

All

Fig. 8 - The phylogenetic context of endophyte symbioses: relative abundance of five classes of Ascomycota among endophytes isolated from three different plant families in southeastern Arizona, USA. Hosts representing the Fagaceae (Quercus spp.; $\mathrm{N}=44$ isolates, dominated by the Sordariomycetes), Pinaceae (Pinus ponderosa; $\mathrm{N}=111$ isolates, dominated by the Leotiomycetes), and Cupressaceae (Cupressus arizonica and Platycladus orientalis; $\mathrm{N}=42$ isolates, dominated by the Dothideomycetes) differ markedly in the relative abundance and dominance of each class. The predominant classes listed here also dominate endophyte communities associated with these host families in other sites, including mesic semideciduous forest (North Carolina; all families) and boreal forest (Québec; Pinaceae and Cupressaceae), Adapted from: (Arnold 2007).

defenses.

\section{Effect of Environment on Endophytes}

Environmentally, the endophyte may be metabolically aggressive by affecting host defense chemicals (Cabral et al. 1993, Peters et al. 1998, Schulz et al. 1999). Such a hostile environment may account for the evolution of the potentially increased synthetic ability of the endophytes. This perhaps explains the apparent anomaly observed when a species of endophyte isolated from a plant host produces a bioactive compound but fails to do so when isolated from another plant species (Li et al. 1996). The herbicidal activity of secondary metabolites of an endophytic Phyllosticta capitalensis differed with the plant host from which the endophyte was isolated. This probably means that the plant host (and ultimately its metabolism) influences the synthetic ability of an endophyte. This indicates that bioprospecting for endophyte natural products should be host plant based as opposed to fungal taxon based. In this regard, the endophyte-plant host association could also be exploited in enhancing the production of useful metabolites by the plant host (Wang et al. 2004).

Endophytes residing in the host tissue in a symptomless state or one that may be beneficial to its host may turn into a pathogen in response to some environmental cue (Hendry et al. 2002); such a shift in the nature of the endophyte would also result in a change in its metabolite profile. Also, the environmental conditions which effect on host plant growth, influence the number and variety of endophytic populations, and affect on metabolites produced by endophytes.

The difference in endophytes, difference in their metabolic profile, and hence difference in their biological activity even if between the same isolates of same species, might be related to the chemical difference of host plants (Paulus et al. 2006). This depends on the environment, and shows the importance of studying host-endophytes relationships, and the effect of host plants on endophytic metabolites production. Hence, the importance of the host plant as well as the ecosystem were influencing endophytes metabolites production, and affect on biological activitites of endophytes. More attention should be given to studying the endophytic biodiversity, the chemistry and bioactivity of endophytic metabolites, and the relation between endophytes and their host plants (Tan \& Zou 2001, Schulz et al. 2002).

\section{Host - Endophytes interaction}

There is a complex relationship between endophytes and their host plants. Host-endophyte interactions can range from mutualism through commensalism to parasitism, as the phenotypes of the 
interactions are often plastic, depending on the genetic dispositions of the two partners, their developmental stage and nutritional status, but also on environmental factors (Johnson et al. 1997, Redman et al. 2001, Schulz \& Boyle 2005). Commensalism provides benefit to the endophyte by enabling an undisturbed existence and nutrient supply without affecting the host. The mutual relationship benefits the endophytic fungi through provision supply of energy, nutrients, shelter as well as protection from environmental stress. On the other hand fungal endophytes indirectly benefit plant growth by producing special substances mainly secondary metabolites and enzymes, which are responsible for the adaptation of plants to abiotic stresses such as light, drought and biotic stresses, such as herbivore, insect and nematode attack or invading pathogens (Barz et al. 1988, Kogel et al. 2006).

Under certain conditions endophytes may become parasitic, and become pathogens causing symptomatic infection (Brown et al. 1998) and vice versa (ref) Mutation of pathogenic Colletotrichum magna resulted in the loss of a virulence factor and transformation into an endophytic fungus (Freeman \& Rodriguez 1993). Hence, parasitism is an exception in plant-endophytes interactions; it can be regarded as an unbalanced status of a symbiosis when the host is stressed and physiological or ecological conditions favors virulence (Müller et al. 2005, Schulz \& Boyle 2005, Kogel et al. 2006). Endophytes of certain plant could be a pathogen of other plants, depending on the balance between pathogenicity and endophytism of the microorganism in the different hosts (Saikkonen et al. 2004).

Schulz \& Boyle (2005) proposed that asymptomatic colonization of endophytes is a balanced antagonistic interaction between host plant and endophyte (Fig 9), and as long as endophytic virulence and plant defense are balanced the interaction remains asymptomati. Once the host-endophyte interaction becomes imbalanced either disease results in the host plant or the plant defense machinery kills the pathogenic endophytic fungus. Whether the interaction is balanced or imbalanced depends on the general status of the partners, the virulence of the fungus, and the defenses of the host, and both virulence and defense being variable and influenced by environmental factors, nutritional status and developmental stages of the partners. Hence, commensalism and mutualism require a sophisticated balance between the defense responses of the plant and the nutrient demand of the endophyte (Kogel et al. 2006).

Endophytes possess structural similarities with pathogens and both possess many of same virulence factors, such as production of phytotoxic metabolites and exoenzymes which are necessary to infect and colonize the host, so endophytes are object to the host's non-self recognition, i.e. host can respond with the same defense reactions as to a pathogen (Fig 10). Additionally, cell wall penetration by fungi is normally accompanied by the release of plantelicitor. Hence, endophytes must avoid or overcome non-specific resistance responses to achieve successful penetration by reprogramming the invaded cell to accommodate infection structures and to maintain host cell integrity for a long-lasting interaction (Kogel et al. 2006).

Finally, for mutualistic interactions, it is not yet clear to what extent friendly recognition overbalances unfriendly recognition. The avoidance and modification of elicitors circumvents recognition, or antagonistic pathways are engaged to switch off plant defense. Under this view, mutualistic interactions between endophytic invaders and a host plant are deciphered as a balance, under environmental, physiological and genetic control, that results in fitness benefits for both partners, and parasitism is an unbalanced symbiosis (Stracke et al. 2002, Zipfel \& Felix 2005, Kogel et al. 2006). Moricca \& Ragazzi (2008) indicates that the type of interaction between an endophyte and a plant is controlled by the genes of both organisms and modulated by the environment.

\section{Biological Role of Endophytes}

Endophytes play vital roles in various aspects of life varying from its effects on host plants to its effects to environmental and human life. Endophytes are capable of synthesizing bioactive agents that can be used by plants for defense against pathogens and/or stimulating plant growth, and other agents have been proven useful for novel drug discovery process. 


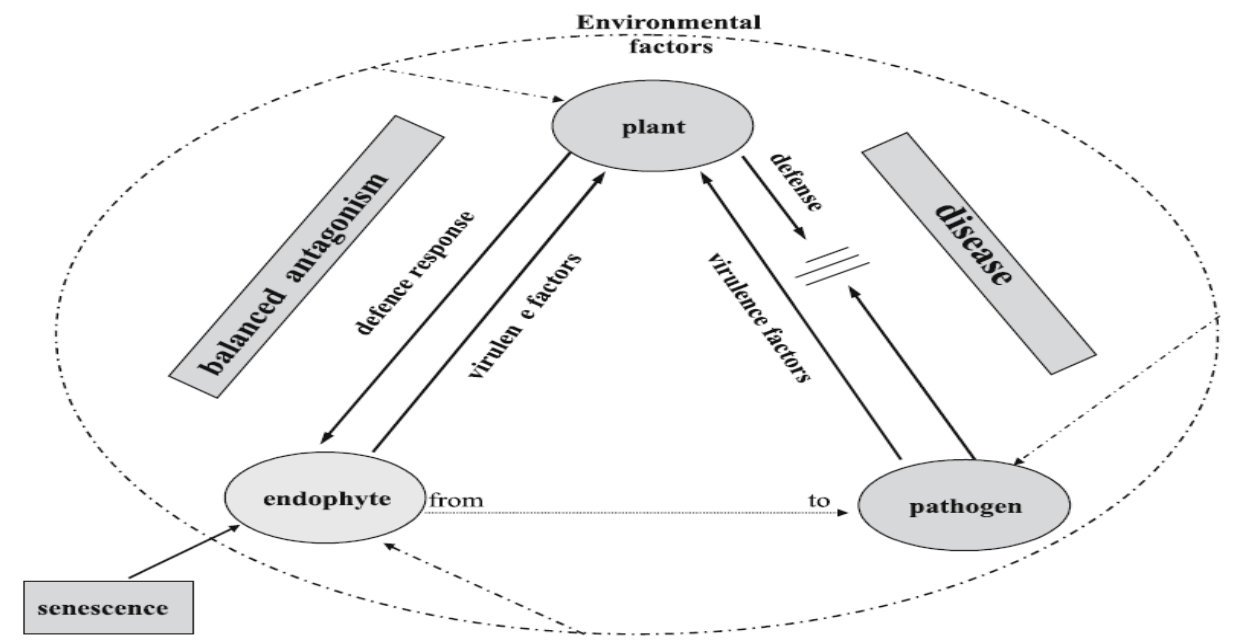

Fig. 9 - Hypothesis: a balance of antagonisms between endophytic virulence and plant defense response results in asymptomatic colonization, Adapted from: (Schulz \& Boyle 2005).

\section{Roles of Endophytes on Host-Plants}

Plants are affected by endophytes in various ways, and the potential functions of endophytes have not been clearly defined, but in the most cases, the presences of endophytic microorganisms in the host plants are beneficial to their host plants. Endophytes can actively or passively promote the plant growth through a variety of mechanisms, as endophytic metabolites provide a variety of fitness to host plants enhanced by increasing plant resistance to biotic and abiotic stresses, as well as enhance plant growth (Fig 11). Many endophytes are reported to be capable of nitrogen $(\mathrm{N})$ fixation, solubilization of phosphate, enhance uptake of phosphorus (P), production of siderophores, ACC deaminase, and plant hormones such as auxin, abscisins, ethylene, gibberellins, and indole acetic acid (IAA), which are important for plant growth and development regulation (Baldani et al. 1986, Goodman et al. 1986, Barraquio et al. 1997, Gasoni \& Gurfmkel 1997, Malinowski et al. 1999, Zou et al. 1999, Malinowski \& Belesky 2000, Boddey et al. 2003, Loiret et al. 2004, Sandhiya et al. 2005, Firáková et al. 2007).

\section{Role of Endophytes in Host Growth and Nutrient Uptake}

One of the most potential functions of endophytic fungi, especially root mycorrhizal fungi is the facilitation of plant nutrient uptake which in contrast leads to growth stimulation. Improved nutrition and growth may have positive indirect effects on the other wellknown functions, such as greater stress tolerance or pathogen resistance in plants (Kageyama et al. 2008).

The mechanisms of enhancement of nutrient uptake by plants colonized by endophytes have remained elusive, but the arguments which are often used in support of mycorrhizal nutrient uptake may be applied: as extramatrical mycelium extending from the host roots may increase the surface area and therefore increase host access to soil nutrients. Barrow \& Osuna (2002) present another interesting possibility, in root exclusion experiment that controlled sources of $\mathrm{P}$ in the substrate, they showed that Atriplex canescens inoculated with endophytic fungus Aspergillus ustus may have gained access to phosphate otherwise it will be unavailable to the host plant.

An endophytic basidiomycet, Piriformospora indica may serve as a smart model system to elucidate the mechanisms of nutrient uptake, host growth and fitness promotion. This Hymenomycete colonizes the roots both inter- and intracellularly and forms coils or round bodies and branches in the cortex without any colonization of the host stele (Verma et al. 1998, Varma et al. 1999). It seems that $P$. indica is capable of mobilizing plant unavailable $\mathrm{P}$ by excreting extracellular phosphatases, as well as mediating uptake and translocation of labeled $\mathrm{P}$ via an energy dependent process (Singh et al. 2000). It is also possible that $P$. indica is involved in $\mathrm{N}$ 

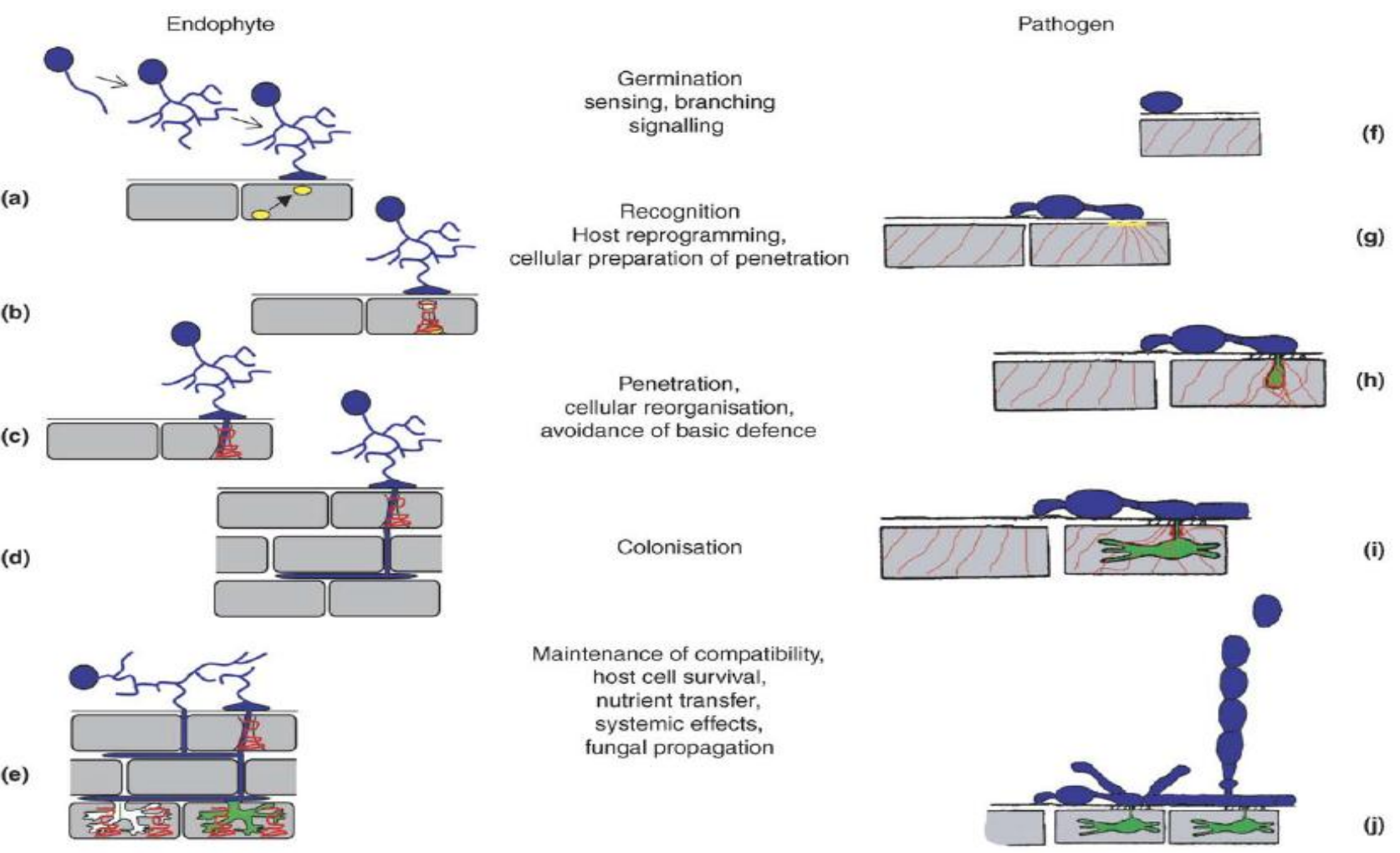

Fig. 10 - Symbiotic development of biotrophic endophytes and pathogens a Once Arbuscular mycorrhiza (AM) spores germinate and the germ tube approaches a root, apical dominance is abandoned and the branching of hyphae is triggered by 5-deoxy-strigol (Akiyama et al. 2005). Upon physical contact, the fungus forms an appressorium, which appears to induce the movement of the plant nucleus towards the contact site $\mathbf{b}$ Cytoskeletal elements and the endoplasmic reticulum form the pre-penetration apparatus along the axis of nuclear movement (Genre et al. 2005) c The structure is entered by an infection hypha, from which $\mathbf{d}$ colonization of root cortex begins. Initial infestation is accompanied by a balanced induction of plant defense genes. e When the fungus finally reaches the inner cortex, it penetrates the cell wall and builds up a tree-like hyphal structure, the arbuscule. Arbuscule-containing cells have specific cytoskeletal structures and accumulate reactive oxygen species (ROS). While arbuscules develop and decease, the fungus spreads further in the root and also colonizes the surrounding soil. There it takes up mineral nutrients, which are transported into the root and exchanged for carbohydrates $\mathbf{f}$ Once a powdery mildew fungus germinates, it forms an appressorium for host cell wall penetration $\mathbf{g}$ Appressoria seem to release signals for the formation of membrane domains (yellow) into which host susceptibility factors and defense factors are recruited (Bhat et al. 2005). In a compatible interaction, the host nucleus transiently migrates to the site of attempted penetration (not shown) and some action filaments (red) polarize toward this site $\mathbf{h}$ During penetration, host cell membrane is formed around the fungal feeding structure (green), which is closely enveloped by actin filaments and led by a ring of action around the growing tip (Opalski et al. 2005) i When the haustorium matures, a meshwork of cortical actin is maintained around the haustorial neck, whereas actin polarisation resolves $\mathbf{j}$ Eventually, the parasite establishes secondary haustoria and fulfils its lifecycle by producing a new generation of conidia, Adapted from: (Kogel et al. 2006).

accumulation in the shoots of Nicotiana tobaccum and Arabidopsis thaliana. N content in $N$. tobaccum was increased by $22 \%$, indicating a transfer of about $60 \%$ substrate $\mathrm{N}$ into the plants. This $\mathrm{N}$ content increase was correlated with a $50 \%$ increase in nitrate reductase activity, a key enzyme in nitrate assimilation, in N. tobaccum and a similar $30 \%$ increase in A. thaliana (Sherameti et al. 2005). Seed production in $N$. tobaccum were also improved and increased with inoculation with $P$. indica as well as in Hordeum vulgare 
(Barazani et al. 2005, Waller et al. 2005). This endophyte appears to have a broad host range. It has been shown to colonize and enhance growth of, for example, Zea mays, Nicotiana tobaccum, Bacopa monniera, Artemisia annua, Petroselinum crispum, Populus tremula, Oryza sativa, Sorghum vulgare, Triticum sativum, Glycine max, Cicer arientinum, Solanum melongera, and terrestrial orchids like Dactylorhiza purpurella, D. inacrnata, D. majalis and D. fuchsia (Singh et al. 2000, Varma et al. 1999).

\section{Role of Endophytes in Production of Phyto- Hormones}

Endophytes may enhance growth by producing phytohormones without any apparent facilitation of host nutrient uptake or stimulation of host nutrient metabolism. The endophytic fungi may enhance biomass by producing growth hormones or inducing the host hormone production (Petrini 1991, Schulz $\&$ Boyle 2005). The use of fungal culture extracts of endophytes to enhance plant growth, indicate that soluble agents in culture extracts may stimulate host growth similarly to the actively growing fungi, and this prove that endophytic fungi produce phytohormones in vitro as well as in vivo.

For example, the mycelial extract of $P$. fortinii induced a similar increase in Larix decidua shoot and root biomass as did the fungus itself (Rommert et al. 2002), the growth promotion was attributable to IAA as the fungus synthesized the hormone in vitro. A similar effect has also been observed with $P$. indica. When a fungal filtrate $(1 \% \mathrm{w} / \mathrm{v})$ was added to maize seedlings three times a week for 4 weeks, shoot biomass increase was similar to that observed in inoculation experiments with living cultures of the fungus (Varma et al. 1999).

\section{Role of Endophytes in Hosts Tolerance to Stress}

Endophytes may help host plants to tolerate and withstand environmental stress such as drought, salts, and high temperatures (Malinowski \& Belesky 2000). In the herbal plant Dichanthelium lanuginosum, which lives in areas where soil temperatures can reach 57 ${ }^{\circ} \mathrm{C}$, the presence of the endophytes may increase plant fitness as plants with an endophytic fungus Curvularia sp., survived high soil temperature and water stress better than endophyte-free plants (Redman et al., 2002).

Waller et al. (2005) reported the potential of Piriformospora indica to induce resistance to fungal diseases and tolerance to salt stress in barley. The beneficial effect on the defense status was detected in distal leaves, demonstrating a systemic induction of tolerance and resistance by a root endophytic fungus. This systemically alternation was associated with increase of anti-oxidative capacity due to an activation of the glutathioneascorbate cycle and results in an overall increase in grain yield. Hence, such symbioses are of great importance, since they might help plants to adapt to global climate change (Rodriguez et al. 2004).

\section{Role of Endophytes on Photosynthetic Capacity of Hosts:}

Effects of endophytes on photosynthesis have been demonstrated, but they are not always significant. For example, Colletotrichum musae in banana decreased photochemical capacity compared to endophyte-free plants (Pinto et al. 2000).

\section{Role of Endophytes in Resistance against Pathogens and Herbivores (Biological Control)}

Endophytic fungi can protect their host plants from pathogens (Fig 11) and from pests (Arnold et al. 2003, Akello et al. 2007). The systemic and foliar endophytes can reduce herbivory by producing alkaloids toxic to insects and vertebrates (Schardl 2001). Endophytic fungi are also capable of inducing resistance to diseases, and a many of mechanisms have been proposed for this resistance. The mechanisms of endophyteinduced resistance are related to the nutritional status of the host, and to increase the fitness of plants by enhancing their tolerance to abiotic stress (Aguilar \& Barea 1996, Redman et al. 2002, Bae et al. 2008).

\section{Protection from Pathogens:}

There are at least three primary mechanisms by which endophytes can improve host resistance to pathogens (Mandyam \& Jumpponen 2005). 


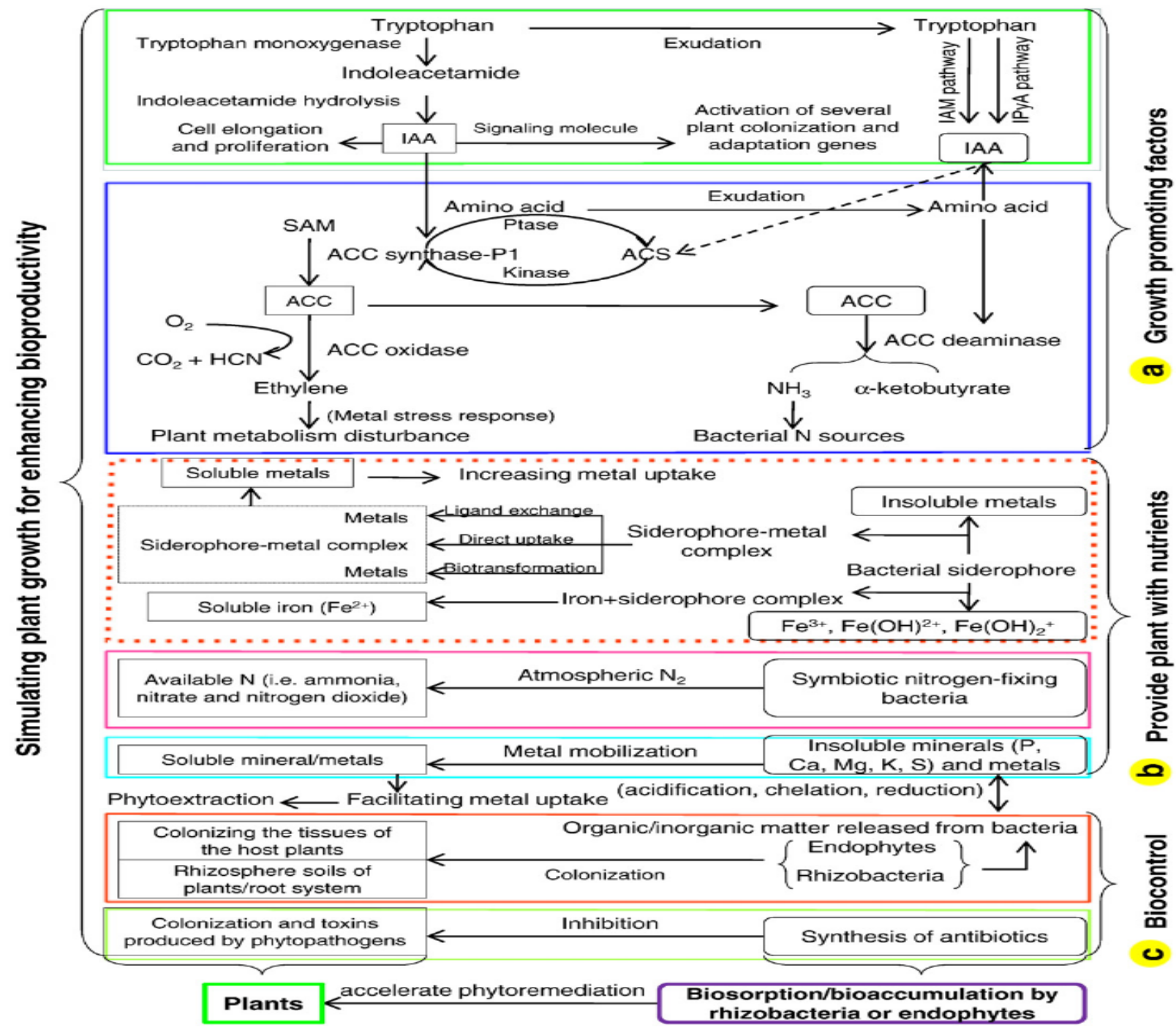

Fig. 11 - Endophytes and rhizobacteria are promoting plant growth, and accelerates phytoremediation process though modulation of (a) plant growth promoting parameters, (b) by providing plants with nutrients, and (c) controlling disease through the production of antifungal metabolites, Adapted from (Ma et al. 2011).

The first mechanism is based on competition between endophyte and pathogen on the same resources (Lockwood 1992). This is clear in a Fusarium oxysporum system. A non-pathogenic endophytic $F$. oxysporum Fo47 inhibits the pathogenic $F$. oxysporum f. sp. radicis-lycopersici and reduces the root rot symptoms of tomato (Bolwerk et al. 2005). Fo47 spores compete with the pathogen for the same C source, thereby reducing nutrient availability to the pathogen. Both of these Fusarium strains exhibit similar colonization strategies, so Fo47 can occupy and reduce the number of suitable sites for spore attachment and subsequent colonization resulting in fewer symptomatic lesions.

The second possible mechanism of pathogen control may be related to ability of endophytes to enhance the host to produce phytoalexins, and/or biocidal compounds, or ability of the endophyte itself to produce fumigants and other antimicrobial agents. As in the case of Spilanthes calva when inoculated with Piriformospora indica, it produces a range of antifungal compounds, as plants inoculated with $P$. indica produced extracts that were inhibitory to soil-borne pathogens ( $F$. oxysporum and Trichophyton mentagrophytes) suggesting induction of antifungal chemical production in the host (Rai et al. 2002).

The third possible mechanism is improving host resistance to pathogens by inducing host defense responses by localized endophytes. This mechanism is often 
encountered in mycorrhizal plants where weak resistance is induced locally or transiently during early mycorrhizal colonization. Structural modifications and induction of defense signaling can similarly result from endophyte colonization (Koide \& Schreiner 1992, Gianinazzi et al. 1996).

An unidentified root-associated endophyte known as LtVB3 restricted the spread of Verticillium longissima in Brassica campestris by forming mechanical barriers, cell wall appositions and thickenings (Narisawa et al. 2004). As a result, external and internal pathogen symptoms were reduced by over $80 \%$. Narisawa et al. (1998) also observed inhibition of Plasmodiophora brassicae-caused clubroot in $B$. campestris by about $5 \%$ by endophytes that were isolated; these endophytes were included Heteroconium chaetospira, Mortierella elongate, Westerdykella sp. as well as three unknown hyaline and melanized species. They proposed that superficial (M. elongata), cortical (hyaline and DSE fungi, Westerdykella sp.), or superficial and cortical (H. chaetospira) colonization created a mechanical barrier to the pathogens.

It is likely that many tissue-penetrating endophytes may induce pathogen resistance and in many cases, more than one of these three mechanisms can act simultaneously. For example, root colonization by Phialophora graminicola can pre-emptively reduce the growth of the pathogen Gaeumannomyces graminis by competition for space and resources. However, it can also form mechanical barriers resulting from thickening of endodermis that inhibits colonization of the stele by the pathogen (Speakman \& Lewis 1978, Deacon 1981). Similarly, any tissue colonizing benign organism reduces available carbon to pathogens and can occupy likely colonization sites resulting in fewer possible sites for pathogen penetration.

\section{Protection from Insects, Worm, Pests and Herbivores}

Some endophytes were found to have negative effects on insects, inhibiting growth, survivorship or oviposition, especially mycorrhizae and systemic and foliar Clavicipetalean grass endophytes which are widely known to reduce herbivory. Clavicipitaceous fungi produce toxic alkaloids against insect and vertebrate herbivores, and most of endophytic fungi may similarly play a role in protection of hosts from pests and herbivores. Mandyam \& Jumpponen (2005) suggested three possible mechanisms by which endophytes can improve resistance of host plants to herbivores and pests.

The first mechanism is based on overall improvement of plant performance by endophytes, which helps plants tolerate herbivory and sustain damage without visible effects on productivity (Gehring \& Whitham 2002).

The second possible mechanism is the alteration of plant nutritional chemistry both qualitatively and quantitatively, by altering the carbohydrate and nitrogen contents, $\mathrm{C}: \mathrm{N}$ ratio and phytosterol composition (Jones \& Last 1991, Bernays 1993, Schulz \& Boyle 2005). The endophytes are capable of altering nutrient levels and content in host plants which coupled with alteration in carbohydrate metabolism, thus affect the host herbivore susceptibility.

The third possible mechanism of host herbivore resistance is the production of feeding deterrents by the endophytes themselves. Toxic alkaloids are produced by foliar endophytes of grasses (Clay 1990, Clay \& Holah 1999). Non-pathogenic F. oxysporum, a common root endophyte in $L$. esculentum, produces soluble toxic metabolites that are present in culture filtrates (Hallman \& Sikora 1996). The filtrate has been shown to be toxic to Meloidogyne incognita, a root nematode. These toxic metabolites reduce nematode mobility, inactivate juveniles and are lethal within a 24-h exposure. The effects of the endophyte filtrates were reproducible in pot experiments (Hallman \& Sikora 1994), indicating that the fungus also produces the metabolites in vivo. Mandyam \& Jumpponen (2005) suggest that extensive endophyte colonization may also prevent grazing on roots, as many endophytes produce abundant melanized structures, where melanin discourages microbial grazing (Bell \& Wheeler 1986, Griffith 1994). Periconia macrospinosa extensively colonizes native grasses in the tallgrass prairie (Mandyam \& Jumpponen 2005). Periconia spp. congeneric to those from native prairies is known to produce chlorine containing compounds that may have antibiotic 


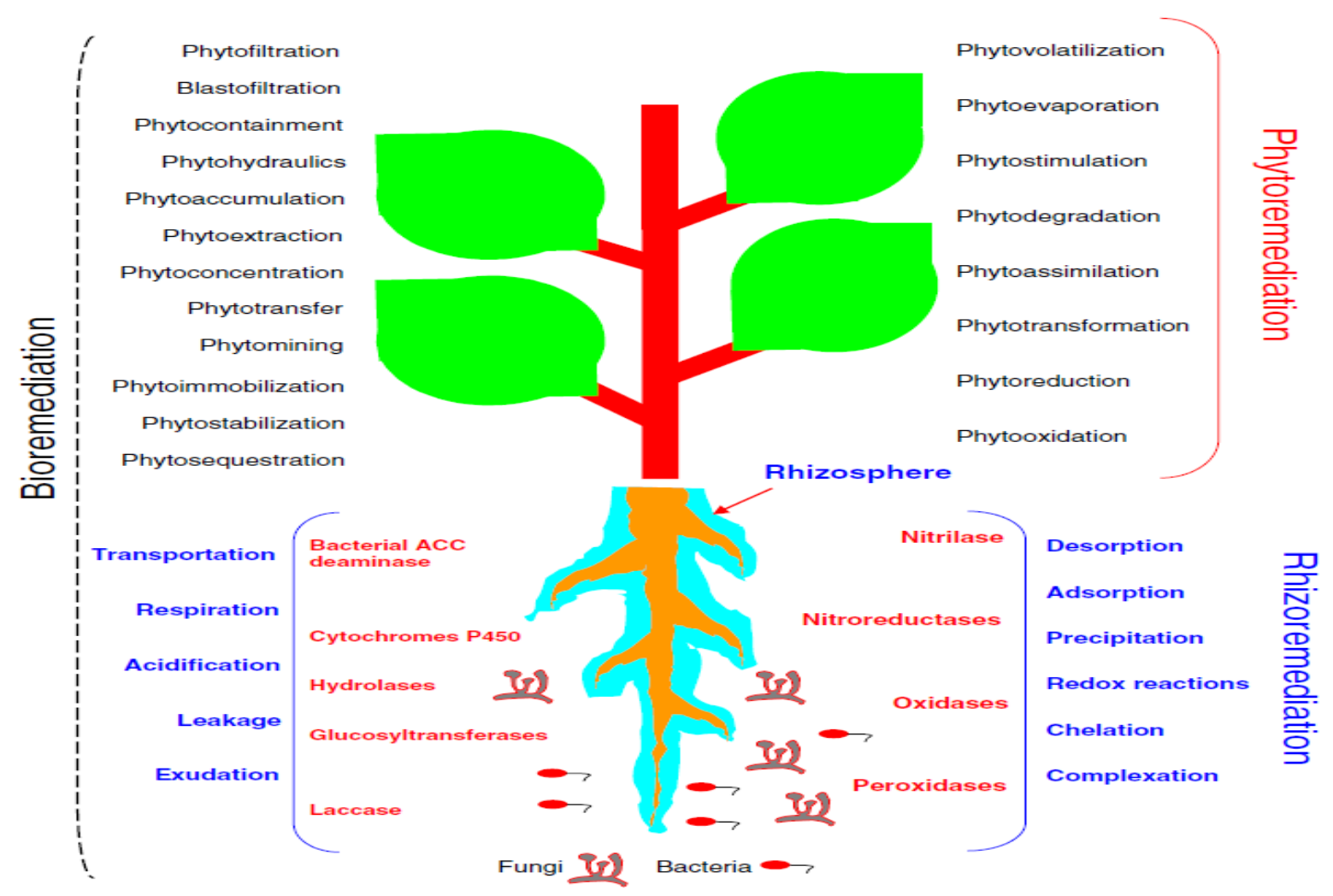

Fig. 12 - Importance of soil-plant-microbial interactions in bioremediation for the cleanup of metals and organics (pesticides, solvents, explosives, crude oil, polyaromatic hydrocarbons), Adapted from (Ma et al. 2011).

properties.

\section{Environmental Role of Endophytes}

Endophytes are found to play an important role in the ecological community, with the aim of decreasing the extent of environmental degradation, loss of biodiversity, and spoilage of land and water caused by excessive toxic organic insecticide, industrial sewage, and poisonous gases. Biological control using endophytes as a new efficient method is becoming widely used in environmental remediation, and in killing insects or pathogens (Guo et al. 2008).

A novel application of endophytes in the area of phytoremediation (plant assisted removal of xenobiotics and heavy metals from soil) has been reported in many reviews (Ma et al. 2011). However, the success of phytoremediation depends upon microbes and plant ability to tolerate and accumulate high concentrations of pollutant, while yielding a large biomass. Due to their importance for practical applications, pollutant-tolerant plantmicrobe associations have been the objective of particular attention due to the potential of microorganisms for bioaccumulating heavy metals and other pollutants from environment or its enhancing plant growth and pollutant uptake from soil by plant (Fig 12) through mobilization/ immobilization of pollutant $(\mathrm{Ma}$ et al. 2011).

Endophytes may play indirect or direct role in phytoremediation process and degradation of environmental toxins, indirectly through enhancing plant growth having ability of phytoremediation and this accelerate phytoremediation process (Fig 11), or directly through degradation and/or accumulating pollutants by itself. Van Aken et al. (2004) reported that new endophytic Methylobacterium populum sp. nov., strain BJ001, was involved in the degradation of energetic compounds such as 2,4,6-trinitrotoluene, hexahydro-1,3,5-trinitro-1,3,5-triazine, and hexahydro-1,3,5-trimtro-1,3,5-triazine. Newman \& Reynolds (2005) reported that plants inoculated with an engineered endophyte strain, had an increased plant tolerance to toluene and decrease in the transpiration of toluene to the atmosphere.

Currently bio-insecticides are becoming 
more widely used. Strobel \& Daisy (2003) summarized several endophytic insecticides naphthalene. Endophytes have a cryptic existence and one of their main role in the ecosystem are decomposers, as they are among the primary colonizers of dead plant tissues (Kumaresan \& Suryanarayanan 2002, Hyde \& Soytong 2008, Oses et al. 2008, Purahong \& Hyde 2011).

\section{Bio-Technological Endophytes}

\section{Applications}

Endophytes have high ability to produce various novel and known enzymes which could be used in various biotechnological applications like environmental applications of degradation enzymes, medical applications, and biotransformations of organic compounds with many advantage over other methods (Firáková et al. 2007, Pimentel et al. 2011, Sury et al. 2012).

\section{Enzymes Production by Endophytes}

Endophytes usually produce the enzymes necessary for the colonization of plant tissues. It has been demonstrated that most endophytes are able to utilize at least in vitro most plant nutrients and cell components. Most of investigated endophytes utilize xylan and pectin, show lipolytic activity and produce non-specific peroxidases and laccases, chitinase and glucanase (Sieber et al. 1991; Leuchtmann et al. 1992, Moy et al. 2002, Li et al. 2004, Promputtha et al. 2011). Endophytes may be a novel and good producers of xylanase and the production of extracellular cellulase and hemicellulases other than xylanases are widespread but usually limited to organisms derived from selected hosts or even host tissues (Leuchtmann et al. 1992; Suto et al. 2002). Thermostable amylolytic enzymes are being investigated to improve industrial processes for starch degradation. Streptosporangium sp. an endophytic actinomycete isolated from leaves of maize (Zea mays L.) showed glucoamylase production. The isolated enzyme exhibited thermostable properties (Stamford et al. 2002). The ability of endophytes to produce various enzymes in vivo and in vitro means that host supplies nutrients as well as habitats for endophyte colonization, and could be used for various biotechnological applications (Tomita 2003).

\section{Bio-Transformation Applications of Endophytes}

Biotransformation can be defined as the use of biological systems to produce chemical changes to compounds that are not in their natural substrates (Borges et al. 2007). The microbial growth, sustenance, and reproduction depends on the availability of a suitable form of reduced carbon source, used as chemical energy, which under normal conditions of culture broth are the common sugars. Microorganisms have high ability to adapt to new environments and to metabolize various foreign substrates to carbon and nitrogen sources (Doble et al. 2004). A molecule can be modified by transforming functional groups, with or without degradation of carbon skeleton. Such modifications result in the formation of novel and useful products not easily prepared by chemical methods (Borges et al. 2009). Pimentel et al. (2011) reported many of biotransformation processes by endophytes as following.

Biotransformation is a useful method for production of novel compounds with overcoming the problems associated with other chemical methods (Suresh et al. 2006). For this reason, the microbial biotransformation using their enzymatic systems has received increased attention as a method for the conversion of lipids, monoterpenes, diterpenes, steroids, triterpenes, alkaloids, lignans, and some synthetic chemicals, carrying out stereospecific and stereoselective reactions for the production of novel bioactive molecules with some potential for pharmaceutical and food industries (Borges et al. 2009, Figueiredo et al. 1996).

Endophytic microorganisms are able to produce many enzymes (Firáková et al. 2007), so they could be used as biocatalysts in the chemical transformation of natural products and drugs, due to their ability to modify chemical structures with a high degree of stereospecificity and to produce known or novel enzymes that facilitates the production of compounds of interest. The biotransformation of a tetrahydrofuran lignan, (-)-grandisin, by the endophytic fungus Phomopsis sp. from 


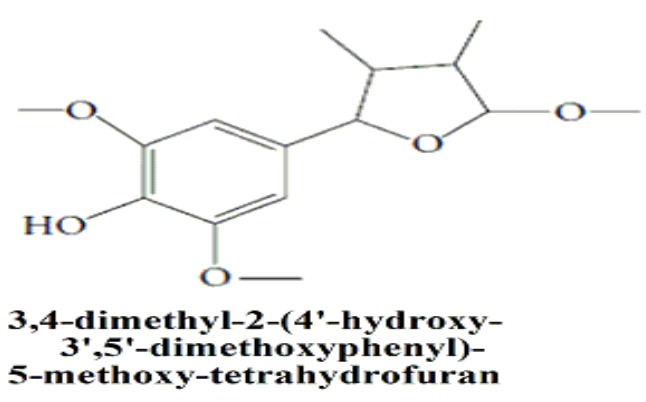

Fig. 13 - Structure of some Bio-transformable Products

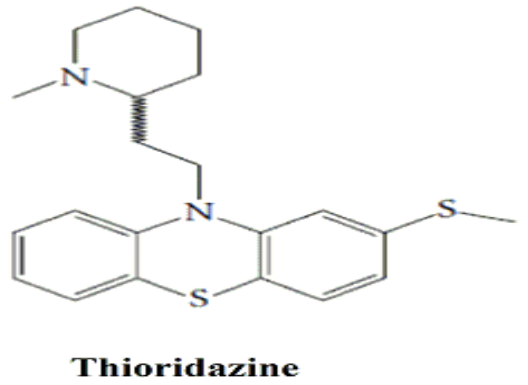

recently using $R$ - (+)-limonene, $L$-menthol, $\alpha$ and $\beta$-pinene, and $\alpha$-farnesene by diverse microorganisms (Farooq et al. 2002a \& b, Miyazawa et al. 2003, Krings et al. 2006, Maróstica \& Pastore 2007, Bicas et al. 2008). Other endophytic microbes were studied for the capability to biotransform natural products like taxoids, alkaloids, pigment curcumim, betulinic, and betulonic acids (Zhang et al. 1998, Shibuya et al. 2003, Bastos et al. 2007, Simanjuntak et al. 2010).

\section{Pharmaceutical applications of Endophyte Secondary Metabolites}

Endophytes are the chemical 3-one (HBOA), into a different series of compounds. The use of endophytic fungi in the stereoselective kinetic biotransformation of "thioridazine (THD)", a phenothiazine neuroleptic drug (Fig 13), was investigated. Results showed that these microorganisms are able to biomimic mammalian metabolism via biotransformation reactions (Borges et al. 2007). Another study employed endophytic fungus on the biotransformation of "propranolol (Prop)" to obtain 4-OH-Prop activemetabolite in enantiomerically pure form (Borges et al. 2009).

Another interesting biotransformation process is the use of endophytes in the biotransformation of terpenes for production of novel compounds through enzymatic reactions carried out by these microbes. "Terpenes" are large class of bioactive secondary metabolites used in the fragrance and flavor industries, and have been extensively used in biotransformation process by microorganisms with focus on the discovery of novel flavor compounds and on the optimization of the process condition (Bicas et al. 2009). Microbial transformations of terpenes were published synthesizers inside plants (Owen \& Hundley 2004). Many of them are capable of synthesizing bioactive compounds that can be used as potential sources of pharmaceutical leads. Endophytic fungi have been proven useful for novel drug discovery as suggested by the chemical diversity of their secondary metabolites. Many endophytic fungi have been reported to produce novel antibacterial, antifungal, antiviral, anti-inflammatory, antitumor, and other compounds belonging to the alkaloids, steroid, flavenoid and terpenoids derivatives and other structure types (Guo et al. 2008, Yu et al. 2010). Aly et al. (2011), De Souza et al. (2011) and Gutierrez et al. (2012) summarized in amazing reviews the up-to-date and comprehensive information on compounds from endophytes fungi from 1995 to 2011, pharmacology and toxicology, and discussed the possible trends and the scope for future research of endophytes.

The pharmaceutical and medical concerns of new drugs are the toxicity of these prospective drugs to human tissues. Since the together with the botany, phytochemistry, 

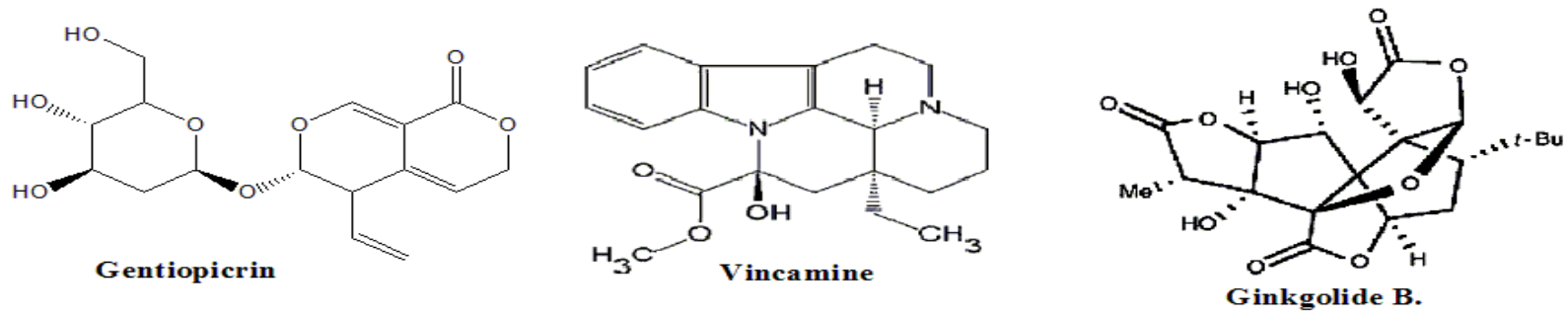

Fig. 14 - Structure of Some Important Phytochemical Metabolites Produced by Endophytes

plant tissue where the endophytes exist is a eukaryotic system, it would appear that the secondary metabolites produced by the endophytes may have reduced cell toxicity; otherwise, death of the host tissue may occur. Thus, the host itself has naturally served as a selection system for microbes having bioactive molecules with reduced toxicity toward higher organisms (Strobel 2003).

Endophytes are universally present in all of the world's higher plants, so it was reasoned that plants might support certain endophytic microorganisms that could synthesize important phytochemicals of medicinal plants as well as the plant itself. Thus, if a microbial source of the drug was available, it could eliminate the need to harvest and extract the slow-growing and relatively rare trees. The price for the drug would also be reduced, since the drugs could be produced via fermentation in such the same way that penicillin is fermented (Strobel 2003).

Many reports supported this idea. It began with the discovery of taxol producing endophytes, the most potent anticancer drug, from the culture of the endophytic fungi, Taxomyces andreanae isolated from Taxus brevifolia tree, and endophytic fungus Pestalotiopsis microspora from medicinal plants Taxus wallichiana and bald cypress Taxodium distichum (Stierle et al. 1993, Strobel et al. 1993, Li et al. 1996, Strobel et al. 1996). Taxol has also been found in a number of different fungal endophytes such as Phyllosticta spinarum, Bartalinia robillardoides, Pestalotiopsis terminaliae, Botryodiplodia theobromae. Also, other common endophytic genera such as Alternaria, Aspergillus, Botrytis, Cladosporium, Fusarium, and Mucor spp. have been reported as producers of taxol (Gangadevi \& Muthumary 2008, Kumaran et al. 2008, Gangadevi \& Muthumary 2009, Pandi et al. 2010, Zhao et al. 2010).
Gentiana macrophylla is a traditional Chinese medicinal plant. Its dominant active constituents are secoiridoids, mainly gentiopicrin (Fig14). The biological and pharmacological effects of its active principles include stomachic, choleretic, antihepatotoxic, antinflammatory, antifungal and antihistamine activities. Endophytic fungal strain QJ18 were found to produce the bioactive compound gentiopicrin like its host plant G. macrophylla (Yin et al. 2009). Also, the medicinal plant Vinca minor contains the alkaloid vincamine (Fig14), which is used in the pharmaceutical industry as a cerebral stimulant and vasodilator. An extract from endophytic fungus ( Vm-J2) were shown to produce the same bioactive ingredient, vincamine, as the host plant (Yin \& Sun 2011). Thus, endophyte production of natural metabolites may help to protect the natural resources and to satisfy the requirement of drugs via production of plant-derived pharmaceutical leads by fermentation. Cui et al. (2012) supported this idea by isolation of ginkgolide B from endophytic fungus Fusarium oxysporum isolated from Ginkgo biloba.

\section{Anti Cancer Agents from Endophytes}

Cancer is a disease characterized by unregulated cell proliferation, and leads to spread of abnormal cells and uncontrolled tissue growth (American Cancer Society 2009). It has been considered one of the major causes of death worldwide (about 13\% of all deaths) in 2004 (WHO 2009). There are some evidences that bioactive compounds produced by endophytes could be alternative approaches for discovery of novel anticancer drugs (Firáková et al. 2007, Guo et al. 2008, Debbab et al. 2011). Chandra (2012) reported many of endophytic fungi as novel sources of anticancer lead molecules.

The discovery of taxol-producing endophytes opened the way for investigating 
the anticancer properties of secondary metabolites of fungal endophytes. A selectively cytotoxic quinone dimmer, torreyanic acid (Fig 15), an important anticancer agent, was isolated from the endophytic fungus, Pestalotiopsis microspora associated with a tree Torreya taxifolia, and was shown 5 to 10 times more potent cytotoxicity in cell lines that are sensitive to protein kinase $\mathrm{C}$ agonists and causes cell death by apoptosis (Lee et al. 1996). Recently, Mirjalili et al. (2012) identified endophytic Stemphylium sedicola SBU-16 from the inner bark of Taxus baccata with Taxus taxadiene synthase (ts) gene, which encodes the enzyme catalyzing the first committed step of taxol biosynthesis.

The alkaloids are one of most potent anticancer agents, usually found in endophytic fungi. Wagenaar et al. (2000) reported identification of three novel cytochalasins alkaloid (Fig 15), possessing antitumor activity, from the endophytic genus Rhinocladiella. Other important anticancer alkaloids are camptothecin (Fig 15) and its derivatives, a potent antineoplastic agents; camptothecin is used as a drug for treatment of skin diseases in China (Guo et al. 2008). Camptothecin and 10-hydroxycamptothecin are two important precursors for the synthesis of the clinically useful anticancer drugs, topotecan, and irinotecan (Uma et al. 2008). An endophytic fungus isolated from the inner bark of the plant Nothapodytes foetida, was found to produce the anticancer lead compound camptothecin when grown in a synthetic liquid medium (Sabouraud broth) under shake flask and bench scale fermentation conditions (Puri et al. 2005). The anticancer compounds Camptothecin and two analogues (9methoxycamptothecin and 10-hydroxycamptothecin) were also obtained from the endophytic fungus Fusarium solani isolated from Camptotheca acuminata (Kusari et al. 2009b). Several reports have described other Camptothecin and/or analogues producing endophytes (Amna et al. 2006, Rehman et al. 2008, Liu et al. 2010b, Shweta et al. 2010).

Lignans are other kinds of anticancer agents originated as secondary metabolites through the shikimic acid pathway and display different biological activities that make them interesting medically (Gordaliza et al. 2004).
Lignans show enormous structural and biological diversity, especially in cancer chemotherapy (Korkina et al. 2007). Puri et al. (2006) identified a novel fungal endophyte (Trametes hirsuta) that is able to produce aryl tetralin lignans "podophyllotoxins" (Fig 15). The lignans produced by the microorganism are biologically active, and exhibit potent antioxidant, anticancer, and radioprotective properties. Derivatives of podophyllotoxins are currently used in cancer chemotherapy against various cancer diseases. Also, phenylpropanoids have attracted much interest for medicinal applications mainly as anticancer and antioxidant agents, and were reported to be produced by endophytes (Korkina et al. 2007). The endophytic Penicillium brasilianum, isolated from root bark of Melia azedarach, promoted the biosynthesis of phenylpropanoid amides (Fill et al. 2010).

The endophytic fungus Curvularia lunata isolated from Niphates olemda, was found to produce cytoskyrins (Fig 15), which show antibacterial activity, and is considered as a potential anticancer agent (Brady et al. 2000, Jadulco et al. 2002). Also, an endophytic fungus Phoma medicaginis associated with medicinal plants Medicago sativa and Medicago lupulina, yielded the antibiotic brefeldine A (Fig 15), which also initiated apoptosis in cancer cells (Weber et al. 2004b). Ergoflavin (Fig 15) is a dimeric xanthene, belonging to the class of ergochromes, and was described as a novel anticancer agent isolated from an endophytic fungi growing in leaves of medicinal plant Mimusops elengi (Deshmukh et al. 2009). Secalonic acid D also belonging to the ergochrome class, and known to have potent anticancer activities, was isolated from the mangrove endophytic fungus and showed high cytotoxicity on HL60 and K562 cells by inducing leukemia cell apoptosis (Zhang et al. 2009).

Many of endophytes fungal metabolites posses' strong cytotoxicty against different cancer cell lines, which could be useful for discovery of lead anticancer drugs. Endophytic unidentified fungus XG8D isolated from leaf tissues of the mangrove plant Xylocarpus granatum, yielded a new nor-chamigrane endoperoxide, merulin A (Fig 15), and new chamigrane endoperoxides, merulin C (Fig 15). 


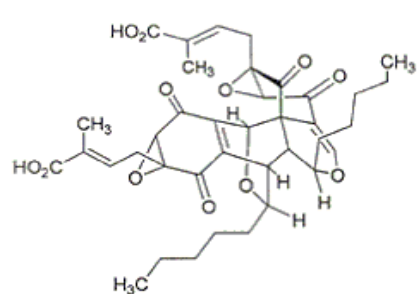

Torreyanic acid

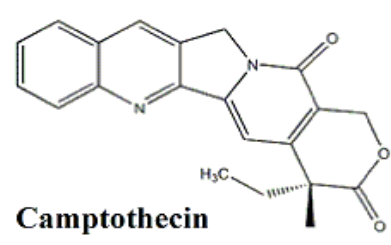

Aryl Tetralin Lignans (Podophyllotoxins)

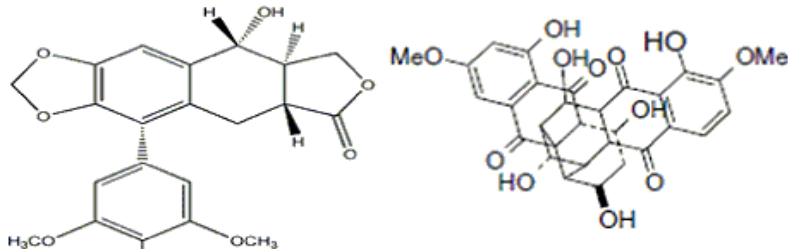

Cytoskyrins

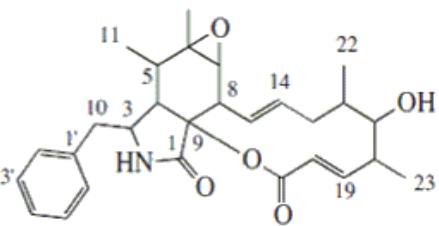<smiles>CCC(C)(O)C(=O)C(C)CCC(=O)OC1C(=O)NC(Cc2ccccc2)C2C1C1OC1(C)C2C</smiles><smiles>CC(CCC(=O)OC1C(=O)NC(Cc2ccccc2)C2C1C1OC1(C)C2C)C(=O)C(CO)CCO</smiles>

Three Novel Cytochalasins Alkaloid<smiles>CC1CCC/C=C/C2=C(CC(O)C2)C(O)/C=C/C(=O)O1</smiles>

Brefeldine A
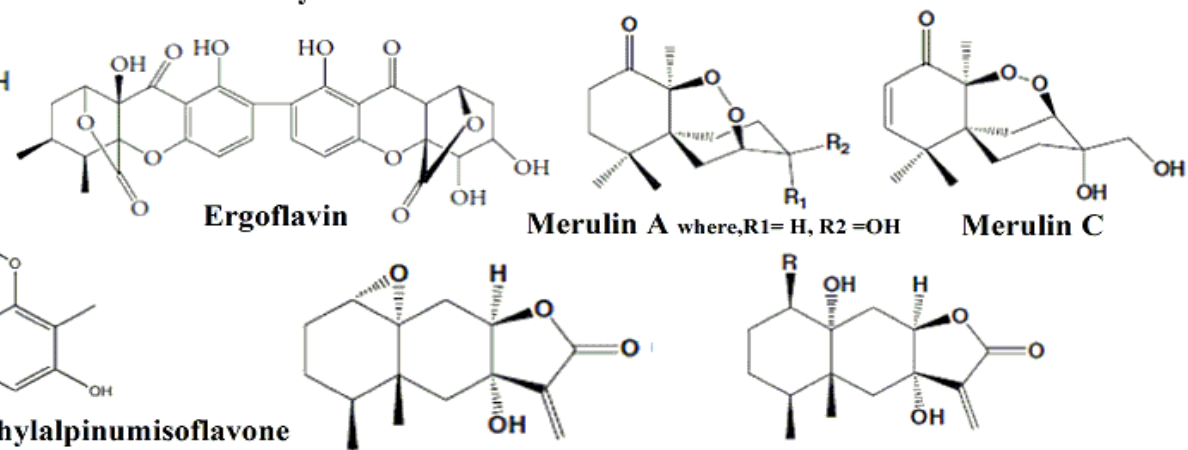

Three sesquiterpenoids Eremophilane-type, where $\mathrm{R}=\mathrm{OH}$-or- $\mathrm{OCH} 3$<smiles>Cc1cc(O)cc(Oc2cc(C)c(Cc3ccc(C(Br)(Br)CCCCC(C)C)c(O)c3)c(O)c2)c1</smiles>

Expansols $A$ and $B$, where $\mathrm{R}=\mathrm{OCH} 3-\mathrm{or}-\mathrm{OH}$<smiles>C=C(/C=C/c1oc(=O)c(CO)c(OC)c1CO)OC</smiles>

Allantopyrone A
Islandic acid-II methyl ester<smiles>[R]C(C)CC(C)c1ccc2c(OC)c1Oc1c(O)cc(C)cc1COC2=O</smiles>

Paeciloxocins A, R $=\mathrm{OH}$

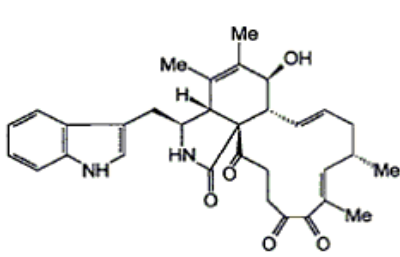

Chaetoglobosin G

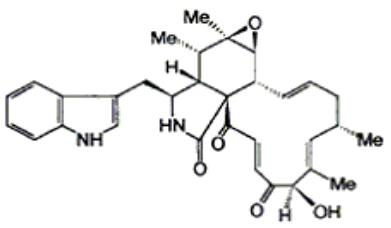

Chaetoglobosin A

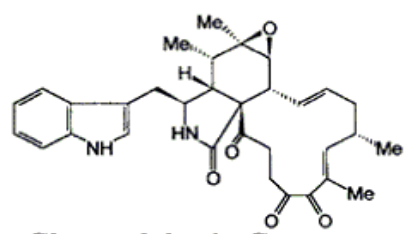

Chaetoglobosin $\mathrm{C}$

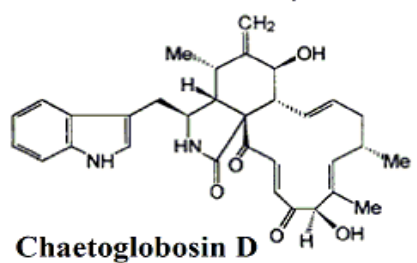

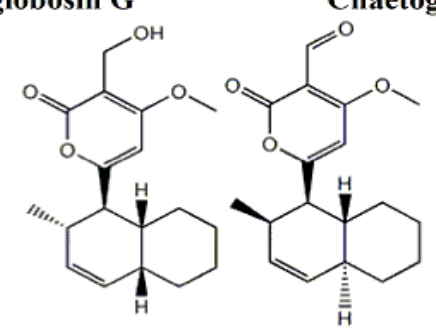

Solanapyrone A Solanapyrone D

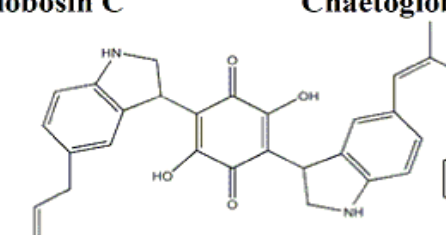

Cochliodinol

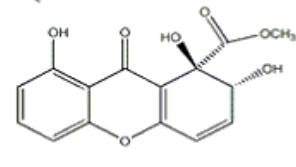

Globosuxanthone
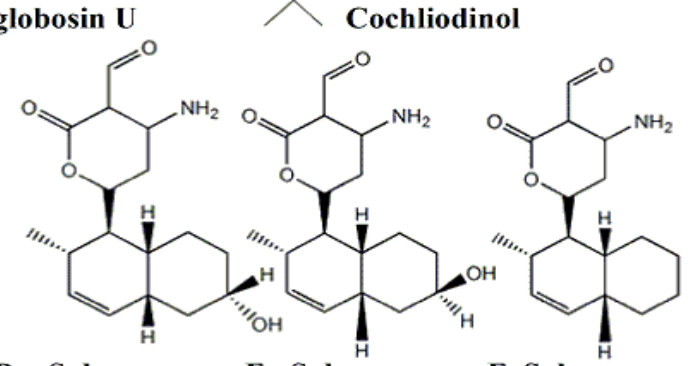

Solanapyrone E Solanapyrone F Solanapyrone G

Fig. 15 - Structure of some Anticancer Agents Isolated from Endophytic Fungi 
They showed cytotoxicity against BT474 cell lines with $\mathrm{IC}_{50}$ values of 19.60 and $5.57 \mu \mathrm{M}$, respectively, and activity against SW620 cell lines with $\mathrm{IC}_{50}$ values of 19.05 and $14.57 \mu \mathrm{M}$, respectively (Chokpaiboon et al. 2010). The chemical investigation of endophytic fungus Fusarium sp., isolated from stems of the mangrove tree Kandelia candel, lead to isolation of new isoflavone,5-O-methyl-2:methoxy-3`-methylalpinumisoflavone (Fig 15), it inhibited the growth of HEp-2 and HepG2 cancer cell lines with $\mathrm{IC}_{50}$ values of 4 and $11 \mu \mathrm{M}$, respectively (Huang et al. 2010). Isaka et al. (2010) isolated three new eremophilanetype sesquiterpenoids (Fig 15) from culture of endophytic fungus Xylaria sp., obtained from the palm Licuala spinosa. The compounds exhibited moderate cytotoxic activities with $\mathrm{IC}_{50}$ values ranging from 3.8 to $21.0 \mu \mathrm{M}$ against human cancer cell lines (KB, MCF-7, and NCIH187) and nonmalignant Vero cells.

$\mathrm{Lu}$ et al. (2010) investigated the endophytic fungus Penicillium expansum, isolated from roots of the mangrove plant Excoecaria agallocha, and found it to produce the new polyphenols, expansols A \& B (Fig 15). Expansols A exhibited moderate cytotoxic activity against HL-60 cell line with an $\mathrm{IC}_{50}$ value of $15.7 \mu \mathrm{M}$, while expansols B showed pronounced activity with $\mathrm{IC}_{50}$ value $1.9 \mu \mathrm{M}$. The endophytic fungal strain Allantophomopsis lycopodina, afforded the new natural product allantopyrone A (Fig 15) and the known islandic acid-II methyl ester (Fig 15). Both compounds exhibited cytotoxic activity against HL60 cells with IC $_{50}$ values of 0.32 and 6.55 $\mu \mathrm{M}$, respectively, with observed internucleosomal fragmentation when cells undergo apoptosis, which indicate induction of apoptosis by this compounds (Shiono et al. 2010). New depsidone-type metabolites, named paeciloxocins A (Fig 15) was isolated from endophytic Paecilomyces sp., isolated from the bark of mangrove. Its showed significant cytotoxicity against $\mathrm{HepG} 2$ cell line $\left(\mathrm{IC}_{50} 2.69 \mu \mathrm{M}\right)$, and it inhibited the growth of microbial pathogen Curvularia lunata and Candida albicans as well (Wen et al. 2010). Finally, other compounds with anticancer properties isolated from endophytic microbes were reported such as phomoxanthones A-B, and photinides A-F (Isaka et al. 2001, Ding et al. 2009).
The screening of crude extracts of endophytic fungi of medicinal plants, showed promising antitumor activity against different cancer cell lines, as $13.4 \%$ of endophytic extracts were cytotoxic on HL-60 cells and $6.4 \%$ on KB cells (Huang et al. 2001). 9.2\% of other endophytic isolates exhibited antitumour activity on human gastric tumour cell line BGC-823 (Li et al. 2005). Another study showed that $3.3 \%$ of endophytic extracts display potent $\left(\mathrm{IC}_{50}<0.01 \mu \mathrm{g} / \mathrm{ml}\right)$ cytotoxic activity against the murine leukemic P388 cell line and $1.7 \%$ against a human chronic myeloid leukemia cell line K562 (Hazalin et al. 2009). Kumar et al. (2004) investigated the crude extracts of 343 endophytic fungi isolates and detect thier in vitro suppressive activity on phytohemaglutinin (PHA) stimulated proliferation of human peripheral blood mononuclear cells (PBMC). In addition, Banu \& Kumar (2009) reported sixteen endophytic fungal isolates exhibit antitumor activity in the yeast cell-based assay.

The cytotoxicity effect of some fungal endophytes on mouse fibroblast cell line L-929 with their effects on nuclear morphology, cell division, actin microfilaments and endomembrane system of PtK2 potoroo kidney cells revealed that some of the endophytes produced metabolites that impair cell division (Suryanarayanan et al. 2009). Among the active endophytes is a genus Chaetomium that produced chaetoglobosins, which are cytochalasin analogs that inhibit actin polymerization (Yahara et al. 1982) (Fig 16). Chaetomium is a genus known to produce different types of cytotoxic metabolites including chaetomin, chaetoglobosins (Fig 15) A, C, D, and G, chaetoquadrins, oxaspirodion, chaetospiron, orsellides and chaetocyclinones (Lösgen et al. 2007). The common endophytic fungus Chaetomium globosum, a lot of its isolated compounds show anticancer activity, produced chaetoglobosin U (Fig 15) which exhibited cytotoxic activity against the human nasopharyngeal epidermoid tumor $\mathrm{KB}$ cell line (Ding et al. 2006), also produced globosuxanthone (Fig 15) which showed strong cytotoxicity against a seven human panel solid tumor cell lines (Wijeratne et al. 2006), and produce cochliodinol (Fig 15) which proved to be highly active against the cancer cell line 


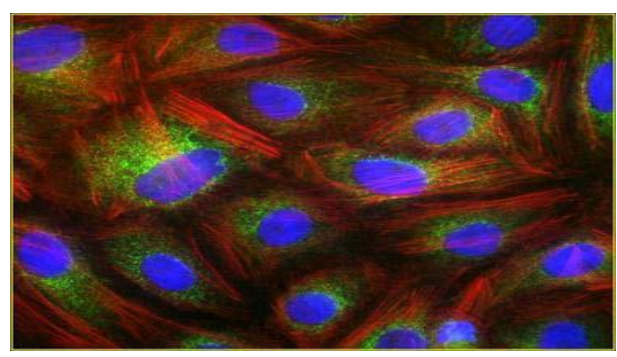

Control

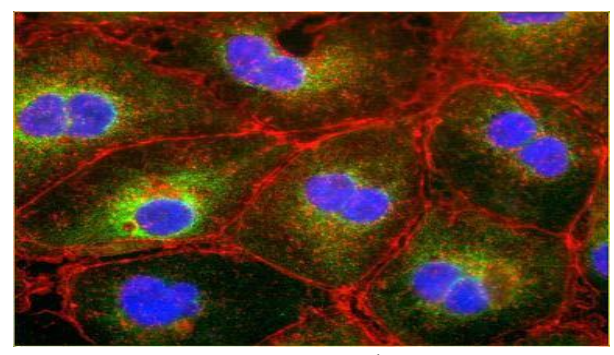

Treated

Fig. 16 - Effect of culture extract from endophytic Chaetomium sp. on mouse fibroblast cell line L-929. Note cell enlargement, loss of actin fibres and failure of cell division after nuclear division. (Nucleus stained with blue florescent dye and actin with red fluorescent dye). Adapted from: (Suryanarayanan et al. 2009).

(L5178Y mouse lymphoma cell line) with an $\mathrm{EC}_{50}$ of $7.0 \mu \mathrm{g} / \mathrm{ml}$ (Debbab et al. 2009).

An endophytic Alternaria sp. elaborated several solanapyrones (Fig 15) A, $\mathrm{D}, \mathrm{E}, \mathrm{F}$, and $\mathrm{G}$, which are inhibitors of DNA polymerases (Mizushina et al. 2002). Endophytic Nigrospora oryzae produced aphidicolin and several of its derivatives, nigrosporolide, phomalactone, bostrycin and epoxyexserohilone. Aphidicolin is a tetracyclic diterpene-tetraol and an inhibitor of nuclear DNA synthesis in eukaryotes, it inhibited DNA synthesis by interfering with DNA polymerase $\alpha$ enzyme, also this metabolite reported to inhibit the $\mathrm{S}$ phase of the cell cycle (Ikegami et al. 1979, Spadari et al. 1982). Furthermore, endophytic Fusarium sp. was shown to produce apicidin which is a histone deacetylase inhibitor that inhibits cell division, and enniatins which are known to function as inhibitors of the yeast transporter protein Pdr5p (Han et al. 2000, Hiraga et al. 2005). From the previous, certain endophytic genera such as Alternaria, Chaetomium, Colletotrichum, Curvularia, Nigrospora and Xylaria produce a larger number of cytotoxic compounds that could be used in discovery of new anticancer agents (Suryanarayanan et al. 2009).

\section{Antimicrobial Agents from Endophytes}

Antimicrobial metabolites (Antibiotics) can be defined as low-molecular-weight organic compounds made by microorganisms that are active at low concentrations against other microorganisms, not required for its growth, produced as an adaptation for specific functions in nature, and are the most bioactive natural products isolated from endophytes (Demain 1981, Strobel \& Daisy 2003, Guo et al. 2008). Endophytes are believed to carry out a resistance mechanism to overcome pathogenic invasion by producing secondary metabolites bearing antimicrobial activity. It is believed that screening for antimicrobial compounds from endophytes is a promising way to overcome the increasing threat of drug resistant microbes of human and plant pathogen (Tan \& Zou 2001, Yu et al. 2010). The antimicrobial compounds can be used not only as drugs by humankind but also as food preservatives in the control of food spoilage and food-borne diseases, a serious concern in the world food chain (Liu et al. 2008).

The screening of endophytic fungi crude extracts for their antimicrobial activity indicates that they may possess the steadiness antimicrobial activity against tested pathogens such as Staphylococcus aureus, Bacillus subtilis, Saccharomyces cerevisiae and Alternaria sp., etc. Li et al. (2005) reported $30 \%$ of tested isolates exhibited antifungal activity, also antimicrobial activity was demonstrated for $8 \%-92 \%$ of endophytic extracts in other studies (Banu \& Kumar 2009, Hazalin et al. 2009, Tong et al. 2011).

Cryptocin (Fig 17.a) and cryptocandin (Fig 17.b) are antifungal metabolites obtained from the endophytic fungus Cryptosporiopsis cf. quercina. Cryptocandin demonstrated excellent antifungal activity against some important human fungal pathogens, including Candida albicans and Trichophyton spp., and against a number of plant pathogenic fungi, including Sclerotinia sclerotiorum and Botrytis cinerea. Cryptocandin and its related compounds are currently being considered for use against a number of fungi causing diseases of the skin and nails (Strobel \& Daisy 2003). Cryptocin however possesses potent activity against plant pathogens only, especially against 
Pyricularia oryzae, the causal organism of one of the worst plant diseases in the world, with minimum inhibitory concentration $0.39 \mu \mathrm{g} / \mathrm{ml}$ (Strobel et al. 1999b, Li et al. 2000). The endophytic fungus Pestalotiopsis microspora was found to produce number of antifungal metabolites, like ambuic acid, pestaloside, and pestalotiopsins A and B (Fig 17.a). They showed activity against many of pathogenic fungi, while pestaloside possess also phytotoxic properties. An endophytic fungi Pestalotiopsis jesteri and Pestalotiopsis adusta were found to synthesized jesterone (Fig 17.a) and Pestalachlorides A respectively, which exhibit antifungal activity against a variety of plant pathogenic fungi ( $\mathrm{Li}$ et al. 2008a). Pestalachlorides A was proven to display significant antifungal activity against three plant pathogenic fungi, Fusarium culmorum, Gibberella zeae, and Verticillium albo-atrum (Lee et al. 1995b, Pulici et al. 1996, Li et al. 2001, Li \& Strobel 2001, Li et al. 2008a).

$\mathrm{Lu}$ et al. (2000) isolated three metabolites (Fig 17.a) from the culture of endophytic fungus Colletotrichum sp., residing in the medicinal Artemisia annua. These compounds were shown to have not only have activity against human-pathogenic fungi and bacteria but also be fungistatic to plantpathogenic fungi. Krohn et al. (2002) reported fusidikactones (Fig 17.a) with antifungal activity from endophytic Fusidium species. Preaustinoid A, B (Fig 17.a) isolated from Penicillium sp., exhibited moderate bacteriostatic effect on Escherichia coli, Staphylococcus aureus, Pseudomonas aeruginosa, Bacillus sp. (Dos Santos \& Rodrigues-Fo 2003). Kim et al. (2004) isolated antibacterialpericonicins A and B (Fig 17.b) from endophytic fungus Periconia sp. isolated from host plant Taxus cuspidate. Among metabolites produced by the endophytic fungus Aspergillus fumigatus CY018 asperfumoid (Fig 17.a), fumigaclavine $\mathrm{C}$, fumitremorgin $\mathrm{C}$, physcion, and helvolic acid were shown to inhibit Candida albicans (Liu et al. 2004).

Investigation of endophytic fungus Rhizoctonia sp. yielded rhizoctonic acid (Fig 17.a) with anti-helicobacter pylori activity, the causative bacteria of peptic ulcer ( $\mathrm{Ma}$ et al. 2004). Song et al. (2004) reported isolation of rubrofusarin $\mathrm{B}$, fonsecinone $\mathrm{A}$, asperpyrone $\mathrm{B}$, and aurasperone A (Fig 17.a) from Aspergillus niger IFB-E003, an endophyte in Cyndon dactylon. The four metabolites exhibited growth inhibitions against the pathogenic microbes with minimal inhibitory concentrations (MICs) ranging in between 1.9 and 31.2 $\mu \mathrm{g} / \mathrm{ml}$. Another novel antibiotic-phomol was isolated from fermentations of an endophytic fungus Phomopsis species, another two antimicrobial agents cytosporone B and C (Fig 17.b) were isolated, from the same genus Phomopsis sp.; they inhibited two fungi Candida albicans and $F$. oxysporum with the MIC value ranging from 32 to $64 \mathrm{mg} / \mathrm{ml}$. Investigation of endophytic Phomopsis cassia, ethyl 2,4-dihydroxy-5,6-dimethylbenzoate and phomopsilactone displayed strong antifungal activity against two phytopathogenic fungi, Cladosporium cladosporioides, and $C$. sphaerospermum (Weber et al. 2004, Silva et al. 2005, Huang et al. 2008b).

Chemical investigations of corn endophyte Acremonium zeae led to the discovery of two antibiotics pyrrocidines A and B (Fig 17.b), which displayed significant antifungal activity against Aspergillus flavus and Fusarium verticillioides (Wicklow et al. 2005). More than $50 \%$ of endophytic fungal strains residing in Quercus variabilis possessed growth inhibition against at least one pathogenic fungi or bacteria. Cladosporium sp., displaying the most active antifungal activity, was investigated and found to produce a secondary metabolite known as brefeldin A with antibiotic activity (Wang et al. 2007). The antimicrobial agents Hypericin (Fig 17.a) and Emodin were produced by Hypericum perforatum. Both compounds possessed antimicrobial activity against several bacteria and fungi, including Staphylococcus aureus ssp. aureus, Klebsiella pneumoniae ssp. ozaenae, Pseudomonas aeruginosa, Salmonella enterica ssp. Enteric, and Escherichia coli, and fungal and candidal pathogens Aspergillus niger and C. albicans (Kusari et al. 2008). Chaetoglobosins $\mathrm{A}$ and $\mathrm{C}$ with antifungal activities were characterized from the culture of an endophytic Chaetomium globosum isolated from leaves of Ginkgo biloba. In agar diffusion method, these two metabolites were shown antimicrobial activity against Mucor miehei (Qin et al. 2009). 
The endophytic genus Xylaria was investigated as producers of many antifungal agents; species produce griseofulvin (Fig 17.a) which is used for the treatment of human and veterinary animals mycotic diseases. Sordaricin and multiplolides had antifungal activity against Candida albicans,7-amino-4methylcoumarin showed broad-spectrum inhibitory activity against several food-borne and food spoilage microorganisms. It was suggested for use as natural preservatives in food. In vitro and in vivo antifungal activity of endophyte-produced griseofulvin against plant pathogenic fungi were effective for controlling effectively the development of various food crops diseases (Boonphong et al. 2001, Cafěu et al. 2005, Park et al. 2005, Liu et al. 2008, Pongcharoen et al. 2008).

Curvularide B (Fig 17.a) was isolated from the endophyte Curvularia geniculata and showed antifungal activity with increase in inhibition zone in the presence of fluconazole (example of currently used azol drug), which indicated the synergistic effect of both drugs against Candida albicans. The minimum inhibitory concentrations (MIC) values that produced no visible growth (MIC-0) for fluconazole and curvularide B were 26.1 and $782.8 \mu \mathrm{M}$, respectively. While in combination, the MIC- 0 values decreased to 3.2 and $48.9 \mu \mathrm{M}$, respectively. Curvularide $\mathrm{B}$ did not exhibit cytotoxicity towards ten human cancer cell lines even at a concentration of $50 \mu \mathrm{g} / \mathrm{ml}$, which indicates positive results for using it to improve activity of azol antifungal drugs (Chomcheon et al. 2010). The mangrove derived endophytic fungus Talaromyces sp. produced the antimicrobial metabolites (7-epiaustdiol, stemphyperylenol and secalonic acid A). 7-epiaustdiol (Fig 17.a) displayed significant inhibitory activity against Pseudomonas aeruginosa, a multidrug resistant opportunistic pathogen, with MIC value of $26.48 \mu \mathrm{M}$. Stemphyperylenol (Fig 17.a) inhibited Sarcina ventriculi with MIC value of $8.86 \mu \mathrm{M}$, which is lower than that of ampicillin $(35.81 \mu \mathrm{M})$, while secalonic acid A (Fig 17.a) exhibited high activities against all tested organisms. Furthermore, the three compounds showed moderate to strong cytotoxicity against $\mathrm{KB}$ and KBv200 cell lines (Liu et al. 2010c).

Fumigants are produced by many of endophytes. Muscodor is a novel endophytic fungal genus that produces bioactive volatile organic compounds (VOCs). This fungus, as well as its VOCs, has enormous potential for uses in agriculture, industry and medicine. Endophytic Muscodor albus and the most recent discovered Muscodor crispans produce a mixture of VOCs that act synergistically to kill a wide variety of plant and human pathogenic fungi and bacteria. It is also effective against nematodes and certain insects. This mixture of gases consists primarily of various alcohols, acids, esters, ketones and lipids (Fig 17.a). Artificial mixtures of the VOCs mimic the biological effects of the fungal VOCs when tested against a wide range of fungal and bacterial pathogens. Potential applications for "mycofumigation" by this genus are currently used for treating various plant diseases, buildings, soils, agricultural produce and human wastes. Another promising option includes its use to replace methyl bromide fumigation as a means to control soilborne plant diseases (Strobel 2006 a \& b, Strobel 2011).

Recently, Tuberculosis inhibitors were found among endophytes, some of endophytes were found to inhibit Mycobacterium aurum and Mycobacterium tuberculosis, the causative organisms of tuberculosis. Rukachaisirikul et al. (2008) isolated phomoenamide (Fig 17.b) which exhibited in vitro antimycobacterial activity against $M$. tuberculosis H37Ra. The screening of endophytic extracts, lead to isolation of endophytic isolate from Vaccinium myrtillus which show MIC $8 \mu \mathrm{g} / \mathrm{ml}$ against $M$. aurum, and endophytes from Calluna vulgaris, Empetrum nigrum, Vaccinium vitis-idaea and $V$. myrtillus which show 90 to $96 \%$ inhibition at $100 \mu \mathrm{g} / \mathrm{ml}$ against $M$. tuberculosis (Gordien et al. 2010). Chemical analysis of mangrove endophytes Fusarium sp. led to the isolation of fusaric acid which used for synthesis a variety of metal complexes of fusaric acid. Antimycobacterial assays showed that Cadmium (II) and Copper (II) complexes exhibited potent inhibitory activity against $M$. bovis BCG strain with MIC $4 \mu \mathrm{g} / \mathrm{mL}$ and $M$. tuberculosis H37Rv strain with MIC $10 \mu \mathrm{g} / \mathrm{ml}$ (Pan et al. 2011). Verma et al. (2011) reported the endophytic fungus Periconia sp. produces piperine with strong antimycobacterial activity 

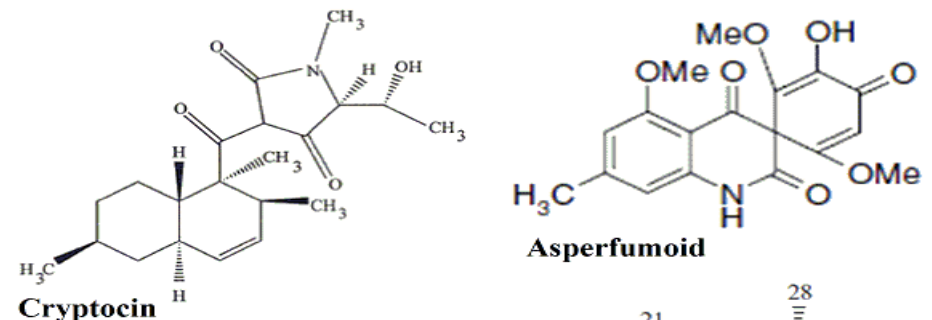

Asperfumoid

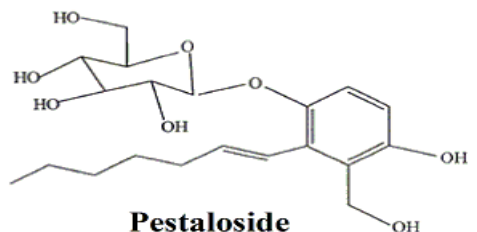

Pestaloside

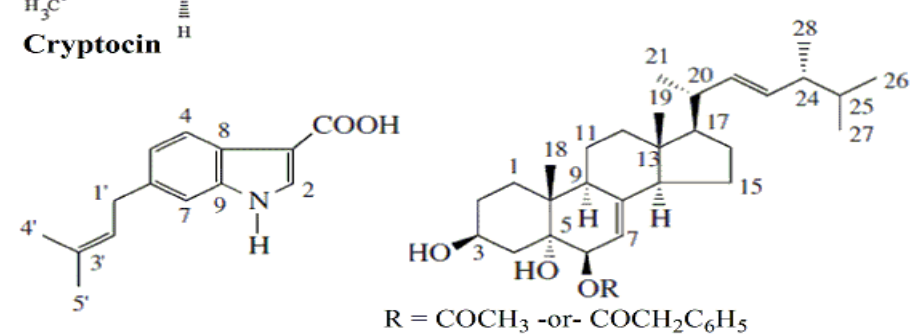

$\mathrm{R}=\mathrm{COCH}_{3}$-or- $\mathrm{COCH}_{2} \mathrm{C}_{6} \mathrm{H}_{5}$

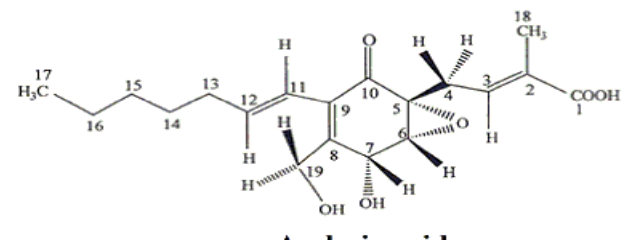

Ambuic acid

Three metabolites from the culture of endophytic Colletotrichum sp.

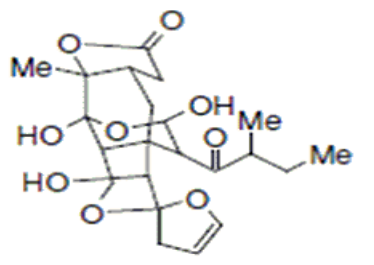

Fusidikactones

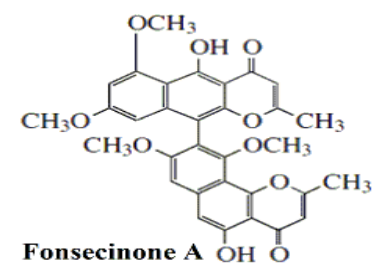

Fonsecinone $\mathrm{A}$ OH

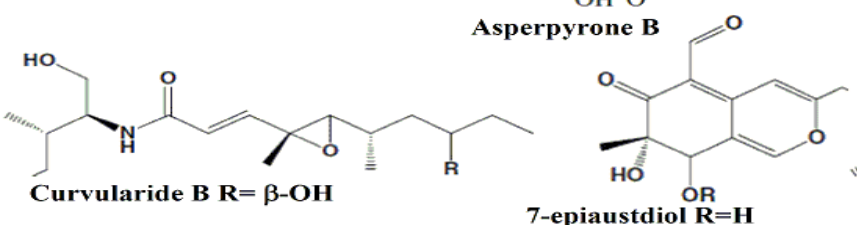

7-epiaustdiol $\mathbf{R}=\mathbf{H}$

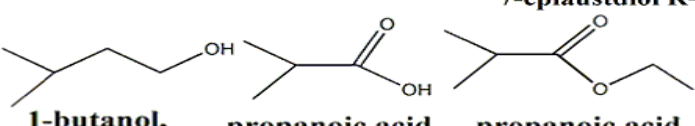

1-butanol, 3- methyl

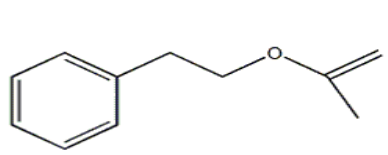

Acetic acid, 2-phenylethyl ester

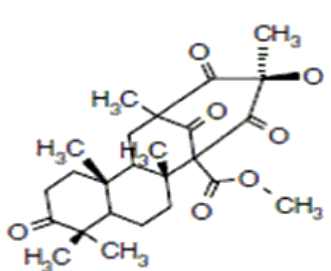

Preaustinoid

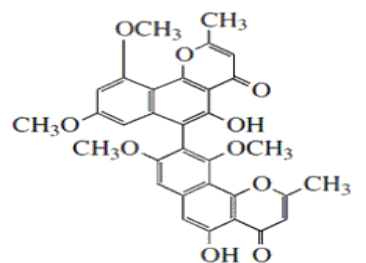

Asperpyrone

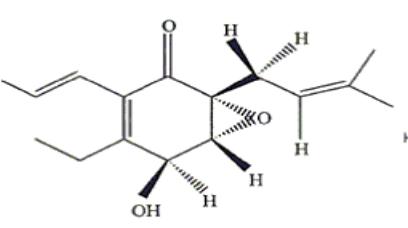

Jesterone

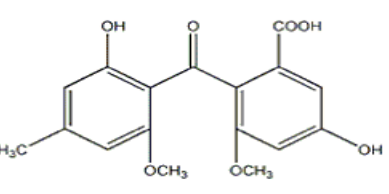

Rhizoctonic acid<smiles>COC(=O)[C@]12Oc3c(Cl)c(OC)cc(OC)c3[C@]1(C(=O)O)[C@H](C)CC(=O)C=C2OC</smiles>

Hypericin
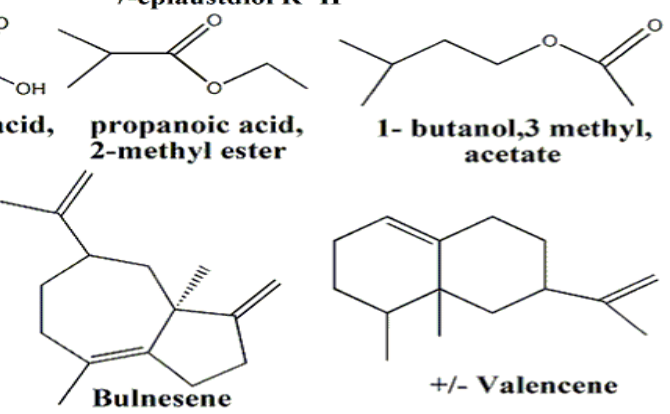

acetate

Secalonic acid $A$

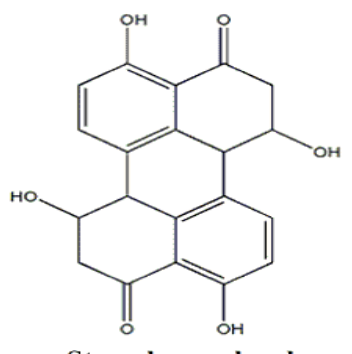

+/- Valencene

Stemphyperylenol

Fig. 17a - Structure of Some Antimicrobial Metabolites from Endophyets.

against $M$. tuberculosis and $M$. smegmetis with MIC 1.74 and $2.62 \mu \mathrm{g} / \mathrm{ml}$, respectively.

$\mathrm{Yu}$ et al. (2010) published a remarkable review of antimicrobial metabolites (Fig 17b) isolated from endophytes, and belong to several classes, including: alkaloids, peptides, steroids, terpenoids, phenols, quinines, and flavonoids. They concluded that as so many antimicrobial compounds were isolated from endophytes which only occupied a small portion of total endophyte species, it is obvious that there is a great opportunity to utilize endophytes as a new source for production of reliable and novel antimicrobial agents. They also stated that this could be a promising way to solve the problem of microbial resistance to commonly used drugs and meet the emergency demand of discovering highly effective, low toxicity, and environmentally friendly antibiotics, which may be used as clinically effective antibiotics in future. 


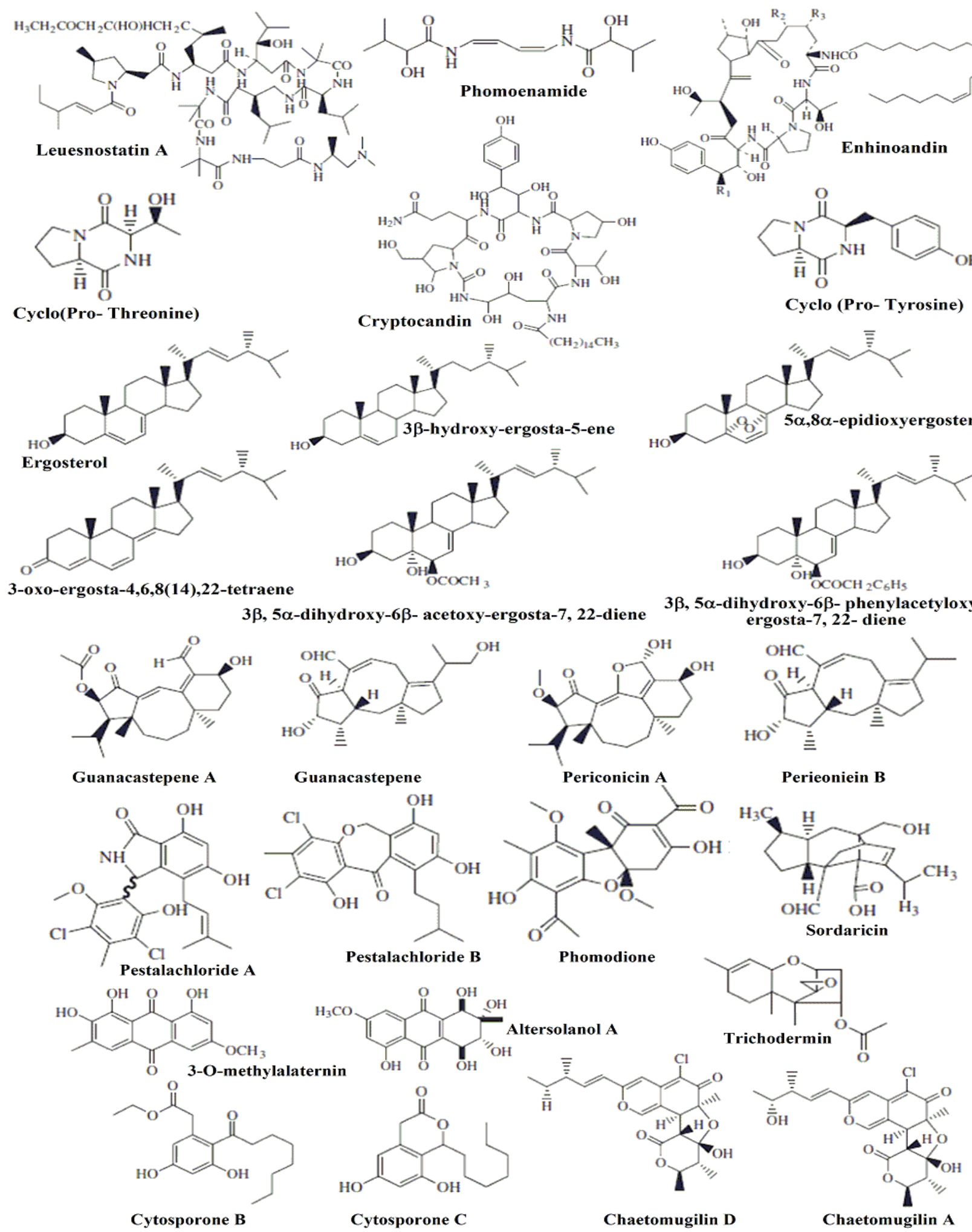

Fig. 17b - Structure of Some Antimicrobial Metabolites from Endophytes that reported in Yu et al. (2010).

\section{AntiOxidant Agents from Endophytes}

The importance of compounds bearing antioxidant activity lies in the fact that they are highly effective against damage caused by reactive oxygen species (ROSs) and oxygenderived free radicals, which contribute to a variety of pathological effects. For instance, DNA damages, carcinogenesis, and cellular degeneration (Huang et al. 2007, Seifried et al. 2007). Antioxidants have been considered promising therapy for prevention and treatment of ROS-linked diseases as cancer, 

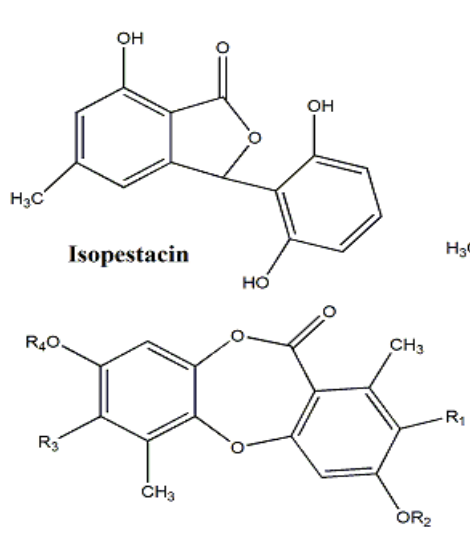

Corynesidones $\mathrm{A} \quad \mathrm{R} 1=\mathrm{H}, \mathrm{R} 2=\mathrm{H}, \mathrm{R} 3=\mathrm{H}, \mathrm{R} 4=\mathrm{H}$ Corynesidones B, $\mathrm{R} 1=\mathrm{OH}, \mathrm{R} 2=\mathrm{H}, \mathrm{R} 3=\mathrm{COOH}, \mathrm{R} 4=\mathrm{H}$
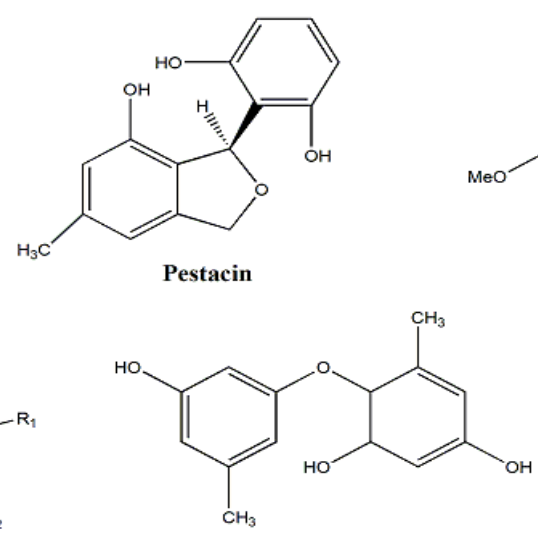

Diaryl ether LL-V125 $\alpha$
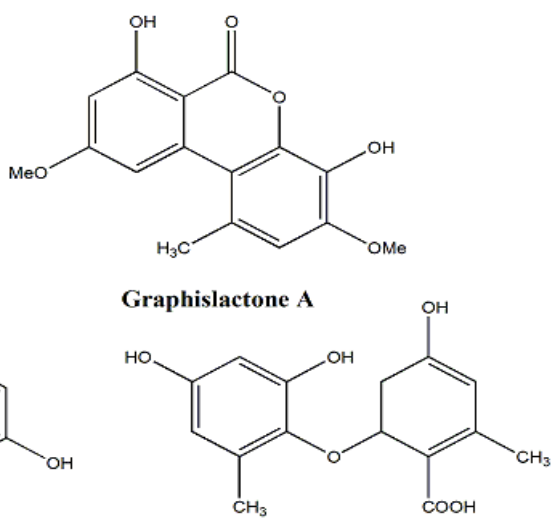

Corynether A

Fig. 18 - Structure of Some Antioxidant Compounds Isolated from Endophytic Fungi

cardiovascular disease, atherosclerosis, hypertension, ischemia/reperfusion injury, diabetes mellitus, neurodegenerative diseases (Alzheimer and Parkinson diseases), rheumatoid arthritis, and ageing (Valko et al. 2007).

Fungal endophytes associated with higher plants appear to be a good source of novel antioxidants as well as plants. Pestacin and isopestacin (Fig 18) are compounds displaying potent antioxidant activity and have been obtained from culture of endophytic fungus Pestalotiopsis microspora isolated from host plant Terminalia morobensis. Besides antioxidant activity, pestacin and isopestacin also show antimycotic and antifungal activities, respectively. Isopestacin antioxidant activity was attributed to its structural similarity to the flavonoids, it is able to scavenge superoxide and hydroxyl free radicals in solution. The proposed antioxidant activity of pestacin arises primarily via cleavage of an unusually reactive $\mathrm{C}-\mathrm{H}$ bond and, to a lesser extent, through $\mathrm{OH}$ abstraction; it is believed to have antioxidant activity 11 times greater than trolox, a vitamin E derivative (Strobel et al. 2002, Harper et al. 2003).

The endophytic Cephalosporium sp. IFB-E001 and Microsphaeropsis olivacea were isolated from host plants Trachelospermum jasminoides and Pilgerodendron uviferum respectively; both produced a phenolic metabolite graphislactone A (Fig18), which displayed potent in vitro antioxidant and free radical-scavenging activity stronger than the standards, butylated hydroxytoluene (BHT) and ascorbic acid (Hormazabal et al. 2005, Song et al. 2005).
Huang et al. (2007) investigated the antioxidant capacities of endophytic fungal cultures of medicinal Chinese plants and its correlation to their total phenolic contents. They suggested that the phenolic content were the major antioxidant constituents of the endophytes (Huang et al. 2008a). The methanol extract of an endophyte Xylaria sp. isolated from the medicinal plant Ginkgo biloba exhibited strong antioxidant capacity due to the presence of "phenolics" and "flavonoids" among identified compounds (Liu et al. 2007).

Recently, the endophytic Corynespora cassiicola was found to produce potent antioxidant compounds corynesidones $\mathrm{A}$ and $\mathrm{B}$, and corynether $\mathrm{A}$, together with a known diaryl ether (LL-V125 $\alpha$ ) (Fig 18), as revealed by oxygen radical absorbance capacity (ORAC) assay with units ranging between 4.35.9. Corynesidone B could also scavenge 2,2diphenyl-1-picrylhydrazyl (DPPH) free radicals with an $\mathrm{IC}_{50} 22.4 \mu \mathrm{M}$, at the same activity as that of ascorbic acid. Beside antioxidant activity of corynesidone A, its exhibit aromatase inhibitory activity with an $\mathrm{IC}_{50}$ value of $5.30 \mu \mathrm{M}$; this activity magnitude is comparable to the first generation aromatase inhibitor drug, aminoglutethimide. Both antiaromatase and antioxidant activities of corynesidone $\mathrm{A}$ are interesting functions because this dual biological activity may be useful for cancer chemoprevention, particularly for breast cancer (Chomcheon et al. 2009). Also, the endophyte fungus Phyllosticta sp. isolated from Guazuma tomentosa was also found to exhibit strong antioxidant activity (Srinivasan et al. 2010). Zeng et al. (2011) 
reported many of endophytic fungi as potential novel source of natural antioxidants from medicinal plant Scapania verrucosa.

\section{Antiviral Activities of Endophytic Fungi}

Many reports demonstrated the importance of endophytic fungi in production of antiviral agents, such as, cytonic acids $\mathrm{A}$ and $\mathrm{B}$, novel human cytomegalovirus (hCMV) protease inhibitors, which had been isolated from solid-state fermentation of the endophytic fungus Cytonaema sp., (Guo et al. 2000). Investigation of endophytes associated with leaves of Quercus coccifera lead to isolation of the endophyte with the ability to synthesize hinnuliquinone, a potent inhibitor of human immunodeficiency virus type 1 (HIV-1) protease (Singh et al. 2004).

Endophytic isolates (582) with 360 morphologically distinct fungi were obtained from 81 Thai medicinal plant species. Extracts of 92 isolates could inhibit Mycobacterium tuberculosis, while 6 extracts inhibited Plasmodium falciparum, and strong anti-viral activity against Herpes simplex virus type 1 was observed in 40 isolates (Wiyakrutta et al. 2004). Mellisol and 1,8-dihydroxynaphthol 1O-a-glucopyranoside were isolated from endophytic fungus Xylaria mellisii, which possess activity against herpes simplex virustype 1 (Pittayakhajonwut et al. 2005).

Florke et al. (2006) reported antihepatitis $\mathrm{C}$ virus (HCV) activity of dihydroisocoumarin (R)-(-)-mellein (Fig 19). It inhibits $\mathrm{HCV}$ protease with an $\mathrm{IC}_{50}$ value of $35 \mathrm{mM}$. This compound had been isolated from a number of endophytic fungi, such as Pezicula livida, Plectophomella sp., and Cryptosporiopsis malicoticis (Krohn et al. 1997). Pullularins A (Fig 19), which had been isolated from ethyl acetate extract of endophytic fungus Pullularia sp., was also shown to have antiviral activity against herpes simplex virus type $1(\mathrm{HSV}-1)$ with $\mathrm{IC}_{50} 3.3 \mathrm{mg} / \mathrm{ml}$ (Isaka et al. 2007). Pestalotheol C (Fig 19), which was isolated from the endophyte Pestalotiopsis theae, was found to have anti-HIV properties (Li et al. 2008b).

The aryl tetralin lignans, such as podophyllotoxin and its analogs showed antiviral and cytotoxicity activities and used as the precursor for many drugs for treatment cancer and viral infections, like etoposide, teniposide, and etopophos phosphate. Podophyllotoxin was found to produced by many endophytes: Trametes hirsute, Aspergillus fumigates, Phialocephala fortinii, and Fusarium oxysporum ( Eyberger et al. 2006, Puri et al. 2006, Kour et al. 2008, Kusari et al. 2009a).

Arunpanichlert et al. (2010) investigated the secondary metabolites of endophytic fungus Penicillium sclerotiorum, and isolated the known compound (+)Sclerotiorin. (+)-Sclerotiorin (Fig 19) was evaluated for its inhibitory effect on human immunodeficiency virus HIV-1 integrase and protease and for antifungal activity, and found to exhibit anti-HIV-1 integrase and protease activities with $\mathrm{IC}_{50}$ values of 45.88 and $198.41 \mu \mathrm{M}$, respectively, and showed weak anti-fungal activity against Candida albicans and Cryptococcus neoformans with MIC values of 202.53 and $101.26 \mu \mathrm{M}$, respectively.

The endophyte Phomopsis sp., isolated from Musa acuminata, was found to produce hexaketide $\gamma$-lactones. Oblongolides Z, and 2deoxy-4 $\alpha$-hydroxyoblongolide $X$ (Fig 19) showed anti-herpes simplex virus type 1 (HSV1) activity $\mathrm{IC}_{50}$ values of $14 \mu \mathrm{M}$ and $76 \mu \mathrm{M}$, respectively. Oblongolides $\mathrm{Z}$ exhibited comparable cytotoxic activity against $\mathrm{KB}, \mathrm{BC}$, NCI-H187, and nonmalignant Vero cell lines with $\mathrm{IC}_{50}$ values of $37,26,32$, and $60 \mu \mathrm{M}$, respectively (Bunyapaiboonsri et al. 2010). New chlorinated pupukeananes possessing a unique spiroketal peroxide skeleton, named chloropupukeanolides A (Fig 19), were isolated from endophytic Pestalotiopsis fici. This compound was found to inhibit HIV-1 replication in vitro in $\mathrm{C} 8166$ cells with an $\mathrm{IC}_{50}$ value of $6.9 \mu \mathrm{M}$, and showed cytotoxicity against human cancer cell lines HeLa, MCF-7 and MDA-MB-231 with $\mathrm{IC}_{50}$ values of 16.9 , 15.5 and $15.9 \mu \mathrm{M}$, respectively (Liu et al. 2010a).

Zhang et al. (2011) reported isolation and structure elucidation of Emerimidine A, and B (Fig 19) from culture of endophytic fungus Emericella sp., both of them showed moderate inhibition to Influenza virus $\mathrm{H}_{1} \mathrm{~N}_{1}$ with $\mathrm{IC}_{50}$ values of $42.07 \mathrm{mg} / \mathrm{ml}$ and 62.05 $\mathrm{mg} / \mathrm{ml}$ respectively. 


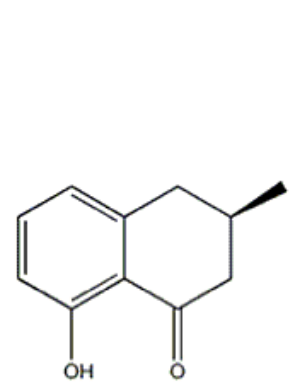

(R)-(-)-mellein

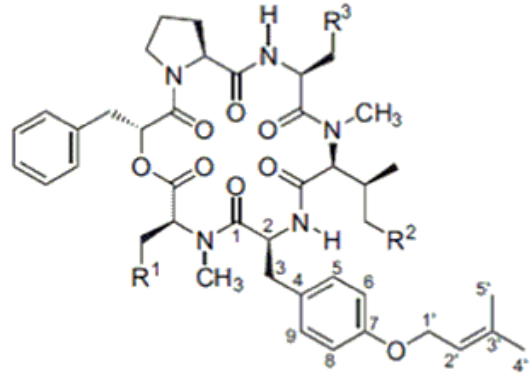

Pullularins A: $\mathrm{R} 1=\mathrm{H}, \mathrm{R} 2=\mathrm{CH} 3, \mathrm{R} 3=\mathrm{OH}$

Pullularins B: $\mathrm{R} 1=\mathrm{CH} 3, \mathrm{R} 2=\mathrm{CH} 3, \mathrm{R} 3=\mathrm{OH}$

Pullularins $\mathrm{C}: \mathrm{R} 1=\mathrm{H}, \mathrm{R} 2=\mathrm{H}, \mathrm{R} 3=\mathrm{OH}$
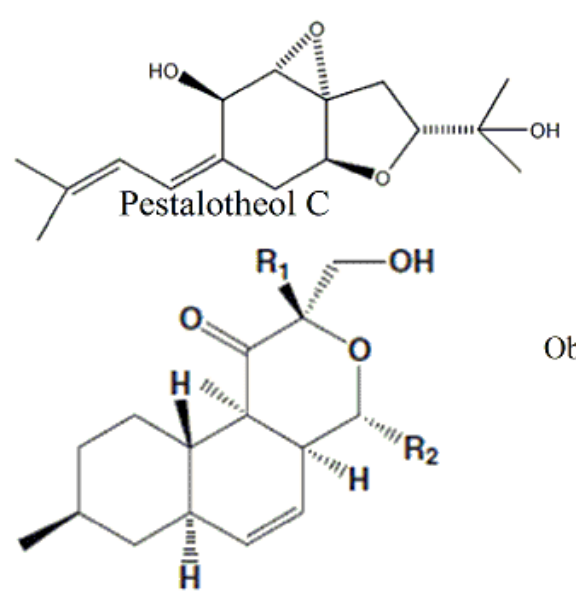

2-deoxy-4 $\alpha$-hydroxyoblongolide $\mathrm{X}: \mathrm{R} 1=\mathrm{H}, \mathrm{R} 2=\mathrm{OH}$

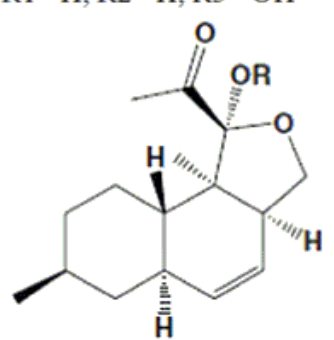

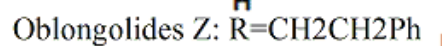<smiles>[R]c1c(OC)cc2c(c1Br)CNC2=O</smiles>

Emerimidine $\mathrm{A}: \mathrm{R} 1=\mathrm{OH}, \mathrm{R} 2=\mathrm{OMe}$

Emerimidine $\mathrm{B}: \mathrm{R} 1=\mathrm{OMe}, \mathrm{R} 2=\mathrm{OH}$

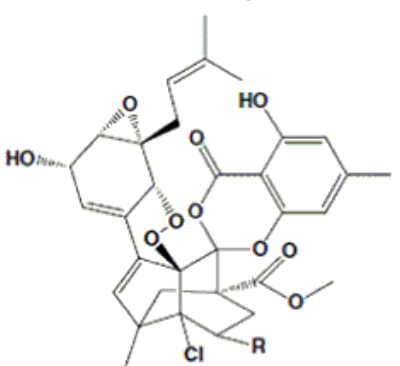

Chloropupukeanolides $\mathrm{A}, \mathrm{R}=\mathrm{OCH} 3$

Fig. 19 - Structure of Antiviral Compounds isolated from some Endophytic Fungi

\section{Other Biological Activities of Endophytic Fungi}

Endophytic fungi are also known as producers of many other metabolites of biological interest, such as anti-inflammatory, anti-diabetic, anti-malarial and immunesuppressant agents, as well as insecticidal and antinematodes agents.

Immunosuppressive drugs are used to prevent allograft rejection in organ transplantation, and could be used to treat autoimmune diseases such as rheumatoid arthritis and insulin-dependent diabetes. Lee et al. (1995a) reported endophytic Fusarium subglutinans can produce compounds (Subglutinol A and B) that can influence the immune system of animals. Subglutinol A (Fig 20) and $\mathrm{B}$ are noncytotoxic diterpene pyrones; both of compounds have $\mathrm{IC}_{50}$ values of $0.1 \mu \mathrm{M}$ and were roughly as potent as the immunosuppressant drug cyclosporin A. The lack of toxicity associated with subglutinols $\mathrm{A}$ and $\mathrm{B}$ suggests that they could be use as immunosuppressant agents. Recently, the endophytic Pestalotiopsis leucothes isolated from Trypterygium wilfordii was found to produce compounds which have variable effects on T- and B-cells and monocyte, these compounds may represent a new source of immunomodulatory agents or for treatment of human immune mediated diseases (Kumar et al. 2005). A new compound named Collutelin A, has been isolated from endophytic Colletotrichum dematium and was shown to exhibit strong immunosuppressive activity as it inhibited CD4 (+) Tcell activation of Interleukin 2 production (Ren et al. 2008). Gliocladicillins A and B were reported as effective antitumor agents in vitro and in vivo, since they induced tumor cell apoptosis and showed significant inhibition on proliferation of melanoma B16 cells implanted into immunodeficient mice (Chen et al. 2009).

Zhang et al. (1999) investigated the anti-diabetic activity of endophytic fungi by isolation of nonpeptidal L-783, 281 from an endophytic Pseudomassaria sp., this compound was found to act as insulin, with 
advance that it is not destroyed in the digestive tract and may be given orally. Oral administration of L-783,281 in two mouse models of diabetes resulted in significant lowering of blood glucose levels, these results may lead to a new therapeutic agent for diabetes. Insulin-mimetic compound demethyl asterriquinone B-1 (Fig 20) has been isolated from culture of endophytic Pseudomassaria sp. (Salituro et al. 2001, Strobel 2002).

Many reports indicated that endophytic fungi are capable of producting of antiinflammatory compounds, such as phomol and mevinic acid (Fig 20), which had been isolated from culture of the endophytic fungus Phomopsis. (Weber et al. 2004a). Both compounds showed strong anti-inflammatory activity. Phenylpropanoids compounds were reported to be isolated from endophytes; they have received more interest for medicinal applications as they have multifold activities, such as anticancer, antioxidant, antimicrobial, anti-inflammatory and immunosuppressive properties (Korkina 2007).

Wang et al. (2010) reported isolation of four compounds (Epicoccins M \& R, Entepicoccin G, and Diketopiperazine) that exhibited potent anti-inflammatory activities from cultures of endophytic Epicoccum nigrum. The compounds were found to inhibit the platelet activating factor-induced release of $\beta$-glucuronidase from rat polymorphonuclear leukocytes in vitro with $\mathrm{IC}_{50}$ values of 4.16 , $4.95,3.07$ and $1.98 \mu \mathrm{M}$, respectively, in comparison to the positive control ginkgolide $\mathrm{B}$ which show $\mathrm{IC}_{50} 2.35 \mu \mathrm{M}$ values.

Recent studies showed that chronic inflammation might be contributed to inflammation-associated cancer. Nuclear factor kappa $\mathrm{B}(\mathrm{NF}-\kappa \mathrm{B})$ is known to regulate diverse cellular processes including inflammation, immune response, differentiation, proliferation, apoptosis and cancer. The role of $\mathrm{NF}-\kappa \mathrm{B}$ activation pathway in acute inflammation and cell-survival, as well as its sustained activation in several cancer cases has been reported. Linking inflammation to tumor promotion and progression, so interfering $\mathrm{NF}-\mathrm{\kappa B}$ activation, and targeting NF- $\kappa \mathrm{B}$ in chronic inflammatory diseases could reduce cancer incidence. NF- $\kappa \mathrm{B}$ inhibitors " $11 \beta$-methoxycurvularin, $11 \alpha$ methoxycurvularin, Trans-dehydrocurvularin, and 1-chloro-2,4-dihydroxy-5-methoxy-7methylanthraquinone" (Fig 20) have been isolated from culture of Penicillium sp., an endophyte isolated from Egyptian plant Limonium tubiflorum, with $\mathrm{IC}_{50}$ values ranging from 1.6 to $10.1 \mu \mathrm{M}$ for isolated compounds (Aly et al. 2011).

Xanthine oxidase (XO) is a key enzyme that catalyzes the oxidation of xanthine and hypoxanthine into uric acid, and plays a vital role in hyperuricemia and gout. Allopurinol is a clinically used to inhibit XO in the treatment of gout, but it has unwanted side effects. Many endophytes were reported to produce compounds exhibit strong xanthine oxidase inhibitory activity, like Alternariol (Fig 20) which has been isolated from endophytic Alternaria brassicicola, with $\mathrm{IC}_{50} 15.5 \mu \mathrm{M}$ inhibitory activity. Compounds from endophytic Aspergillus niger, named rubrofusarin B, aurasperone A (Fig 20), also showed strong co-inhibition of xantin oxidase, cytotoxicity to colon cancer cell lines and was an inhibitor of some microbial pathogens (Song et al. 2004, Gu 2009).

Yang et al. (2010) investigated an endophytic Phomopsis sp., isolated from the stem of the mangrove tree Excoecaria agallocha and reported isolation of PhomopsisH76 A, B and C from culture filtrate. Phomopsis-H76 A (Fig 20) was found to induce formation of ectopic vessels in the subintestinal vessel plexus (SIV), whereas Phomopsis-H76 C (Fig 20) was found to inhibit blood vessel formation.

Isaka et al. (2007) reported isolation of pullularin A, B and C (Fig 19) from culture of endophytic fungus Pullularia sp. These compounds showed strong anti-malarial activity as they inhibit activity of Plasmodium falciparum $\mathrm{K} 1$ (K1, refer to multi-drug resistant strain) with $\mathrm{IC}_{50} 3.6,3.3$, and 9.8 $\mu \mathrm{g} / \mathrm{ml}$ values respectively. Romero et al. (2008) isolated lactones from endophytic Xylaria sp., with potential activity against Plasmodium falciparum, which could use as leads for anti-malarial drugs. Butyrolactone $\mathrm{V}$ compound (Fig 20) has also been isolated from endophytic Aspergillus terreus, showing antimalarial activity with an $\mathrm{IC}_{50} 17.95 \mu \mathrm{M}$ (Haritakun et al. 2010). Isaka et al. (2010) also isolated sesquiterpenoids compounds (Fig 15) 

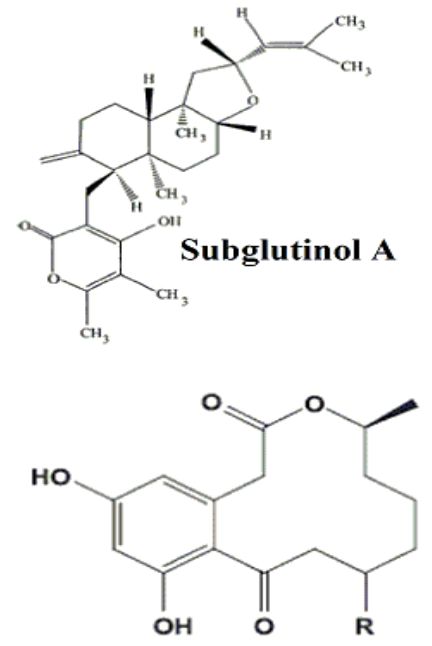

11 $\beta$-methoxycurvularin: $\mathrm{R}=\beta-\mathrm{OCH} 3$ $11 \alpha$-methoxycurvularin: $\mathrm{R}=\alpha-\mathrm{OCH}$

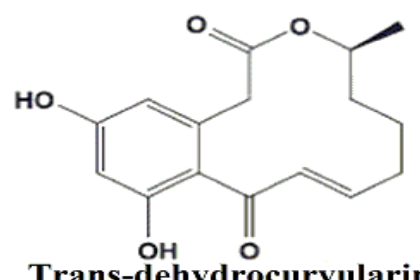

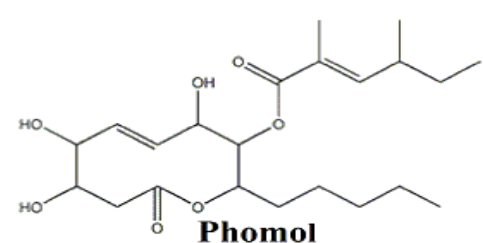<smiles>[R20]c1cc(O)c2c(=O)oc3cc(O)cc(C)c3c2c1</smiles>

Rubrofusarin B

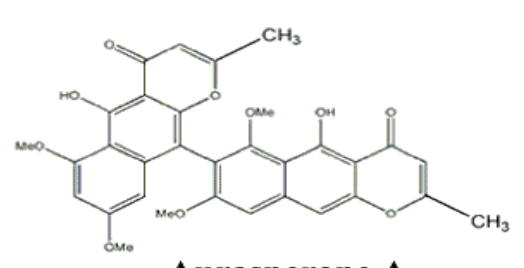

Aurasperone A

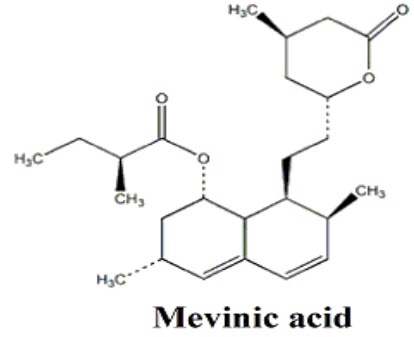<smiles>[R]Cc1cc(OC)c2c(c1)C(=O)c1c([R2])c(O)cc(O)c1C2=O</smiles>

1-chloro-2,4-dihydroxy-5-methoxy-7methylanthraquinone: $\mathrm{R} 1=\mathrm{H}, \mathrm{R} 2=\mathrm{Cl}$

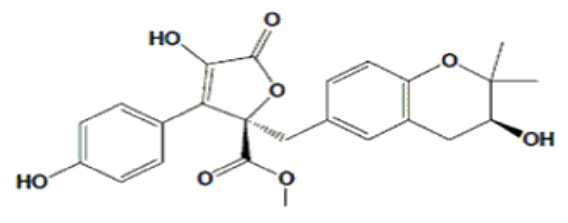

Butyrolactone $\mathrm{V}$

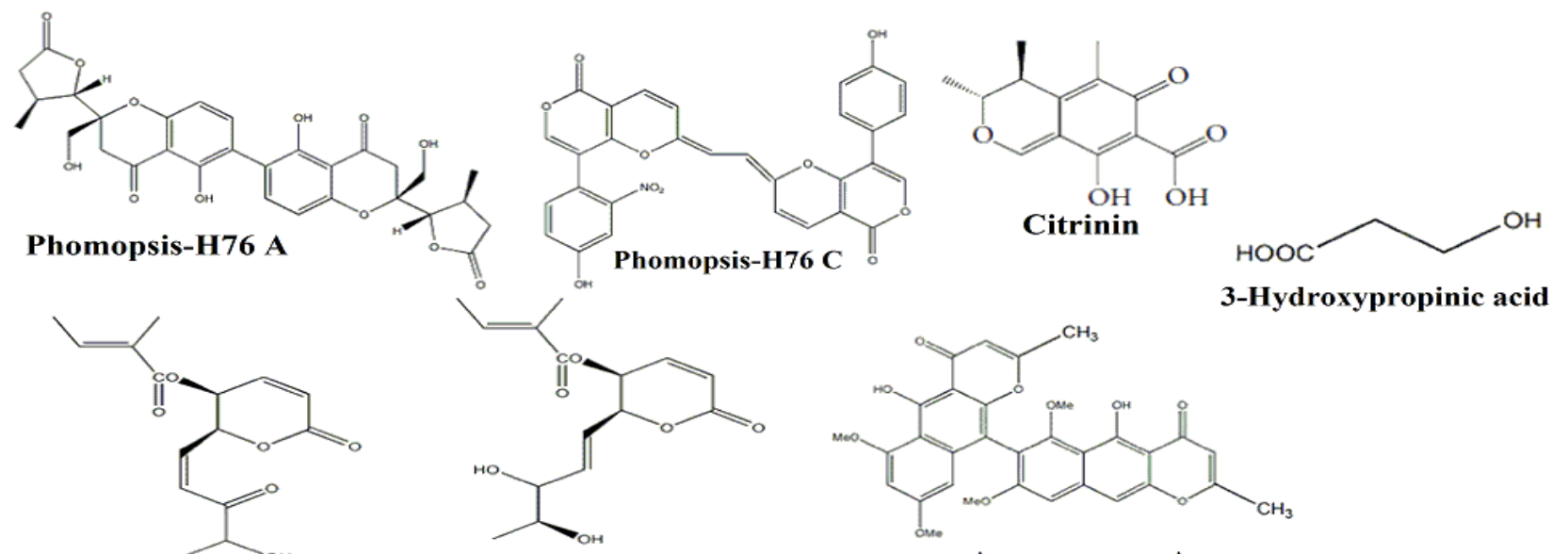

Phomopsolide A

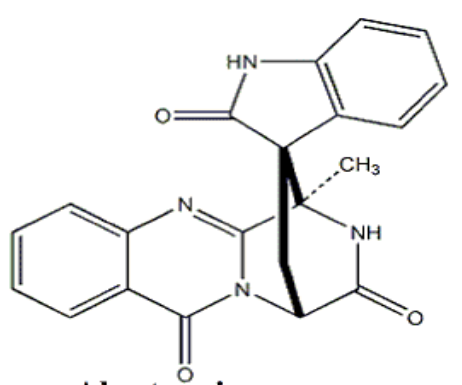

Phomopsolide B

Aurasperone A<smiles>CC(C)OC(=O)c1c(-c2ccc[nH]2)[nH]c2ccccc2c1=O</smiles><smiles></smiles>

Alantrypinene

Fig. 20 - Structure of some Endophytic metabolites showing variable biological activities.

eremophilane-type, with anti-malarial activity with $\mathrm{IC}_{50}$ values ranging between $8.1-13.0 \mu \mathrm{M}$, from endophytic Xylaria.

The polyketide Citrinin (Fig 20), produced by endophytic fungus Penicillium janthinellum from fruits of Melia azedarach, was found to show $100 \%$ anti-parasitic activity against Leishmania sp. (Marinho et al. 2005). Aly et al. (2011) investigated the antitrypanosomal activity of endophytic fungi by isolation 


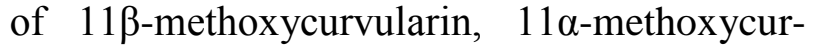
vularin, 5-chloro-6,8,10-trihydroxy-1-methoxy -3-methyl-9(10H)-anthracenone, and trichodimerol (Fig 20) from endophytic Penicillium sp. These compounds showed inhibitory activity against parasitic protozoan Trypanosoma bruce $i$, the causative agent of trypanosomiasis (sleeping sickness), with $\mathrm{IC}_{50} 4.96,9.68,9.75$, and $6.29 \mu \mathrm{M}$, respectively.

A number of endophytic fungi could be classified as entomopathogenic and nematophagous fungi and considered as biocontrol agents, as they serve as leads to the development of new insecticides or nematicides. An endophytic Phomopsis sp. was found to produce phomopsolide A and B (Fig 20) which have been reported to act as boring and feeding deterrents of elm bark beetles (Grove 1985). Demain (2000) investigated production of nodulisporic acids (novel indole diterpenes), from an endophytic Nodulisporium sp. which exhibit potent insecticidal properties against the larvae of the blowfly, Endophytic Muscodor vitigenus showed promising preliminary results as an insect deterrent with production of naphthalene, a widely used compound to exploit insects, this endophytes has exhibited potent insect repellent against the wheat stem sawfly Cephus cinctus (Daisy et al. 2002 a \& b).

Schwarz et al. (2004) isolated 3Hydroxypropinic acid (Fig 20), from endophytic Phomopsis phaseoli. It shows nematicidal activity against the nematdoes Meloidogyne incognita and Caenorhabditis elegans. Endophytic Eupenicillium spp., was found to produce Alantryphenone, Alantrypinene (Fig 20), and Alantryleunone, which showed insecticidal activity (Fábio et al. 2005).

Penicinoline (Fig 20), a new pyrrolyl 4quinolinone alkaloid, was isolated from cultures of endophytic Penicillium sp. This compound showed strong insecticidal activity against the sucking pest Aphis gossypii with $100 \%$ mortality on a mixed population at 1000 $\mathrm{ppm}$, in addition to it exhibited in vitro cytotoxicty activity toward 95-D and HepG2 cell lines with $\mathrm{IC}_{50}$ values of 2.2 and $25.5 \mu \mathrm{M}$, respectively (Shao et al. 2010). Zhang et al. (2010) reported significant insecticidal activity of Claviceps purpurea and Claviceps chaetomium, towards the cotton aphis (Aphis gossypii).

\section{Conclusion}

Isolation of endophytic fungi from medicinal and other plants may result in methods to produce biologically active agents for biological utilization on a large commercial scale as they are easily cultured in laboratory and fermentor instead of harvesting plants and affecting the environmental biodiversity.

\section{Reference}

Aguilar AC, Barea JM. 1996 - Arbuscular mycorrhizas and biological control of soil-borne plant pathogens - an overview of the mechanisms involved. Mycorrhiza 6, 457-464.

Akello J, Dubois T, Gold CS, Coyne D, Nakavuma J, Paparu P. 2007 Beauveria bassiana (Balsamo) vuillemin as an endophyte in tissue culture banana (Musa spp.). Journal of Invertebrate Pathology 96, 34-42.

Akiyama K, Matsuzaki K, Hayashi H. 2005 Plant sesquiterpenes induce hyphal branching in arbuscular mycorrhizal fungi. Nature 435, 824-827.

Aly AH, Debbab A, Clements C, Ebel RAE, Orlikova B, Diederich M, Wray V, Lin WH, Proksch P. 2011 - NF kappa B inhibitors and antitrypanosomal metabolites from endophytic fungus Penicillium sp. isolated from Limonium tubiflorum. Bioorganic and Medicinal Chemistry 19, 414-421.

Aly AH, Debbab A, Proksch P. 2011 - Fungal endophytes: unique plant inhabitants with great promises. Applied Microbiology \& Biotechnology 90, 18291845.

American Cancer Society. 2009 - Cancer Facts \& Figures. American Cancer Society, Atlanta, Ga, USA.

Amna T, Puri SC, Verma V, Sharma JP, Khajuria RK, Musarrat J, Spiteller M, Qazi GN. 2006 - Bioreactor studies on the endophytic fungus Entrophospora infrequens for the production of an anticancer alkaloid camptothecin. 
Canadian Journal of Microbiology 52, 189-196.

Anke T, Thines E. 2007 - Fungal metabolites as lead structures for agriculture. In: Exploitation of Fungi (Robson GD, VanWest P, Gadd GM, eds.): 45-58 Cambridge University Press, Cambridge, UK.

Arnold AE, Mejia LC, Kyllo D, Rojas EI, Maynard Z, Robbins N, Herre EA. 2003 - Fungal endophytes limit pathogen damage in a tropical tree. PNAS Journal 100, 15649-15654.

Arnold AE. 2007 - Understanding the diversity of foliar endophytic fungi: progress, challenges, and frontiers. Fungal Biology Reviews 21, 51-66.

Arunpanichlert J, Rukachaisirikul V, Sukpondma Y, Phongpaichit S, Tewtrakul S, Rungjindamai S, Sakayarojd J. 2010 - Azaphilone and isocoumarin derivatives from the endophytic fungus Penicillium sclerotiorum PSU-A13. Chemical and Pharmaceutical Bulletin 58, 1033-1036.

Bacon CW, White JF. 1994 - Stain, media and procedure for analyzing endophytes. In: Biotechnology of endophytic fungi of grasses (Bacon $\mathrm{CW}$, White JF, eds.): 47-56 CRC Press, Boca Raton.

Bacon CW, White JF. 2000 - Microbial Endophytes. Marcel Deker, NewYork, USA.

Bae H, Kim S, Sicher Jr RC, Kim MS, Strem MD, Bailey BA. 2008 - The beneficial endophyte, Trichoderma hamatum, delays the onset of drought stress in Theobroma cacao. Biological Control 46, 24-35.

Baldani JI, Baldani VLD, Seldin L, Döbereiner J. 1986 - Characterization of Herbaspirillum seropedicae gen. nov., sp. nov., a root-associated nitrogen-fixing bacterium. International Journal of Systematic Bacteriology 36, 86-93.

Banu GS, Kumar G. 2009 - Preliminary Screening of Endophytic Fungi from Medicinal Plants in India for Antimicrobial and Antitumor Activity. International Journal of Pharmaceutical Sciences and Nanotechnology 2, 566571.
Barazani O, Benderoth M, Groten K, Kuhlemeier C, Baldwin IT. 2005 Piriformospora indica and Sebacina vermifera increase growth performance at the expense of herbivore resistance in Nicotiana attenuata. Oecologia 146, 234-243.

Barnett HL, Hunter BB. 1998 - Illustrated Genera of Imperfect Fungi. APS Press, St. Paul, Minnesota, USA.

Barraquio WL, Revilla L, Ladha JK. 1997 Isolation of endophytic diazotrophic bacteria from wetland rice. Plant and Soil 194, 15-24.

Barrow JR, Osuna P. 2002 - Phosphorous solubilization and uptake by dark septate fungi in four wing saltbush, Artiplex canescens (Prush) Nutt. Arid environ journal 51, 449-451.

Barz W, Daniel S, Hinderer W, Jaques U, Kessmann H, Koster J, Tiemann K. 1988. In: Plant Cell Biotechnology (Pais M, Mavituna F, Novais J, eds.): 211-213 Springer (NATO ASI series), Berlin, Heidelberg, New York.

Bastos DZL, Pimentel IC, De-Jesus DA, DeOliveira BH. 2007 - Biotransformation of betulinic and betulonic acids by fungi. Phytochemistry 68, 834-839.

Bell AA, Wheeler MH. 1986 - Biosynthesis and functions of fungal melanins. Annual Review of Phytopathology 24, 4111-4451.

Bérdy J. 2005 - Bioactive microbial metabolites: a personal view. Journal of Antibiotics 58, 1-26.

Bernays EA. 1993 - Plant sterols and hostplant affiliations of herbivores. In: Insect-plant interactions, vol IV (Bernays EA, ed): 45-57 CRC, Boca Raton.

Bhat RA, Miklis M, Schmelzer E, SchulzeLefert P, Panstruga R. 2005 Recruitment and interaction dynamics of plant penetration resistance components in a plasma membrane microdomain. PNAS Journal 102, 3135-3140.

Bicas JL, Barros FFC, Wagner R, Godoy HT, Pastore GM. 2008 - Optimization of $R$ $(+)-\alpha$-terpineol production by the biotransformation of $R$-(+)-limonene. 
Journal of Industrial Microbiology and Biotechnology 35, 1061-1070.

Bicas JL, Dionísio AP, Pastore GM. 2009 Bio-oxidation of terpenes: an approach for the flavor industry. Chemical Reviews 109, 4518-4531.

Boddey RM, Urquiaga S, Alves BJR, Reis V. 2003 - Endophytic nitrogen fixation in sugarcane: present knowledge and future applications. Plant and Soil 252, 139-149.

Bode HB, Bethe B, Höfs R, Zeek A. 2002 Big effects from small changes: possible ways to explore nature's chemical diversity. ChemBioChem 3, 619-627.

Bolwerk A, Lagopodi AL, Lugtenberg BJJ, Bloemberg GV. 2005 - Visulaization of interactions between a pathogenic and a beneficial Fusarium strain during biocontrol of tomato foot and root rot. Molecular Plant-Microbe Interactions 18, 710-721.

Boonphong S, Kittakoop $\mathrm{P}$, Isaka $\mathrm{M}$, Pittayakhajonwut D, Tanticharoen M, Thebtaranonth Y. 2001 - Multiplolides $\mathrm{A}$ and $\mathrm{B}$, new antifungal 10-membered lactones from Xylaria multiplex. Journal of Natural Products 64, 965967.

Borges KB, Borges WDS, Durán-Patrón R, Pupo MT, Bonato PS, Collado IG. 2009 - Stereoselective biotransformations using fungi as biocatalysts. Tetrahedron Asymmetry 20, 385-397.

Borges KB, Borges WDS, Pupo MT, Bonato PS. 2007 - Endophytic fungi as models for the stereoselective biotransformation of thioridazine. Applied Microbiology and Biotechnology 77, 669674.

Brady SF, Wagenaar MM, Singh MP, Janso JE, Clardy J. 2000 - The cytosporones, new octaketide antibiotics isolated from an endophytic fungus. Organic Letters 14, 4043-4046.

Bunyapaiboonsri T, Yoiprommarat S, Srikitikulchai P, Srichomthong K, Lumyong S. 2010 - Oblongolides from the endophytic fungus Phomopsis sp. BCC 9789. Journal of Natural Products $73,55-59$.
Cabral D, Stone JK, Carroll GC. 1993 - The internal mycobiota of Juncus spp.: microscopic and cultural observations of infection patterns. Mycological Research 97, 367-376.

Cafěu MC, Silva GH, Teles HL, Bolzani VS, Araújo AR, Young MCM, Pfenning LH. 2005 - Antifungal compounds of Xylaria sp., an endophytic fungus isolated from Palicourea marcgravii (Rubiaceae). Quimica Nova 28, 991995.

Carmichael JW, Kendrick BW, Conners IL, Lynne S. 1980 - Genera of Hyphmycetes. The University of Alberta Press, Edmonton, Alberta CA.

Chandra S. 2012 - Endophytic fungi: novel sources of anticancer lead molecules. Applied Microbiology and Biotechnology (under press).

Chen Y, Guo H, Du Z, Liu XZ, Che Y, Ye X. 2009 - Ecology-based screen identifies new metabolites from a Cordycepscolonizing fungus as cancer cell proliferation inhibitors and apoptosis inducers. Cell Proliferation 42, 838847.

Chin YW, Balunas MJ, Chai HB, Kinghorn AD. 2006 - Drug discovery from natural sources. The AAPS Journal 8, 239-253.

Chokpaiboon S, Sommit D, Teerawatananond T, Muangsin N, Bunyapaiboonsri T, Pudhom K. 2010 - Cytotoxic norchamigrane and chamigrane endoperoxides from a basidiomycetous fungus. Journal of Natural Products 73, 10051007.

Chomcheon P, Wiyakrutta S, Aree T, Sriubolmas N, Ngamrojanavanich N, Mahidol C, Ruchirawat S, Kittakoop P. 2010 - Curvularides A- E: antifungal hybrid peptide-polyketides from the endophytic fungus Curvularia geniculata. Chem Eur J 16:11178-11185.

Chomcheon P, Wiyakrutta S, Sriubolmas N, Ngamrojanavanich $\mathrm{N}$, Kengtong $\mathrm{S}$, Mahidol C, Ruchirawat S, Kittakoop P. 2009 - Aromatase inhibitory, radical scavenging, and antioxidant activities of depsidones and diaryl ethers from the endophytic fungus Corynespora 
cassiicola L36, Phytochemistry 70 ,407-413.

Chun E, Han CK, Yoon JH, Sim TB, Kim YK, Lee KY. 2005 - Novel inhibitors targeted to methionine aminopeptidase 2 (MetAP2) strongly inhibit the growth of cancers in xenografted nude model. International Journal of Cancer 114, 124-130.

Clay K, Holah J 1999 - Fungal endophyte symbiosis and plant diversity in successional fields. Science 285, 17421744.

Clay K. 1990 - Fungal endophytes of grasses. Annual Review of Ecology and Systematics 21, 255-297.

Cohen SD. 2006 - Host selectivity and genetic variation of Discula umbrinella isolates from two oak species: analyses of intergenic spacer region sequences of ribosomal DNA. Microbial Ecology 52, 463-469.

Cragg GM, Newman DJ, Snader KM. 1997 Natural products in drug discovery and development. Journal of Natural Products 60, 52-60.

Cui Y, Yi D, Bai X, Sun B, Zhao Y, Zhang Y. 2012 - Ginkgolide B produced endophytic fungus (Fusarium oxysporum) isolated from Ginkgo biloba. Fitoterapia 83, 913-920.

Curran MP, Keating GM. 2005 - Mycophenolate sodium delayed release: prevention of renal transplant rejection. Drugs 65, 799-805.

Daisy B, Strobel GA, Castillo U, Ezra D, Sears J, Weaver D, Runyon JB. 2002a Naphthalene, an insect repellent, is produced by Muscodor vitigenus, a novel endophytic fungus. Microbiology 148: 3737-41.

Daisy B, Strobel GA, Ezra D, Castillo U, Baird G, Hess WM. 2002b - Muscodor vitigenus anam. sp. nov., an endophyte from Paullinia paullinioides. Mycotaxon 84, 39-50.

Darkes MJM, Plosker GL. 2002 - Cefditoren pivoxil. Drugs 62, 319-336.

De Souza JJ, Vieira IJ, Rodrigues-Filho E, Braz-Filho R. Terpenoids from endophytic fungi. Molecules 16, 10604-10618.
Deacon JW. 1981 - Ecological relationships with other fungi: competitors and hyperparasites. In: Biology and control of take all (Asher MJC, Shipton PJ, eds.): 75-101 Academic, London.

Debbab A, Aly AH, Ebel RAE, Müller WEG, Mosaddak M, Hakiki A, Ebel R, Proksch P. 2009 - Bioactive secondary metabolites from the endophytic fungus Chaetomium sp. isolated from Salvia officinalis growing in Morocco. Biotechnology, Agronomy, Society and Environment, 13, 229-234.

Debbab A, Aly AH, Proksch P. 2011 Bioactive secondary metabolites from endophytes and associated marine derived fungi. Fungal Diversity 49, 112.

Demain AL. 1981 - Industrial Microbiology. Science 214,987-994.

Demain AL. 2000 - Microbial natural products: a past with a future. In: Biodiversity: new leads for pharmaceutical and agrochemical industries (Wrigley SK, Hayes MA, Thomas R, Chrystal EJT, Nicholson N, ed): 3-16 The Royal Society of Chemistry, Cambridge, United Kingdom.

Deshmukh SK, Mishra PD, Almeida AK, Verekar S, Sahoo MR, Periyasamy G, Goswami H, Khanna A, Balakrishnan A, Vishwakarma R. 2009 - Antiinflammatory and anticancer activity of ergoflavin isolated from an endophytic fungus. Chemistry and Biodiversity 6, 784-789.

Ding G, Song YC, Chen JR, Xu C, Ge HM, Wang XT, Tan RX. 2006 Chaetoglobosin U, a Cytochalasan Alkaloid from Endophytic Chaetomium globosum IFB-E019, Journal of Natural Products 69, 302-304.

Ding G, Zheng Z, Liu S, Zhang H, Guo L, Che Y. 2009 - Photinides A-F, cytotoxic benzofuranone-derived $\gamma$ - lactones from the plant endophytic fungus Pestalotiopsis photiniae. Journal of Natural Products 72, 942-945.

Doble M, Kruthiventi AK, Gaikar VG. 2004 Biotransformations and Bioprocesses. Marcel Dekker, New York, USA.

Donadio S, Monicardini P, Alduina R, Mazzaa 
P, Chiocchini C, Cavaletti L, Sosio M, Puglia AM. $2002-$ Microbial technologies for the discovery of novel bioactive metabolites, Journal of Biotechnology 99, 187-198.

Dos Santos RMG, Rodrigues-Fo E. 2003 Further meroterpenes produced by Penicillium sp., an endophyte obtained from Melia azedarach. Z Naturforsch 58, 663-669.

Doss PR, Welty RE. 1995 - A polymerase chain reaction based procedure for detection of Acremonium coenophialum in tall fescue. Phytopathology 85, 913917.

Dreyfuss MM, Chapela IH. 1994. In: The discovery of natural products with therapeutic potential (Gullo VP, ed): 49-80 Butterworth-Heinemann, Stoneham.

Eyberger L, Dondapati R, Porter JR. 2006 Endophyte fungal isolates from Podophyllum peltatum produce podophyllotoxin. Journal of Natural Products 69, 1121-1124.

Fábio A., Barros P, Filho ER. 2005 - Four spiroquinazoline alkaloids from Eupenicillium sp. isolated as an endophytic fungus from leaves of Murraya paniculata (Rutaceae). Biochemical Systematics and Ecology 33, 257-268.

Farooq A, Choudhary MI, Tahara S, Rahman AU, Basęr KH, Demirci F. 2002a - The microbial oxidation of (-)- $\beta$-pinene by Botrytis cinerea. Zeitschrift fur Naturforschung C 57, 686-690.

Farooq A, Tahara S, Choudhary MI, Rahman AU, Ahmed Z, Başer KHC, Demirci F. $2002 b$ - Biotransformation of (-)- $\alpha-$ pinene by Botrytis cinerea. Zeitschrift fur Naturforschung C 57, 303-306.

Figueiredo C, Almendra MJ, Barroso JG, Scheffer JJC. 1996 - Biotransformation of monoterpenes and sesquiterpenes by cell suspension cultures of Achillea millefolium L. ssp. Millefolium. Biotechnology Letters 18, 863-868.

Fill TP, Da Silva BF, Rodrigues-Fo E. 2010 Biosynthesis of phenylpropanoid amides by an endophytic penicillium brasilianum found in root bark of Melia azedarach. Journal ofMicrobiology and Biotechnology 20, 622-629.

Firáková S, Šturdíková M, Múčková M. 2007 Bioactive secondary metabolites produced by microorganisms associated with plants. Biologia 62/3, 251-257.

Fisher PJ, Pertini O, Petrini LE, Sutton BC. 1994 - Fungal endophytes from leaves and twigs of Quercus ilex L. from England, Majorca and Switzerland. New Phytologist 127, 133-137.

Flörke U, Krohn K, Zia-Ullah, Hussain H. 2006 - An orthorhombic modification of $\quad(R)$-(-)-8-hydroxy-3-methyl-3,4dihydro-1H-2benzopyran-1-one[( $R)-(-)$ mellein]. Acta Crystallographica E 62, 03539-03541.

Frattarelli DAC, Reed MD, Giacoia GP, Aranda JV. 2004 - Antifungals in systemic neonatal candidiasis. Drugs 64, 949-968.

Freeman S, Rodriguez RJ. 1993 - Genetic conversion of a fungal plant pathogen to a nonpathogenic, endophytic mutualist. Science 260, 75-78.

Fröhlich J, Hyde KD, Petrini O. 2000 Endophytic fungi associated with palm. Mycological Research 104, 1202-1212.

Gamboa MA, Bayman P. 2001 -Communities of endophytic fungi in leaves of a tropical timber tree (Guarea guidonia). Biotropica 33, 352-360.

Gangadevi V, Muthumary J. 2008 - Taxol, an anticancer drug produced by an endophytic fungus Bartalinia robillardoides Tassi, isolated froma medicinal plant, Aegle marmelos Correa ex Roxb. World Journal of Microbiology and Biotechnology 24, 717-724.

Gangadevi V, Muthumary J. 2009 - Taxol production by Pestalotiopsis terminaliae, an endophytic fungus of Terminalia arjuna (arjun tree). Biotechnology and Applied Biochemistry 52, 9-15.

Garcia FJE, Langenheim JH. 1990 - The leaf fungal endophyte community of a coastal red wood population diversity and spatial patterns. New Phytologist 116, 89-97.

Gehring CA, Whitman TG. 2002 Mycorrhizae-herbivore interactions: 
population and community consequences. In: Mycorrhizal ecology (Van der Heijden M, Sanders I, eds.): 295320 Springer, Berlin.

Genre A, Chabaud M, Timmers T, Bonfante P, Barker DG. $2005-$ Arbuscular mycorrhizal fungi elicit a novel intracellular apparatus in Medicago truncatula root epidermal cells before infection. Plant Cell 17, 3489-3499.

Gianinazzi PV, Dumas-Gaudot E, Golotte A, Tahiri-Alaoui A, Gianinazzi S 1996 Cellular and molecular defence-related root responses to invasion by arbuscular mycorrhizal fungi. New Phytologist 133, 45-47.

Gonthier P, Gennaro M, Nicolotti G. 2006 Effect of water stress on endophytic mycota of Quercus robur. Fungal Diversity 21, 69-80.

Goodman RN, Kiraly Z, Wood RKS. 1986 The Biochemistry and Physiology of Plant Disease. University of Missouri Press, Columbia.

Gordaliza M, García PA, Del Corral JMM, Castro MA, Gómez-Zurita MA. 2004 Podophyllotoxin: distribution, sources, applications and new cytotoxic derivatives. Toxicon 44, 441-459.

Gordien AY, Gray AI, Ingleby K, Franzblau SG, Seidel V. 2010 - Activity of Scottish Plant, Lichen and Fungal Endophyte Extracts against Mycobacterium aurum and Mycobacterium tuberculosis. Phytotherapy Research 24, 692-698.

Griffith GW. 1994 - Phenoloxidases in Aspergillus nidulans: 50 years on. In: Progress in industrial Microbiology, vol 29 (Martinelli SD, Kinghorn JR eds.): 763-788 Elsevier, Amsterdam.

Grove JF. 1985 - Metabolic products of Phomopsis oblonga, Part 2. Phomopsolide A and B, tiglic esters of two 6substituted 5,6- dihydro-5hydroxypyran-2-ones. Journal of the Chemical Society, Perkin Transactions 1, 865-869.

$\mathrm{Gu}$ W. 2009 - Bioactive metabolites from Alternaria brassicicola ML-P08, an endophytic fungus residing in Malus halliana. World Journal of
Microbiology and Biotechnology 25, 1677-1683.

Gunatilaka AAL. 2006 - Natural products from plant-associated microorganisms: Distribution, structural diversity, bioactivity, and implications of their occurrence. Journal of Natural Products 69, 509-526.

Guo B, Dai JR, Ng S, Huang Y, Leong C, Ong W, Carte BK. 2000 - Cytonic acids A \& B: novel tridepside inhibitors of hCMV protease from the endophytic fungus Cytonaema species. Journal of Natural Products 63, 602-604.

Guo B, Wang Y, Sun X, Tang K. 2008 Bioactive Natural Products from Endophytes: A Review ${ }^{1}$. Applied Biochemistry and Microbiology 44, 136-142.

Guo LD, Hyde KD, Liew ECY. 1998 - A method to promote sporulation in palm endophytic fungi. Fungal Diversity 1, 109-113.

Guo LD, Hyde KD, Liew ECY. 2000 Identification of endophytic fungi from Livistona chinensis based on morphology and rDNA sequences. New Phytologist 147, 617-630.

Gutierrez RM, Gonzalez AM, Ramirez AM. 2012 - Compounds derived from endophytes: A review of phytochemistry and pharmacology. Current Medicinal Chemistry (under press).

Hallmann J, Sikora RA. 1994 - Influence of Fusarium oxysporum, a mutualistic fungal endophyte, on Meloidogyne incognita infection of tomato. Journal of Plant Diseases and Protection 101,475-481.

Hallmann J, Sikora RA. 1996 - Toxicity of fungal endophyte secondary metabolites to plantparasitic nematodes and soil-borne plant-pathogenic fungi. European Journal of Plant Pathology 102, 155-162.

Han JW, Ahn SH, Park SH, Wang SY, Bae GU, Seo DW, Kwon HK, Hong S, Lee HY, Lee YW, Lee HW. 2000 Apicidin, a histone deacetylase inhibitor, inhibits proliferation of tumor cells via induction of $\mathrm{p} 21^{\mathrm{WAF} 1 / \mathrm{Cip} 1}$ and Gelsolin. Cancer Research 60, 6068- 
6074

Haritakun R, Rachtawee P, Chanthaket R, Boonyuen N, Isaka M. 2010 Butyrolactones from the fungus Aspergillus terreus BCC 4651. Chemical and Pharmaceutical Bulletin 58, 1545-1548.

Harper JK, Arif AM, Ford EJ, Strobel GA, Porco JAJr, Tomer DP, Oneill KL, Heider EM, Grant DM. 2003 Pestacin: a 1,3- dihydro isobenzofuran from Pestalotiopsis microspora possessing antioxidant and antimycotic activities. Tetrahedron 59, 2471-2476.

Hawksworth DL. 2004 - Fungal diversity and its implications for genetic resource collections. Studies in Mycology 50, 918.

Hazalin NA, Ramasamy K, Lim SM, AbdulWahab I, Cole ALJ, Abdul Majeed A. 2009 - Cytotoxic and antibacterial activities of endophytic fungi isolated from plants at the National Park, Pahang, Malaysia. BMC Complementary and Alternative Medicine 9, 46-50.

Hendry SJ, Boddy L, Lonsdale D. 2002 Abiotic variables effect differential expression of latent infections in beech (Fagus sylvatica). New Phytologist 155, 449-460.

Hiraga K, Yamamoto S, Fukuda H, Hamanaka N, Oda K. 2005 - Enniatin has a new function as an inhibitor of Pdr5p, one of the ABC transporters in Saccharomyces cerevisiae. Biochemical and Biophysical Research Communications 328, 1119-1125.

Holliday P. 1998 - A Dictionary of Plant Pathology. Cambridge University Press, Cambridge, UK.

Hormazabal E, Schmeda-Hirschmann G, Astudillo L, Rodriguez J, Theoduloz C. 2005 - Metabolites from Microsphaeropsis olivacea, an endophytic fungus of Pilgerodendron uviferum. $\mathrm{Z}$. Naturforsch [C] 60, 11-21.

Huang WY, Cai YZ, Hyde KD, Corke H, Sun M. 2008a - Biodiversity of endophytic fungi associated with 29 traditional Chinese medicinal plants. Fungal
Diversity 33, 61-75.

Huang WY, Cai YZ, Surveswaran S, Hyde KD, Corke H, Sun M. 2009 Molecular phylogenetic identification of endophytic fungi isolated from three Artemisia species. Fungal Diversity 36: 69-88.

Huang WY, Cai YZ, Xing J, Corke H, Sun M. 2007 - Potential antioxidant resource: endophytic fungi isolated from traditional Chinese medicinal plants. Economic Botany 61, 14-30.

Huang Y, Wang J, Li G, Zheng Z, Su W. 2001 - Antitumor and antifungal activities in endophytic fungi isolated from pharmaceutical plants Taxus mairei, Cephalataxus fortunei and Torreya grandis. FEMS Immunology and Medical Microbiology 31, 163-167.

Huang Z, Cai X, Shao C, She Z, Xia X, Chen Y, Yang J, Zhou S, Lin Y 2008b Chemistry and weak antimicrobial activities of phomopsins produced by mangrove endophytic fungus Phomopsis sp. ZSU-H76. Phytochemistry 69, 1604-1608.

Huang Z, Yang J, She Z, Lin Y. 2010 Isoflavones from the mangrove endophytic fungus Fusarium sp. (ZZF41). Natural Product Communications 5, 1771-1773.

Hyde KD, Soytong K. 2008 - The fungal endophyte dilemma. Fungal Diversity 33: 163-173.

Ikegami S, Amemiya S, Oguro M, Nagano H, Mano Y, 1979 - Inhibition by aphidicolin of cell cycle progression and DNA replication in sea urchin embryos. Journal of Cellular Physiology 100, 439-444.

Isaka M, Berkaew $\mathrm{P}$, Intereya $\mathrm{K}$, Komwijit S, Sathitkunanon T. 2007 - Antiplasmodial and antiviral cyclohexadepsipeptides from the endophytic fungus Pullularia sp. BCC 8613. Tetrahedron 63, 6855-6860.

Isaka M, Chinthanom P, Boonruangprapa T, Rungjindamai N, Pinruan U. 2010 Eremophilane-type sesquiterpenes from the fungus Xylaria sp. BCC 21097. Journal of Natural Products 73, 683687. 
Isaka M, Jaturapat A, Rukseree $\mathrm{K}$, Danwisetkanjana K, Tanticharoen M, Thebtaranonth Y. $2001 \quad-$ Phomoxanthones $\mathrm{A}$ and $\mathrm{B}$, novel xanthone dimers from the endophytic fungus Phomopsis species. Journal of Natural Products, 64, 1015-1018.

Jadulco R, Brauers G, Edrada RA, Ebel R, Wray V, Sudarsono V, Proksch P. 2002 - New metabolites from spongederived fungi Curvularia lunata and Cladosporium herbarum. Journal of Natural Products 65, 730-733.

Jeewon R, Liew ECY, Hyde KD. 2004 Phylogenetic evaluation of species nomenclature of Pestalotiopsis in relation to host association. Fungal Diversity 17, 39-55.

Ji ZQ, Wu WJ, Wang MA, Gu AG. 2005 Identification of fungicidal compounds from endophytic fungi Fusarium proliferatum in Celastrus angulatus. Journal of North-west Sci-Tech University of Agriculture and Forest 33(5), 61-64.

Johnson NC, Graham JH, Smith FA. 1997 Functioning of mycorrhizal associations along the mutualism-parasitism continuum. New Phytologist 135, 575585.

Jones CG, Last FT. 1991 - Ectomycorrhizae and trees: implications for aboveground herbivory. In: Microbial mediation of plant-herbivore interactions (Barbosa B, Krischik VA, Jones CG, eds.): 65103 New York, Wiley-Interscience.

Kageyama, SA, Mandyam, KG, Jumpponen A. 2008 - Diversity, Function and Potential Applications of the RootAssociated Endophytes, in: Mycorrhiza - State of the Art, Genetics and Molecular Biology, Eco-Function, Biotechnology, Eco-Physiology, Structure and Systematics (Varma A. 3rd edition).

Kim SU, Strobel GA, Ford E. 1999 Screening of taxol-producing endophytic fungi from Ginkgo biloba and Taxus cuspidata in Korea. Agricultural Chemistry and Biotechnology 42, 97-99.

Kock, JLF, Strauss T, Pohl CH, Smith DP,
Botes PJ, Pretorius EE, Tepeny T, Sebolai O, Botha A, Nigam S. 2001 Bioprospecting for novel oxylipins in fungi: the presence of 3-hydroxy oxylipins in Pilobolus. Antonie van Leeuwenhoek 80, 93-99.

Koehn FE, Carter GT. 2005 - The evolving role of natural products discovery. Natural Reviews of Drug Discovery 4, 206-220.

Kogel KH, Franken P, Hückelhoven R. 2006 Endophyte or parasite - what decides? Current Opinion in Plant Biology 9, 358-363.

Koide RT, Schreiner RP. 1992 - Regulation of the vesicular-arbuscular mycorrhizal symbiosis. Annual Review of Plant Physiology and Plant Molecular Biology 43,557-581.

Korkina LG. 2007 - Phenylpropanoids as naturally occurring antioxidants: from plant defense to human health. Cellular and Molecular Biology 53, 15-25.

Kour A, Shawl AS, Rehman S, Sultan P, Qazi PH, Suden P, Khajuria RK, Verma V. 2008 - Isolation and identification of an endophytic strain of Fusarium oxysporum producing podophyllotoxin from Juniperus recurva. World Journal of Microbiology and Biotechnology 24, 1115-1121.

Krings M, Taylor TN, Hass H, Kerp H, Dotzler N, Hermsen EJ. 2007 - Fungal endophytes in a 400-million-yr-old land plants: infection pathways, spatial distribution, and host response. New Phytologist 174, 648-657.

Krings U, Hardebusch B, Albert D, Berger RG, Maróstica JM, Pastore GM. 2006Odor-active alcohols from the fungal transformation of $\alpha$-farnesene. Journal of Agricultural and Food Chemistry 54, 9079- 9084.

Krohn K, Bahramsari R, Florke U, Ludewig K, Kliche-Spory C, Michel A, Aust HJ, Draeger S, Schulz B, Antus S. 1997 Dihydroisocoumarins from fungi: Isolation, Structure elucidation, circular dichroism and biological activity. Phytochemistry 45, 313-320.

Krohn K, Biele C, Drogies KH, Steingrover K, Aust HJ, Draeger S, Schulz B. 2002 - 
Fusidilactones, a new group of polycyclic lactones from an endophyte, Fusidium sp. European Journal of Organic Chemistry 14, 2331-2336.

Kumar DSS, Lau CS, Wan JMF, Yang D, Hyde KD. 2005 - Immunomodulatory compounds from Pestalotiopsis leucoth? (HKUCC 10197), an endophytic fungus of Tripterygium wilfordii. Life Sciences 78, 147-156.

Kumar SS, Cheung HY, Lau CS, Chen F, Hyde KD. 2004 - In vitro studies of endophytic fungi from Tripterygium wilfordii with anti-proliferative activity on human peripheral blood mononuclear cells. Journal of Ethnopharmacology 94, 295-300.

Kumaran RS, Muthumary J, Hur BK. 2008 Production of taxol from Phyllosticta spinarum, an endophytic fungus of Cupressus sp. Engineering in Life Sciences 8, 438-446.

Kumaresan V, Suryanarayanan TS. 2001 Occurrence and distribution of endophytic fungi in a mangrove community. Mycological Research 105, 1388-1391.

Kumaresan V, Suryanarayanan TS. 2002 Endophyte assemblages in young, mature and senescent leaves of Rhizophora apiculata: evidence for the role of endophytes in mangrove litter degradation. Fungal Diversity 9: 81-91.

Kusari S, Lamshöft M, Spiteller M. 2009a Aspergillus fumigates Fresenius, an endophytic fungus from Juniperus communis L. Horstmann as a novel source of the anticancer pro-drug deoxypodophyllotoxin. Journal of Applied Microbiology 107, 1019-1030.

Kusari S, Lamshöft M, Zühlke S, Spiteller M. 2008 - An endophytic fungus from Hypericum perforatum that produces hypericin. Journal of Natural Products 71, 159-162.

Kusari S, Zühlke S, Spiteller M. 2009b - An endophytic fungus from Camptotheca acuminata that produces camptothecin and analogues. Journal of Natural Products 72, 2-7.

Lacap DC, Hyde KD, Liew ECY. 2003 - An Evaluation of the fungal "morphotyoe" concepts based on ribosomal DNA sequence. Fungal Diversity 12, 53-66.

Lee J, Lobkovsky E, Pliam NB, Strobel GA, Clardy J. 1995a - Subglutinols A \& B: immunosuppressive compounds from the endophytic fungus Fusarium subglutinans. Journal of Organic Chemistry 60, 7076-7077.

Lee JC, Strobel GA, Lobkovsky E, Clardy J. 1996 - Torreyanic acid: a selectively cytotoxic quinone dimer from the endophytic fungus Pestalotiopsis microspora. Journal of Organic Chemistry 61, 3232-3233.

Lee JC, Yang X, Schwartz M, Strobel GA, Clardy J. 1995b - The relationship between an endangered North Americn tree and an endophytic fungus. Chemistry and Biology 2, 721-727.

Leuchtmann A, Petrini O, Petrini LE, Carroll GC. 1992 - Isozyme polymorphism in six endophytic Phyllosticta species. Mycological Research 96, 287-294.

Li E, Jiang L, Guo L, Zhang H, Che Y. 2008a - Pestalachlorides A-C, antifungal metabolites from the plant endophytic fungus Pestalotiopsis adusta. Bioorganic and Medicinal Chemistry 16, 7894-7899.

Li E, Tian R, Liu S, Chen X, Guo L, Che Y. 2008b - Pestalotheols A-D, bioactive metabolites from the plant endophytic fungus Pestalotiopsis theae. Journal of Natural Products 71, 664-668.

Li H, Qing C, Zhang Y, Zhao Z. 2005 Screening for endophytic fungi with antitumour and antifungal activities from Chinese medicinal plants. World Journal of Microbiology and Biotechnology 21, 1515-1519.

Li HM, Sullivan R, Moy M, Kobayashi DY, Belanger FC. 2004 - Expression of a novel endophytic fungal chitinase in the infected host grass. Mycologia 96, 526536.

Li JY, Harper JK, Grant DM, Tombe BO, Bashyal B, Hess WM, Strobel GA. 2001 - Ambuic acid, a highly functionalized cyclohexenone with antifungal activity from Pestalotiopsis spp. and Monochaetia sp. Phytochemistry 56, 463-468. 
Li JY, Sidhu RS, Ford E, Hess WM, Strobel GA. 1998 - The induction of taxol production in the endophytic fungusPericonia sp. from Torreya grandifolia. Journal of industrial Microbiology 20, 259-264.

Li JY, Strobel GA, Harper JK, Lobkovsky E, Clardy J. 2000 - Cryptocin, a potent tetramic acid antimycotic from the endophytic fungus Cryptosporiopsis $c f$. quercina. Organic Letters 2, 767-770.

Li JY, Strobel GA, Sidhu R, Hess WM, Ford E. 1996 - Endophytic taxol producing fungi from Bald Cypress Taxodium distichum. Microbiology 142, 22232226.

Li JY, Strobel GA. 2001 - Jesterone and hydroxy-jesterone antioomycete cyclohexenenone epoxides from the endophytic fungus Pestalotiopsis jesteri. Phytochemistry 57, 261-265.

Liew ECY, Guo LD, Ranghoo VM, Goh TK, Hyde KD. 1998 - Molecular approaches to assessing fungal diversity in the natural environment. Fungal Diversity 1, 1-17

Limsuwan S, Trip EN, Kouwenc TRHM, Piersmac S, Hiranrat A, Mahabusarakam W, Voravuthikunchai SP, Van Dijl JM, Kayser O. 2009 Rhodomyrtone: A new candidate as natural antibacterial drug from Rhodomyrtus tomentosa. Phytomedicine 16, 645-651.

Liu CH, Zou XW, Lu H, Tan RX. 2001 Antifungal activity of Artemisia annua endophyte cultures against phytopathogenic fungi. Journal of Biotechnology 88, 277-282.

Liu F, Cai XL, Yang H, Xia XK, Guo ZY, Yuan J, Li MF, She ZG, Lin YC. 2010a - The bioactive metabolites of the mangrove endophytic fungus Talaromyces sp. ZH-154 isolated from Kandelia candel (L.). Planta Medica 76, 185-189.

Liu JY, Song YC, Zhang Z, Wang L, Guo ZJ, Zou WX, Tan RX. 2004 - Aspergillus fumigates CY018, an endophytic fungus in Cynodon dactylon as a versatile producer of new and bioactive metabolites. Journal of Biotechnology
114, 279-287.

Liu K, Ding X, Deng B, Chen W. 2009 Isolation and characterization of endophytic taxol-producing fungi from Taxus chinensis. Journal of industrial Microbiology Biotechnol 36, 11711177.

Liu K, Ding X, Deng B, Chen W. 2010b - 10Hydroxycamptothecin produced by a new endophytic Xylaria sp., M20, from Camptotheca acuminate. Biotechnology Letters 32, 689-693.

Liu L, Niu S, Lu X, Chen X, Zhang H, Guo L, Che Y. 2010c - Unique metabolites of Pestalotiopsis fici suggest a biosynthetic hypothesis involving a Diels-Alder reaction and then mechanistic diversification. Chemical Communications 46, 460-462.

Liu X, Dong M, Chen X, Jiang M, Lu X, Yan G. 2007 - Antioxidant activity and phenolics of an endophytic Xylaria sp. from Ginkgo biloba. Food Chemistry 105, 548-554.

Liu X, Dong M, Chen X, Jiang M, Lv X, Zhou J. 2008 - Antimicrobial activity of an endophytic Xylaria sp.YX-28 and identification of its antimicrobial compound 7-amino- 4-methylcoumarin. Applied Microbiology and Biotechnology 78, 241-247.

Lockwood JL. 1992 - Exploitation competition. In: The fungal community- its organization and role in the ecosystem (Carroll GC, Wicklow DT, eds.): 243-263 Dekker, New York.

Loiret FG, Ortega D, Kleiner P, Ortega R, Rodes R, Dong Z. 2004 - A putative new endophytic nitrogen-fixing bacterium Pantoea sp. from sugarcane. Journal of Applied Microbiology 97, 504-511.

Lösgen S, Schlörke O, Meindl K, Herbst-Irmer R, Zeeck A. 2007 - Structure and biosynthesis of chatocyclinones, new polyketides produced by and endosymbiotic fungus. European Journal of Organic Chemistry 2191-2196.

Lu H, Zou WX, Meng JC, Hu J, Tan RX. 2000 - New bioactive metabolites produced by Colletotrichum sp., an endophytic fungus in Artemisia annua. Plant 
Science 151, 67-73.

Lu Z, Zhu H, Fu P, Wang Y, Zhang Z, Lin H, Liu P, Zhuang Y, Hong K, Zhu W. 2010 - Cytotoxic polyphenols from the marine-derived fungus Penicillium expansum. Journal of Natural Products 73, 911-914.

Ma LJ, Catramis CM, Rogers SO, Starmer WT. 1997 - Isolation and characterization fungi entrapped in glacial ice. Inoculum 48, 23-24.

Ma Y, Prasad MNV, Rajkumar M, Freitas H. 2011 - Plant growth promoting rhizobacteria and endophytes accelerate phytoremediation of metalliferous soils. Biotechnology Advances 29, 248-258.

Ma YM, Li Y, Liu JY, Song YC, Tan RX. 2004 - Anti-Helicobacter pylori metabolites from Rhizoctonia sp. Cy064, an endophytic fungus in Cynodon dactylon. Fitoterapia 75, 451456.

Malinowski, DP, Belesky DP. 2000 Adaptations of Endophyte-Infected Cool-Season Grasses to Environmental Stresses: Mechanisms of Drought and Mineral Stress Tolerance. Crop Science 40, 923-940.

Malinowski, DP, Brauer DK, Belesky DP. 1999 - Neotyphodium coenophialumendophyte affects root morphology of tall fescue grown under phosphorus deficiency. Journal of Agronomy and Crop Science 183, 53-60.

Mandyam K, Jumpponen A. 2005 - Seeking the elusive functions of the rootcolonizing dark septate endophytic fungi. Studies in Mycology 53:173-189.

Marinho AMR, Rodrigues-Filho E, Moitinho MDLR, Santos LS. 2005 - Biologically active polyketides produced by Penicillium janthinellum isolated as an endophytic fungus from fruits of Melia azedarach. Journal of the Brazilian Chemical Society16280-283.

Maróstica JMR, Pastore GM. 2007 Production of $R$-(+)- $\alpha$-terpineol by the biotransformation of limonene from orange essential oil, using cassava waste water as medium. Food Chemistry 101, 345-350.

Matsushima T. 1971 - Microfungi of the
Solomon Islands and Papua New Guinea. Matsushima, Kobe, Japan.

McMorris TC, Kelner MJ, Wang W, Yu J, Estes LA, Taetle R. 1996 (Hydroxymethyl) acylfulvene: an illudin derivative with superior antitumour properties. Journal of Natural Products 59, 896-899.

Mirjalili MH, Farzaneh M, Bonfill M, Rezadoost H, Ghassempour A. 2012 Isolation and characterization of Stemphylium sedicola SBU-16 as a new endophytic taxol-producing fungus from Taxus baccata grown in Iran. FEMS Microbiology Letters 328, 122 129.

Mitchell AM, Strobel GA, Hess WM, Vargas PN, Ezra D. 2008 - Muscodor crispans, a novel endophyte from Anans ananassoides in the Bolivian Amazon, Fungal Diversity 31, 37-43.

Mittermeier RA, Meyers N, Gil PR, Mittermeier CG. 1999 - Hotspot: Earth's Biologically Richest and Most Endangered Ecoregions, Washington DC, CEMEX Conservation International.

Miyazawa M, Kawazoe H, Hyakumachi M. 2003 - Biotransformation of 1-menthol by twelve isolates of soil-borne plant pathogenic fungi (Rhizoctonia solani) and classification of fungi. Journal of Chemical Technology and Biotechnology 78, 620-625.

Mizushina Y, Kamisuki S, Kasai N, Shimazaki $\mathrm{N}$, Takemura M, Asahara H, Linn S, Yoshida S, Matsukage A, Koiwai O, Sugawara F, Yoshida H, Sakaguchi K. 2002 - A plant phytotoxin, Solanapyrone A, is an inhibitor of DNA polymerase $\mathrm{b}$ and 1 . Journal of Biological Chemistry 277, 630-638.

Moricca S, Ragazzi A. 2008 - Fungal endophytes in Mediterranean oak forests: a lesson from Discula quercina. Phytopathology 98, 380-386.

Moy M, Li HJM, Sullivan R, White JF, Belanger FC. 2002 - Endophytic fungal $\beta$-1,6-glucanase expression in the infected host grass. Plant Physiology 130, 1298-1308.

Müller CB, Krauss J: Symbiosis between 
grasses and asexual fungal endophytes. Current Opinion in Plant Biology $8,450-456$.

Murali TS, Suryanarayanan TS, Geeta R. 2006 - Endophytic Phomopsis species: host range and implications for diversity estimates. Canadian Journal of Microbiology 52, 673-680.

Narisawa K, Tokumasu S, Hashiba T. 1998 Suppression of club root formation in Chinese cabbage by the root endophytic fungus, Heteroconium chaetospira. Plant Pathology 47, 206-210.

Narisawa K, Usuki F, Hashiba T. 2004 Control of verticillium yellows in chinese cabbage by the dark septate endophytic fungus LtVB3. Phytopathology 94, 412-418.

Newman DJ, Cragg GM, Snader KM. 2003 Natural products as sources of new drugs over the period 1981-2002. Journal of Natural Products 66, 10221037.

Newman DJ, Cragg, GM. 2007 - Natural products as sources of new drugs over the last 25 years. Journal of Natural Products 70, 461-477.

Newman LA, Reynolds CM. 2005 - Bacteria and phytoremediation: new uses for endophytic bacteria in plants. Biotechnology 23, 6-8.

Ni ZW, Li GH, Zhao PJ, Shen YM. 2008 Antimicrobial components of the endophytic fungal strain Chaetomium globosum Ly50'from Mantenus hookeri. Natural product research and development 20, 33-36.

Nicolaou KC, Yang Z, Liu JJ, Ueno H, Nantermet PG, Guy RK, Claiborne CF, Renaud J, Couladouros EA, Paulvannan K, Sorensen EJ. 1994 - The total synthesis of taxol. Nature 367, 630634.

Opalski KS, Schultheiss H, Kogel KH, Hückelhoven R. 2005 - The receptorlike MLO protein and the RAC/ROP family G-protein RACB modulate actin reorganization in barley attacked by the biotrophic powdery mildew fungus Blumeria graminis f. sp. hordei. Plant Journal 41, 291-303.

Oses R, Valenzuela S, Freer J, Sanfuentes E,
Rodriguez J. 2008 - Fungal endophytes in xylem of healthy chilean trees and their possible role in early wood decay. Fungal Diversity 33: 77-86.

Owen NL, Hundley N. 2004 - Endophytes-the chemical synthesizers inside plants. Science Progress 87, 79-99.

Pan JH, Chen Y, Huang YH, Tao YW, Wang J, Li Y, Peng Y, Dong T, Lai XM, Lin YC. 2011 - Antimycobacterial activity of fusaric acid from a mangrove endophyte and its metal complexes. Archives of Pharmacal Research 34, 1177-1181.

Pandey AK, Reddy MS, Suryanarayanan TS. 2003 - ITS-RFLP and ITS sequence analysis of a foliar endophytic Phyllosticta from different tropical trees. Mycological Research 107, 439444.

Pandi M, Manikandan R, Muthumary J. 2010 Anticancer activity of fungal taxol derived from Botryodiplodia theobromae Pat., an endophytic fungus, against 7, 12 dimethyl benz(a)anthracene (DMBA)-induced mammary gland carcinogenesis in Sprague dawley rats. Biomedicine and Pharmacotherapy 64, 48-53.

Park JH, Choi GJ, Lee HB, Kim KM, Jung HS, Lee SW, Jang KS, Cho KY, Kim JC. 2005 - Griseofulvin from Xylaria sp. strain F0010, an endophytic fungus of Abies holophylla and its antifungal activity against plant pathogenic fungi. Journal of Microbiology and Biotechnology 15, 112-117.

Paulus B, Kanowski J, Gadek P, Hyde KD. 2006 - Diversity and distribution of saprobic microfungi in leaf litter of an Australian tropical rainforest. Mycological Research 110, 1441-1454.

Peláez F. 2005 - Biological activities of fungal metabolites. In: Handbook of Industrial Mycology (An Z., ed.): 49-92. Marcel Dekker, New York, USA.

Peters S, Dammeyer B, Schulz B. 1998 Endophyte-host interactions I. Plant defense reactions to an endophyte and a pathogenic fungus. Symbiosis 25, 193211.

Petrini O, Stone J, Carroll FE. 1982 - 
Endophytic fungi in evergreen shrubs in western Oregon: a preliminary study. Canadian Journal of Botany 60, 789796.

Petrini, O. 1991 - Fungal endophytes of tree leaves. In: Microbila ecology of leaves, (Andrews J, Hirano S, eds.): 179-197 Springer, Berlin Heidelberg New York.

Pimentel MR, Molina G, Dionísio AP, Junior MRM, Pastore GM. 2011 - The Use of Endophytes to Obtain Bioactive Compounds and Their Application in Biotransformation Process. Biotechnology Research International 2011, 1-11.

Pinto RCLS, Azevedo JL, Pereira JO, Carneiro Vieira ML, Labate CA. 2000 Symptomless infection of banana and maize by endophytic fungi impairs photosynthetic efficiency. New Phytologist 147, 609-615.

Pittayakhajonwut P, Suvannakad R, Thienhirun S, Prabpai S, Kongsaeree $P$, Tanticharoen M. 2005 - An anti-herpes simplex virus-type 1 agent from Xylaria mellisii (BCC 1005). Tetrahedron Letters 46, 1341-1344.

Pongcharoen W, Rukachaisirikul V, Phongpaichit S, Kühn T, Pelzing M, Sakayaroj J, Walter C. Taylor WC. 2008 - Metabolites from the endophytic fungus Xylaria sp. PSU-D14. Phytochemistry 69, 1900-1902.

Promputtha I, Jeewon R, Lumyong S, McKenzie EHC, Hyde KD. 2005a - A phylogenetic evaluation of whether endophytes become saprotrophs at host senescence. Microbial Ecology 53, 579-590.

Promputtha I, Jeewon R, Lumyong S, McKenzie EHC, Hyde KD. 2005b Ribosomal DNA fingerprinting in the identification of non sporulating endophytes from Magnolia liliifera (Magnoliaceae). Fungal Diversity 20, 167-186.

Pulici M, Sugawara F, Koshino H, Uzawa J, Yoshida S. 1996 - Pestalotiopsin-A and pestalotiopsin-B new caryophyllenes from an endophytic fungus of Taxus brevifolia. Journal of Organic Chemistry 61, 2122-2124.
Puri SC, Nazir A, Chawla R, Arora R, Hasan RUS, Amna T, Ahmed B, Verma V, Singh S, Sagar R, Sharma A, Kumar R, Sharma RK, Qazi GN. 2006 - The endophytic fungus Trametes hirsuta as a novel alternative source of podophyllotoxin and related aryl tetralin lignans. Journal of Biotechnology 122, 494-510.

Puri SC, Verma V, Amna T, Qazi GN, Spiteller M. 2005 - An endophytic fungus from Nothapodytes foetida that produces camptothecin. Journal of Natural Products 68, 1717-1719.

Qin JC, Zhang YM, Gao JM, Bai MS, Yang SX, Laatsch H, Zhang AL. 2009 Bioactive metabolites produced by Chaetomium globosum, an endophytic fungus isolated from Ginkgo biloba. Bioorganic and Medicinal Chemistry Letters 19, 1572-1574.

Rai MK, Varma A, Pandey AK. 2002 Antifungal potential of Spilanthes calva after inoculation of Piriformospora indica. Mycoses 47, 479-481.

Ranghoo VM, Hyde KD, Liew ECY, Spatafora JW. 1999 - Family placement of Ascotaiwanian and Ascolacicola based on DNA sequences from the large subunit rRNA gene. Fungal Diversity 2, 159-168.

Redman RS, Dunigan DD, Rodriguez RJ. 2001 - Fungal symbiosis from mutualism to parasitism: who controls the outcome, host or invader? New Phytologist 151, 705-716.

Redman RS, Sheehan KB, Stout RG, Rodriguez RJ, Henson JM. 2002 Thermotolerance conferred to plant host and fungal endophyte during mutualistic symbiosis. Science 298, 1581.

Rehman S, Shawl AS, Verma V, Kour A, Athar M, Andrabi R, Sultan P, Qazi GN. 2008 - An endophytic Neurospora sp. from Nothapodytes foetida producing camptothecin. Applied Biochemistry and Microbiology 44, 203-209.

Ren Y, Strobel GA, Graff JC, Jutila M, Park SG, Gosh S, Teplow D, Condron M, Pang E, Hess WM, Moore E. 2008 - 
Colutellin A, an immunosuppressive peptide from Colletotrichum dematium. Microbiology 154, 1973-1979.

Rodriguez RJ, Redman RS, Henson JM. 2004 - The role of fungal symbioses in the adaptation of plants to high stress environments. Mitigation Adaptation Strategies Global Change 9, 261-272.

Rollo F, Sassaroli S, Ubaldi M. 1995 Molecular phylogeny of the fungi of the Iceman's grass clothing. Current Genetics 28, 289-297.

Romero JC, Barria OE, Arnold AE, Rios CL. 2008 - Activity against Plasmodium falciparum of lactones isolated from the endophytic fungus Xylaria sp. Pharmaceutical Biology 46, 1-4.

Rommert AK, Oros-Sichler M, Aust H-J, Lange T, Schulz B (2002) Growth promoting effects of endophytic colonization of the roots of larch (Larix decidua) with Cryptosporiopsis sp. and Phialophora sp. 7th International Mycological Congress, Oslo, Norway, p 309. In Schulz B, Boyle C (2005) The endophytic continuum. Mycological Research 109:661-686.

Rukachaisirikul V, Sommart U, Phongpaichit S, Sakayaroj J, Kirtikara K. 2008 Metabolites from the endophytic fungus Phomopsis sp. PSU-D15. Phytochemistry 69, 783-787.

Saikkonen K, Wäli P, Helander M, Faeth SH. 2004 - Evolution of endophyte-plant symbioses. Trends in Plant Science 9, 275-280.

Salituro GM, Pelaez F, Zhang BB. 2001 Discovery of a small molecule insulin receptor activator. Recent Progress in Hormone Research 56,107-126.

Sanders IR. 2004 - Plant and arbuscular mycorrhizal fungal diversity-are we looking at the relevant levels of diversity and are we using the right techniques? New Phytologist 164, 415418.

Sandhiya GS, Kumari STC, Balachandar D, Kumar K. 2005 Endophytic colonization and in planta nitrogen fixation by a diazotrophic Serratia sp. in rice, Indian Journal of Experimental Biology 43, 802-807.
Schardl CL. 2001 - Epichloe festucae and related mutualistic symbionts of grasses. Fungal Genetics and Biology 33, 69-82.

Schneider P, Misiek M, Hoffmeister D. 2008 In vivo and in vitro production options for fungal secondary metabolites. Molecular pharmacology 5, 234-242.

Schulz B, Boyle C, Draeger S, Römmert AK. 2002 - Endophytic fungi: a source of novel biologically active secondary metabolites. Mycological Research 106, 996-1004.

Schulz B, Boyle C. 2005 - The endophytic continuum. Mycological Research 109, 661-686.

Schulz B, Römmert AK, Dammann U, Aust HJ, Strack D. 1999 - The endophytehost interaction: a balanced antagonism? Mycological Research 103, 1275-1283.

Schwarz M, Köpcke B, Weber RWS, Sterner O, Anke H. 2004 - 3-Hydroxypropionic acid as a nematicidal principle in endophytic fungi. Phytochemistry 65 , 2239-2245.

Scott LJ, Curran MP, Figgitt DP. 2004 Rosuvastatin: a review of its use in the management of dyslipidemia. American Journal of Cardiovascular Drugs 4, 117-138.

Seifried HE, Anderson DE, Fisher EI, Milner JA. 2007 - A review of the interaction among dietary antioxidants and reactive oxygen species. Journal of Nutritional Biochemistry 18, 567-579.

Shao CL, Wang CY, Gu YC, Wei MY, Pan JH, Deng DS, She ZG, Lin YC. $2010-$ Penicinoline, a new pyrrolyl 4quinolinone alkaloid with an unprecedented ring system from an endophytic fungus Penicillium sp. Bioorganic and Medicinal Chemistry Letters 20, 3284-3286.

Sherameti I, Shahollari B, Venus Y, Altschmied L, Varma A, Oelmuller R. 2005 - The endophytic fungus Piriformospora indica stimulates the expression of nitrate reductase and the starch degrading enzyme glucan-water dikinase in tobacco and Arabidopsis roots through a homeodomain trans- 
cription factor that binds to a conserved motif in their promoters. The Journal of Biological Chemistry 280, 2624126247.

Shibuya H, Kitamura C, Maehara S, Nagahata M, Winarno H, Simanjutak P, Kim HS, Wataya Y, Ohashi H. 2003 Transformation of Cinchona alkaloids into 1-N-oxide derivatives by endophytic Xylaria sp. isolated from Cinchona pubescens. Chemical and Pharmaceutical Bulletin 51, 71- 74.

Shiono Y, Yokoi M, Koseki T, Murayama T, Aburai N, Kimura K. 2010 Allantopyrone A, a new alpha-pyrone metabolite with potent cytotoxicity from an endophytic fungus, Allantophomopsis lycopodina KS-97. Journal of Antibiotics 63, 251-253.

Shweta S, Zuehlke S, Ramesha BT, Priti V, Kumar MP, Ravikanth G, Spiteller M, Vasudeva R, Shaanker UR. 2010 Endophytic fungal strains of Fusarium solani, from Apodytes dimidiate $\mathrm{E}$. Mey. ex Arn (Icacinaceae) produce camptothecin, 10- hydroxycamptothecin and 9-methoxycamptothecin. Phytochemistry 71, 117-122.

Sieber TJ. 2007 - Endophytic fungi in forest trees: are they mutualists? Fungal Biology Reviews 21, 75-89.

Sieber, TN, Sieber-Canavesi F, Dorworth CE. 1991 - Endophytic fungi on red alder (Alnus rubra) leaves and twigs in British Columbia. Canadian Journal of Botany 69, 407-411.

Silva GH, Teles HL, Trevisan HC, Bolzani VdS, Young MCM, Pfenning LH, Eberlin MN, Haddad R, Neto CMC, Araújo ÂR. 2005 - New bioactive metabolites produced by Phomopsis cassiae, an endophytic fungus in Cassia spectabilis. Journal of the Brazilian Chemical Society 16, 1463-1466.

Simanjuntak P, Prana TK, Wulandari D, Dharmawan A, Sumitro E, Hendriyanto MR. 2010 - Chemical studies on a curcumin analogue produced by endophytic fungal transformation. Asian Journal of Applied Sciences 3, 60-66.

Singh A, Sharma J, Rexer KH, Varma A. 2000
- Plant productivity determinants beyond minerals, water and light: Piriformospora indica - A revolutionary plant growth promoting fungus. Current Science 79, 15481554.

Singh SB, Ondeyka JG, Tsipouras N, Ruby C, Sardana V, Schulman M, Sanchez M, Pelaez F, Stahlhut MW, Munshi S, Olsen DB, Lingham RB. 2004 Hinnuliquinone, a C2-symmetric dimeric non-peptide fungal metabolite inhibitor of HIV-1 protease. Biochemical and Biophysical Research Communications 324,108-113.

Song YC, Huang WY, Sun C, Wang FW, Tan RX. 2005 - Characterization of graphislactone $\mathrm{A}$ as the antioxidant and free radical scavenging substance from the culture of Cephalosporium sp. IFBE001, an endophytic fungus in Trachelospermum jasminoides. Biological and Pharmaceutical Bulletin 28, 506-509.

Song YC, Li H, Ye YH, Shan CY, Yang YM, Tan RX. 2004 - Endophytic naphthopyrone metabolites are coinhibitors of xanthine oxidase, SW1116 cell and some microbial growths. FEMS Microbiological Letters 241, 6772.

Spadari S, Sala F, Pedrali-Noy G. 1982 Aphidicolin: a specific inhibitor of nuclear DNA replication in eukaryotes. Trends in Biochemical Sciences 7, 2932.

Speakman JB, Lewis BG. 1978 - Limitation of Gaeumannomyces graminis by wheat root responses to Phialophora radicicola. New Phytologist 80,373380.

Srinivasan L, Jagadish K, Shenbhagaraman R, Muthumary J. 2010 - Antioxidant activity of endophytic fungus Phyllosticta sp. isolated from Guazuma tomentosa. Journal of Phytology 2, 3741.

Stadler M, Keller NP. 2008 - Paradigm shifts in fungal secondary metabolite research. Mycological Research 112, 127-130.

Stamford TL, Stamford NP, Coelho LC, 
Araujo JM. 2002 - Production and characterization of a thermostable glucoamylase from Streptosporangium sp. endophyte of maize leaves. Bioresource Technology 83,105-109.

Stierle A, Strobel GA, Stierle D. 1993 - Taxol and taxane production by Taxomyces andreanae. Science 260, 214-216.

Stracke S, Kistner C, Yoshida S, Mulder L, Sato S, Kaneko T, Tabata S, Sandal N, Stougaard J, Szczyglowski K, Parniske M. 2002 - A plant receptor-like kinase required for both bacterial and fungal symbiosis. Nature 417, 959-962.

Strobel G, Daisy B. 2003 - Bioprospecting for microbial endophytes and their natural products. Microbiology and Molecular Biology Reviews 67, 491-502.

Strobel G, Ford E, Worapong J, Harper JK, Arif AM, Grant DM, Peter C.W. Fung PCW, Chau RMW. 2002 - Isopestacin, an isobenzofuranone from Pestalotiopsis microspora, possessing antifungal and antioxidant activities. Phytochemistry 60, 179-183.

Strobel G, Hess WM, Li JY, Ford E, Sears J, Sidhu RS, Summerell B. 1997 Pestalotiopsis guepinii, a taxol producing endophyte of the Wollemi Pine, Wollemia nobilis. Australian Journal of Botany 45, 1073-1082.

Strobel G, Li JY, Sugawara F, Koshino H, Harper J, Hess WM. 1999a - Oocydin A, a chlorinated macrocyclic lactone with potent anti-oomycete activity from Serratia marcescens. Microbiologyolgy 145, 3557-3564.

Strobel G, Miller RV, Miller C, Condron M, Teplow DB, Hess WM. 1999b Cryptocandin, a potent antimycotic from the endophytic fungus Cryptosporiopsis $c f$. quercina. Microbiology 145, 1919-1926.

Strobel G, Stierle A, Stierle D, Hess WM. 1993

- Taxomyces andreanae a proposed new taxon for a bulbilliferous hyphomycete associated with Pacific yew. Mycotaxon 47, 71-78.

Strobel G, Yang X, Sears J, Kramer R, Sidhu RS, Hess WM. 1996 - Taxol from Pestalotiopsis microspora, an endophytic fungus of Taxus wallichiana. Microbiology 142, 435440.

Strobel G. 2002 - Microbial gifts from rain forests. Canadian Journal of Plant Pathology24, 14-20.

Strobel G. 2003 - Endophytes as sources of bioactive products. Microbes and Infection 5, 535-544.

Strobel G. 2006a - Harnessing endophytes for industrial microbiology. Current Opinion in Microbiology 9,240-244.

Strobel G. 2006b - Muscodor albus and its biological promise. Journal of Industrial Microbiology and Biotechnology 33, 514-522.

Strobel G. 2011 - Muscodor speciesendophytes with biological promise. Phytochemistry Reviews10, 165-172.

Suffness M. 1995 - Taxol Science and Applications. CRC Press, Boca Raton, Florida, USA.

Sun D, Ran X, Wang J. 2008 - Isolation and identification of a taxol-producing endophytic fungus from Podocrapus. Acta Microbiologica Sinica 48, 589595.

Suresh B, Ritu T, Ravishankar GA. 2006 Biotransformations as applicable to food industries. In: Food Biotechnology (Taylor and Francis $2^{\text {nd }}$ ed.): $1655-1690$ New York, USA.

Suryanarayanan TS, Kumaresan V. 2000 Endophytic fungi of some halophytes from an estuarine mangrove forest. Mycological Research 104, 1465-1467.

Suryanarayanan TS, Thirunavukkarasu N, Govindarajulu MB, Sasse F, Jansen R, Murali TS. 2009 - Fungal endophytes and bioprospecting. Fungal Biology Reviews 23: 9- 19.

Suryanarayanan, TS, Hawksworth DL. 2005 Fungi from little explored and extreme habitats. In: Biodiversity of Fungi; Their Role in Human Life. (Deshmukh SK, Rai MK, eds.): 33-48. Oxford \& IBH Publishing Co. Pvt. Ltd., New Delhi, India.

Suto M, Takebayashi M, Saito K, Tanaka M, Yokota A, Tomita F. 2002 Endophytes as Producers of Xylanase, Journal of BioScience and Bioengineering 93, 88-90. 
Tan RX, Zou WX. 2001 - Endophytes: a rich source of functional metabolites. Natural Product Reports 18, 448-459.

Taylor JE, Hyde KD, Jones EBJ. 1999 Endophytic fungi associated with the temperate palm Trachycarpus fortunei within and outside its natural geographical range, New Phytologist $142,335-346$.

Tomita, F. 2003 - Endophytes in Southeast Asia and Japan: their taxonomic diversity and potential applications. Fungal Diversity 14, 187-204.

Tong WY, Darah I, Latiffah Z. 2011 Antimicrobial activities of endophytic fungal isolates from medicinal herb Orthosiphon stamineus Benth. Journal of Medicinal Plants Research 5, 831836.

Tuntiwachwuttikul P, Taechowisan T, Wanbanjob A, Thadaniti S, Taylor WC, Lansai AD. 2008 - Secondary metabolites from Streptomyces sp. SUC1. Tetrahedron 64, 7583-7586.

Uma SR, Ramesha BT, Ravikanth G, Rajesh PG, Vasudeva R, Ganeshaiah KN. 2008 - Chemical profiling of $N$. nimmoniana for camptothecin, an important anticancer alkaloid: towards the development of a sustainable production system. In: Bioactive Molecules and Medicinal Plants (Ramawat KG, Merillion J, eds.): 198210, Springer, Berlin, Germany.

Valko M, Leibfritz D, Moncol J, Cronin MTD, Mazur M, Telser J. 2007 - Free radicals and antioxidants in normal physiological functions and human disease. International Journal of Biochemistry and Cell Biology 39, 4484.

Van Aken B, Yoon JM, Schnoor JL. 2004 Biodegradation of nitrosubstituted explosives 2,4,6-trinitrotoluene, hexahydro-1,3,5- trinitro-1,3,5-triazine, and octahydro-1,3,5,7-tetranitro-1,3,5tetrazocine by a phytosymbiotic Methylobacterium sp. associated with poplar tissues (Populus deltoides $\mathrm{x}$ nigra DN34). Applied and Environmental Microbiology 70, 508517.
Varma A, Verma S, Sudha, Sahay N, Butehorn B, Franken P. 1999 - Piriformospora indica, a cultivable plant-growthpromoting root endophyte. Applied and Environmental Microbiology 65, 27412744.

Verma S, Varma A, Rexer KH, Hassel A, Kost G, Sarbhoy A, Bisen P, Butehorn B, Franken P. 1998 - Piriformospora indica, gen. et sp. nov., a new rootcolonizing fungus. Mycologia 90, 896903.

Verma VC, Lobkovsky E, Gange AC, Singh SK, Prakash S. 2011 - Piperine production by endophytic fungus Periconia sp. Isolated from Piper longum L. Journal of Antibiotics 64, 427-431.

Verza M, Arakawa NS, Lopes NP, Kato MJ, Pupo MT, Said S, Carvalho I. 2009 Biotransformation of a tetrahydrofuran lignan by the endophytic fungus Phomopsis sp. Journal of the Brazilian Chemical Society 20,195-200.

Wagenaar M, Corwin J, Strobel GA, Clardy J. 2000 - Three new chytochalasins produced by an endophytic fungus in the genus Rhinocladiella. Journal of Natural Products 63:1692-1695.

Waller F, Achatz B, Baltruschat H, Fodor J, Becker $\mathrm{K}$, Fischer $\mathrm{M}$, Heier $\mathrm{T}$, Huckelhoven R, Neumann C, von Wettstein D, Franken P, Kogel KH. 2005 - The endophytic fungus Piriformospora indica reprograms barley to salt-stress tolerance, disease resistance, and higher yield. PNAS Journal 102, 13386-13391.

Wang FW, Jiao RH, Cheng AB, Tan SH, Song YC. 2007 - Antimicrobial potentials of endophytic fungi residing in Quercus variabilis and brefeldin A obtained from Cladosporium sp. World Journal of Microbiology and Biotechnology 23, 79- 83.

Wang JM, Ding GZ, Fang L, Dai JG, Yu SS, Wang YH, Chen XG, Ma SG, Qu J, Xu S, Du D. 2010 - Thiodiketopiperazines produced by the endophytic fungus Epicoccum nigrum. Journal of Natural Products 73, 1240-1249.

Wang JW, Zheng LP, Tan RX. 2004 - 
Stimulation of artemisinin production in Artemisia annua hairy roots by the elicitor from the endophytic Colletotrichum sp. Biotechnology Letters 23: 857-860.

Wani MC, Taylor HL, Wall ME, Goggon P, McPhail AT. 1971 - Plant antitumor agents, VI. The isolation of taxol, a novel antitumor agent from Taxus brevifolia. Journal of American Chemical Society 93, 2325-2327.

Weber D, Sterner O, Anke T, Gorzalczancy S, Martin V, Acevedo C. 2004a - Phomol, a new antinflammatory metabolite from an endophyte of the medicinal plant Erythrina crista-galli. Journal of Antibiotics 57, 559-563.

Weber RW, Stenger E, Meffert A, Hahn M. $2004 \mathrm{~b}$ - Brefeldin A production by Phoma medicaginis in dead precolonized plant tissue: a strategy for habitat conquest? Mycological Research 108, 662-671.

Wei JC. 1979 - Hand Book of Fungi Identification. Technology Press, Shanghai.

Wen L, Chen G, She Z, Yan C, Cai J, Mu L. 2010 - Two new paeciloxocins from a mangrove endophytic fungus Paecilomyces sp. Russian Chemical Bulletin 59, 1656-1659.

WHO. 2009 - Mortality Database, Fact sheet No. 297. February.

Wicklow DT, Roth S, Deyrup ST, Gloer JB. 2005 - A protective endophyte of maize: Acremonium zeae antibiotics inhibitory to Aspergillus flavus and Fusarium verticillioides. Mycological Research 109, 610-618.

Wijeratne EMK, Turbyville TJ, Fritz A, Whitesell L, Gunatilaka AAL. 2006 A new dihydroxanthenone from a plantassociated strain of the fungus Chaetomium globosum demonstrates anticancer activity. Bioorganic \& Medicinal Chemistry 14, 7917-7923.

Wiyakrutta S, Sriubolmas N, Panphut W, Thongon N, Danwisetkanjana K, Ruangrungsi N, Meevootisom V. 2004. World Journal of Microbiology and Biotechnology 20, 265-272.

Yahara I, Harada F, Sekita S, Yoshihira K,
Natori S. 1982 - Correlation between effects of 24 different cytochalasins on cellular structures and cellular events and those on actin in vitro. The Journal of Cell Biology 92, 69-78.

Yang J, Xu F, Huang C, Li J, She Z, Pei Z, Lin Y. 2010 - Metabolites from the mangrove endophytic fungus Phomopsis sp. (\#zsu- H76). European Journal of Organic Chemistry 2010 (5), 3692-3695.

Yin H, Sun YH. 2011 - Vincamine-producing endophytic fungus isolated from Vinca minor. Phytomedicine 18, 802-805.

Yin H, Zhao Q, Sun FM, An T. 2009 Gentiopicrin-producing endophytic fungus isolated from Gentiana macrophylla. Phytomedicine 16, 793797.

Yu H, Zhang L, Li L, Zheng C, Guo L, Li W, Sun P, Qin L. 2010 - Recent developments and future prospects of antimicrobial metabolites produced by endophytes. Microbiological Research 165, 437-449.

Zeng PY, Wu JG, Liao LM, Chen TQ, Wu JZ, Wong KH. 2011 - In vitro antioxidant activities of endophytic fungi isolated from the liverwort Scapania verrucosa. Genetics and Molecular Research 10, 3169-79.

Zhang B, Salituro G, Szalkowski D, Li Z, Zhang Y, Royo I, Vilella D, Díez MT, Pelaez F, Ruby C, Kendall RL, Mao X, Griffin P, Calaycay J, Zierath JR, Heck JV, Smith RG, Moller DE. 1999 Discovery of small molecule insulin mimetic with antidiabetic activity in mice. Science 284:974-981.

Zhang G, Sun S, Zhu T, Lin Z, Gu J, Li D, Gu Q. 2011 - Antiviral isoindolone derivatives from an endophytic fungus Emericella sp. associated with Aegiceras corniculatum. Phytochemistry 72, 1436-1442.

Zhang J, Zhang L, Wang X, Qiu D, Sun D, Gu J, Fang Q. 1998 - Microbial transformation of 10-deacetyl-7epitaxol and $1 \beta$ - hydroxybaccatin I by fungi from the inner bark of Taxus yunnanensis. Journal of Natural Products 61, 497-500. 
Zhang JY, Tao LY, Liang YJ, Yan YY, Dai CL, Xia XK, She ZG, Lin YC, Fu LW. 2009 - Secalonic acid D induced leukemia cell apoptosis and cell cycle arrest of G1 with involvement of GSK$3 \beta / \beta$-catenin/c-Myc pathway. Cell Cycle 8, 2444-2450.

Zhang W, Wildel JF, Clark LG. 1997 Bamboozled again! Inadvertent isolation of fungal rDNA sequences from bamboos (Poaceae: Bambusoideae). Molecular Phylogene-tics and Evolution 8, 205-217.

Zhang X, Shi Y, Wang X, Zhang W, Lou K. 2010 - Isolation, identification and insecticidal activity of endophyte from Achnatherum inebrians. In: Tenguria RK, Firoz Naem Khan FN, Quereshi S. 2011 - Endophytes Mines of Pharmacological Therapeutics. World Journal of Science and Technology 1, 127-149.

Zhao J, Zhou L, Wang J, Shan T, Zhong L, Liu X, Gao X. 2010 - Endophytic fungi for producing bioactive compounds originally from their host plants.
Current Research, Technology Education Topics in Applied Microbiology and Microbial biotechnology 1, 567-576.

Zhou D, Hyde KD. 2001 - Host-specificity, host-exclusivity, and host-recurrence in saprobic fungi. Mycological Research 105, 1449-1457.

Zikmundová M, Drandarov K, Bigler L, Hesse M, Werner C. 2002 - Biotransformation of 2-benzoxazolinone and 2hydroxy-1,4-benzoxazin-3-one by endophytic fungi isolated from Aphelandra tetragona. Applied and Environmental Microbiology 68, 4863-4870.

Zipfel C, Felix G. 2005 - Plants and animals: a different taste for microbes? Current Opinion in Plant Biology 8, 353-360.

Zou WX, Tan RX. 1999 - Advances in Plant Sciences. Beijing: China Higher Education Press, 183-190. In: Bioactive Natural Products from Endophytes: A Review ${ }^{1}$ (Guo B, Wang Y, Sun X, Tang K. 2008 - Applied Biochemistry and Microbiology 44, 136-142. 